
Series: Linköping University Medical Dissertations, No. 1753

\title{
The Social Dynamics of Labor Market Inclusion
}

\author{
Lena Strindlund
}

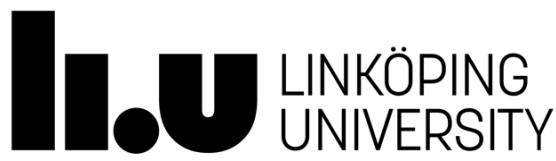

Department of Health, Medicine and Caring Sciences

Linköping University, Sweden

Linköping 2020 
(C) Lena Strindlund, 2020

Cover: Jasmine Strindlund and Marcus Lundberg

Published articles have been reprinted with the permission of the copyright holders.

Printed in Sweden by LiU-Tryck, Linköping, Sweden, 2020

ISBN: 978-91-7929-790-9

ISSN: 0345-0082 
To my beloved children

Jasmine, Jack, Nikki, and Dexter

'Everything we hear is an opinion, not a fact. Everything we see is a perspective, not the truth.' Marcus Aurelius 



\section{CONTENTS}

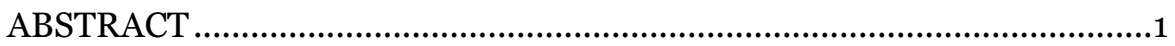

SVENSK SAMMANFATTNING …....................................................... 3

Rekommendationer till praktiken ......................................................... 4

LIST OF PAPERS ……………………………….............................. 7

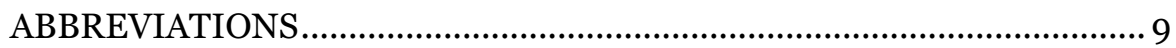

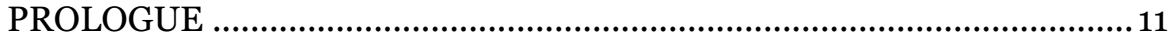

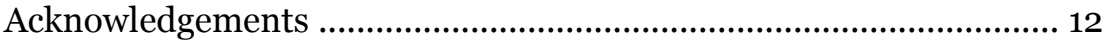

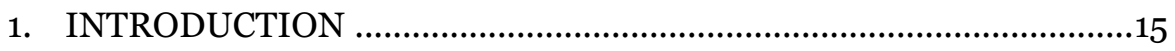

Aim and research questions .................................................................... 16

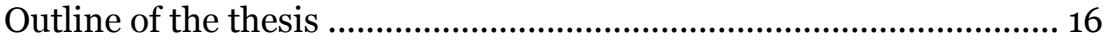

2. BACKGROUND .................................................................................. 19

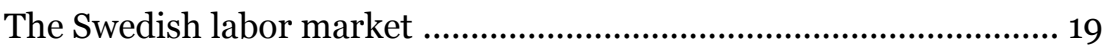

Swedish labor market policy ................................................................. 21

Changes in Swedish labor market policy ................................................ 22

Labor market inclusion: definition and demarcation ............................ 25

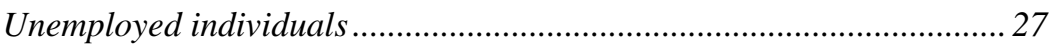

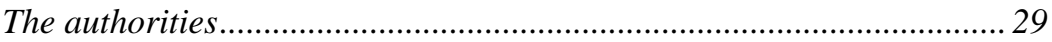

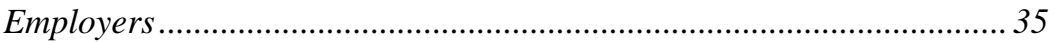

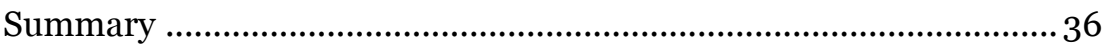

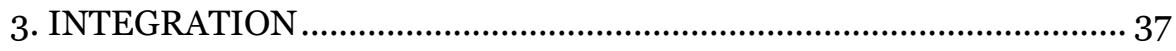

Definition and conceptualization......................................................... 37

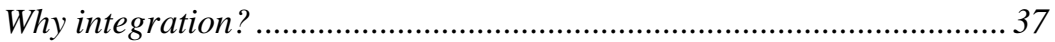

Definitions and dimensions ................................................................... 38

Organizing integration ........................................................................ 39

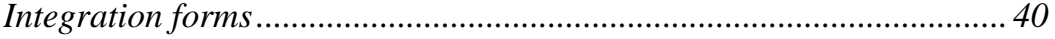

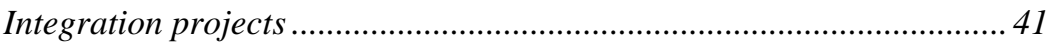

Examples of integration ....................................................................... 42 
The coordination associations.......................................................... 42

Other empirical examples of welfare integration ................................ 43

Summary ................................................................................ 44

4. RESEARCH ON INTEGRATION ................................................. 45

Research on interorganizational integration................................. 45

The theory of collaborative advantage....................................... 45

Central themes for integration ........................................................... 46

Research on intersectoral integration ......................................... 55

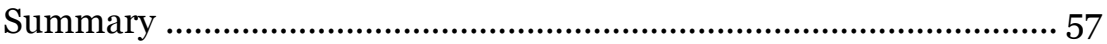

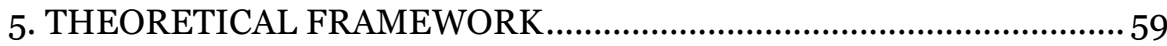

Theorizing (thesis and paper III) …............................................ 59

Practice theory (paper II) ..............................................................60

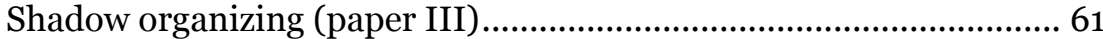

Social capital (paper III) ...............................................................6 62

Social representations (paper IV) .................................................. 63

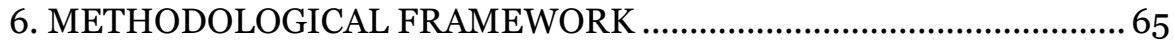

An interactive research approach .................................................6 66

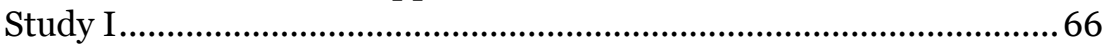

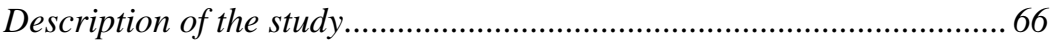

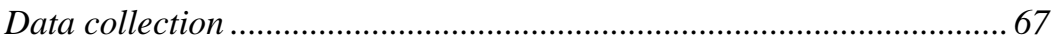

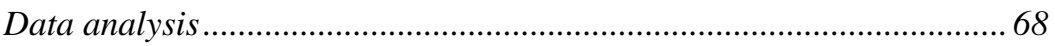

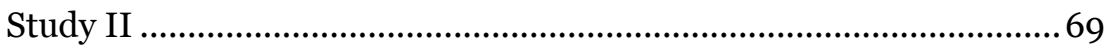

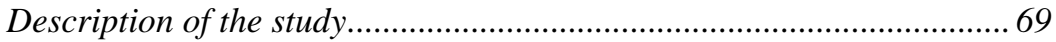

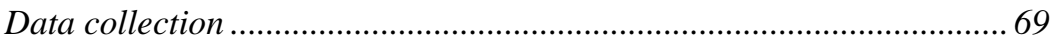

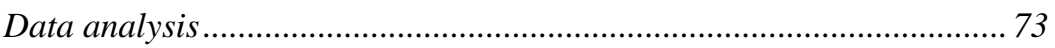

Study III............................................................................ 74

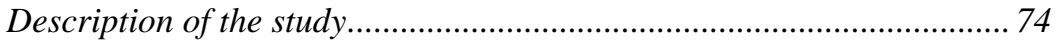

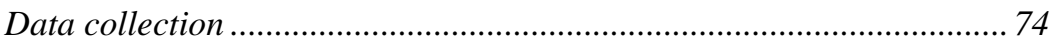

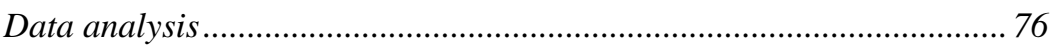

Ethical considerations ................................................................ 76

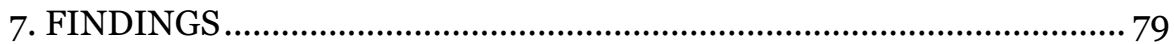

Paper I: Employers' views on disability, employability, and labor market inclusion: a phenomenographic study ................................ 79

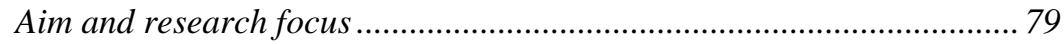




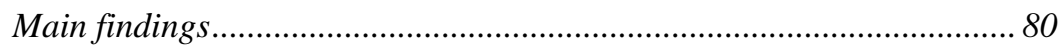

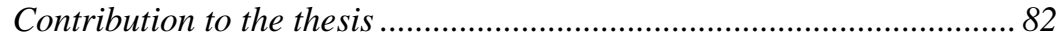

Paper II: Zooming in on labor market cooperation: A study of a failed project to support unemployed young people....................................... 82

Aim and research focus .................................................................... 82

Main finding

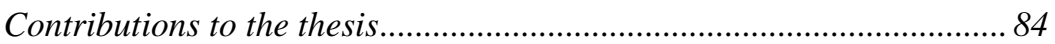

Paper III: When cooperation turns ugly: Exploring the dark side of

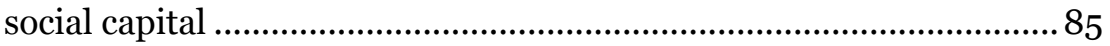

Aim and research focus ......................................................................... 85

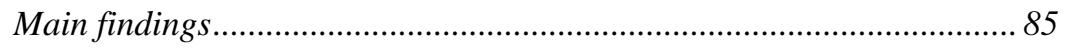

Contribution to the thesis ...................................................................... 87

Paper IV: Social representations and tensions in organizing a labor market inclusion project ....................................................................... 89

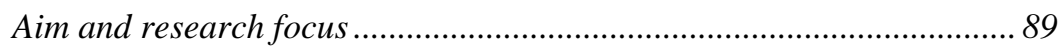

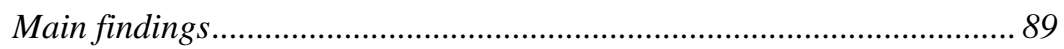

Contribution to the thesis ..................................................................... 91

8. DISCUSSION: THE SOCIAL DYNAMICS OF LABOR MARKET

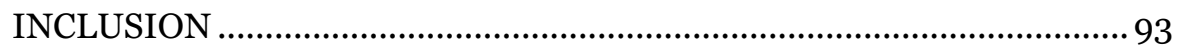

Synthesis of results ................................................................................. 93

Multiple and conflicting views .............................................................94

Grouping processes ………………....................................................... 97

Power struggles ..................................................................................98

Methodological considerations ..........................................................101

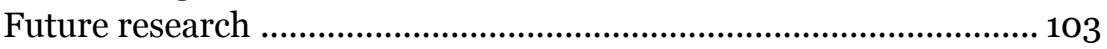

Conclusions .................................................................................... 104

Practical implications.................................................................... 105

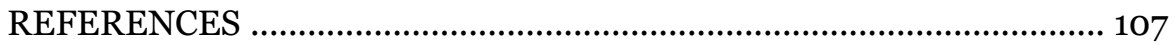





\section{ABSTRACT}

Labor market inclusion is a complex assignment that takes place through a dynamic interaction between unemployed individuals from vulnerable groups, several authority actors and employers.

The overall aim of this thesis was to explore the social dynamics of labor market inclusion, with a particular focus on integration, from the perspectives of employers and authority actors. Three empirical studies have been conducted focusing on different perspectives and integration challenges, using various forms of qualitative methods and theoretical approaches.

Study I was a qualitative phenomenographic interview study of employers' perspectives on labor market inclusion and intersectoral integration. The study showed that employers' views are multifaceted and can be categorized as constrained, independent, and conditional, and can be understood through a complex internal relationship between conceived individual-, workplace- and authority-related aspects in relation to the themes of trust, contribution, and support (paper I).

Study II was a two-year longitudinal case study of an interorganizational integration project, focusing on the authority actors' perspectives. Through ethnographic fieldwork and a practice-theory approach, two divergent rationalities (an empowerment rationality and a coordinating rationality) were identified within the project organization, and four central concepts were highlighted - communication, trust, structure, and steering - contributing to a collapse in integration (paper II). The dysfunctional group processes were further analyzed with the theory of negative effects of social capital and shadow organizing, summarized as three social dynamics: insulation, homogenization, and escalating commitment (paper III).

Study III was a one-year longitudinal case study of a municipal intraorganizational integration project focusing on the perspectives of both authority actors and municipal employers. This study combined ethnographic field work with the theory of social representations, which visualized three different representations among the different professional groups - individual-, employer-, and political-oriented - which contributed to creating tensions within the project, identified as incomprehension, power struggles, expectation gaps, and distrust (paper IV).

By studying two labor market inclusion projects through shadow organizing, the thesis has revealed a complex and dynamic interplay between the various views of the actors involved, as well as social processes within 
the project organizations and organizational aspects, referred to as social dynamics. These social dynamics constitute the key concepts in this thesis, contributing understanding about how integration and organization work within labor market inclusion projects, or rather, what makes them fail. Three social dynamics were identified: multiple and conflicting views, grouping processes, and power struggles.

Greater knowledge and awareness of these complex and social dynamics of labor market inclusion may contribute to better preparedness when organizing integration projects. The results suggest that by identifying and addressing the multiple views characterizing integration projects and not letting incomprehension dominate, the destructive social dynamics may not be given as much space, or may even be avoided, which may stimulate a willingness to integrate rather than the opposite. 


\section{SVENSK SAMMANFATTNING}

Arbetsmarknadsinkludering är ett komplext uppdrag som utspelar sig i en dynamisk samverkan mellan arbetslösa individer från utsatta grupper, flera myndighetsaktörer och arbetsgivare. Denna samverkan är förknippad med olika utmaningar, både när det gäller intra- och interorganisatorisk samverkan mellan olika involverade myndighetsaktörer och intersektoriell samverkan, mellan myndighetsaktörer och arbetsgivare.

Det övergripande syftet med avhandlingen är att utforska de sociala dynamikerna inom arbetsmarknadsinkludering, med särskilt fokus på samverkan, utifrån arbetsgivarnas och myndighetsaktörernas perspektiv. Frågeställningarna berör vilka olika synsätt kring arbetsmarknads-inkludering och samverkan som finns hos arbetsgivare och myndighets-aktörer och hur det påverkar organiseringen och samverkan i arbetsmarknadsinkluderingsprojekt, samt hur detta kan teoretiseras.

Tre empiriska studier har genomförts med fokus på olika perspektiv och samverkansutmaningar genom olika kvalitativa metoder och teoretiska förhållningssätt. Totalt bestod urvalet av drygt 100 informanter (arbetsgivare, projektdeltagare, projektmedarbetare, personal i deltagande organisationer samt ledningsrepresentanter).

Studie I var en fenomenografisk intervjustudie med fokus på arbetsgivares synsätt gällande arbetsmarknadsinkludering av arbetslösa med funktionsnedsättning samt intersektoriell samverkan. Studien visade att arbetsgivares synsätt är mångfacetterade och kan kategoriseras som begränsade, oberoende och villkorade. De olika synsätten kan förstås som ett komplext internt samspel mellan olika individuella, arbetsplats- och myndighetsrelaterade aspekter i förhållande till tre identifierade teman: tillit, värde och stöd (artikel I). Studien visade på vikten av att förstå och ta hänsyn till arbetsgivarnas perspektiv vid organisering av samverkan inom arbetsmarknadsinkludering.

Studie II var en tvåårig longitudinell fallstudie av ett interorganisatoriskt samverkansprojekt med fokus på myndighetsaktörers perspektiv gällande arbetsmarknadsinkludering och organisering. Projektet studerades genom etnografiskt fältarbete, dvs. intervjuer, fokusgrupper, observationer, skuggning samt dokumentstudier. I artikel II analyserades projektet utifrån ett praktikteoretiskt perspektiv. Två motsatta logiker (en empowermentlogik och en samordningslogik) identifierades inom projektorganisationen. I samspel med fyra centrala teman- kommunikation, tillit, struktur och styrning - hade de negativ inverkan på organiseringen och samverkan 
vilket resulterade i en samverkanskollaps. I artikel III analyserades de dysfunktionella grupprocesserna i projektgruppen utifrån teorier om negativa effekter av socialt kapital, samt shadow organizing. Tre negativa sociala dynamiker identifierades: isolering, homogenisering och eskalerande engagemang.

Studie III var en ettårig longitudinell fallstudie av ett kommunalt intraorganisatoriskt samverkansprojekt med fokus på både myndighetsaktörer och kommunala arbetsgivare. Projektet studerades genom etnografiskt fältarbete, dvs. intervjuer, fokusgrupper, observationer, samt dokumentstudier, och analyserades utifrån teorin om sociala representationer. Tre olika sociala representationer av projektet identifierades bland de olika professionella grupperna: en individorienterad, en arbetsgivarorienterad och en politisk orienterad. Dessa bidrog till att skapa spänningar inom projektet, identifierade som oförståelse, maktkamp, förväntningsgap och misstro, vilket stimulerade en ovilja till samverkan (artikel IV).

Genom att studera två arbetsmarknadsinkluderingsprojekt med inspiration från shadow organizing har avhandlingen beskrivit ett komplext och dynamiskt samspel mellan de olika aktörernas olika åsikter, sociala processer inom projektorganisationerna och organisatoriska aspekter, benämnda sociala dynamiker. Dessa sociala dynamiker utgör nyckelbegrepp i denna avhandling och bidrar till förståelse för hur samverkan och organisering fungerar inom arbetsmarknadsinkluderingsprojekt, eller snarare, vad som får dem att misslyckas. Tre sociala dynamiker identifierades: många och motstridiga synsätt, grupprocesser och maktkamp.

Ökad kunskap och medvetenhet om dessa komplexa och sociala dynamiker inom arbetsmarknadsinkludering kan bidra till förbättrad beredskap vid organisering av samverkansprojekt. Resultaten antyder att de destruktiva sociala dynamikerna som beskrivits kan ges mindre utrymme eller till och med undvikas genom att de olika synsätten förs fram i ljuset och skillnader och likheter adresseras. Sådana strategier kan stimulera en vilja att samverka snarare än tvärtom.

\section{Rekommendationer till praktiken}

Denna avhandling har belyst utmaningar med samverkan och organisering av arbetsmarknadsinkluderingsprojekt. Med tanke på alla de utmaningar samverkan är förknippad med följer rekommendationerna Huxham och Vangens råd "Gör det inte om du inte måste" (Huxham and Vangen, 2005, p. 13). Dock, eftersom arbetsmarknadsinkludering är ett fragmenterat och komplext uppdrag som delas av flera myndighetsaktörer i förhållande till arbetslösa individer och arbetsgivare, krävs ofta samverkan i någon form. I dessa fall, för att minska eller undvika samverkansutmaningar, behövs 
samverkanskompetens. En utmärkt källa till samverkanskompetens är Huxham och Vangens teori om fördelar med samverkan. Denna avhandling kan också bidra till sådan kompetens genom att lyfta fram några rekommendationer baserade på lärdomarna från misslyckandena i projekten:

- Organisera samverkansprojekt baserat på programteorier med tydligt angivna mål, målgrupper och arbetssätt.

- Organisera och förtydliga projektorganisationerna angående roller, mandat och uppdrag.

- Prioritera ledning och styrning av samverkansprojekten och säkerställ att dessa representanter har goda kommunikationsförmågor.

- Säkerställ att arbetsgivarnas perspektiv är med vid organisering av projekt och insatser inom arbetsmarknadsinkludering.

- Prioritera utvärdering och skapa förutsättningar för ett utvecklingsinriktat lärande. 


\section{LIST OF PAPERS}

I. Strindlund, L., Abrandt Dahlgren, M., Ståhl, C. (2018): “Employers' views on disability, employability, and labor market inclusion: a phenomenographic study". Disability and Rehabilitation, 41:24, 2910-2917, DOI: 10.1080/09638288.2018.1481150

II. Strindlund, L., Abrandt Dahlgren, M., Ståhl, C. (2020): “Zooming in on labor market cooperation: A study of a failed project to support unemployed young people”. Social Policy \& Administration, 54:3, 410-426.

III. Strindlund, L., Abrandt Dahlgren, M., Ståhl, C. "When cooperation turns ugly: Exploring the dark side of social capital". Submitted 2020 to Qualitative Research in Organizations and Management.

IV. Strindlund, L., Abrandt Dahlgren, M., Ståhl, C., "Social representations and tensions in organizing a labor market inclusion project". Submitted 2020 to Social Policy \& Administration. 


\section{ABBREVIATIONS}

\section{Abbreviations}

PES The Public Employment Service

SIA The Swedish Social Insurance Agency

CA Coordination association

ALMP Active labor market policies

\section{Definitions of central concepts}

Labor market inclusion: The process of getting unemployed individuals from dependency on welfare benefits to self-sufficiency through work.

Integration: Overall concept describing various structures for collaboration and cooperation.

Social dynamics: Refers to tensions in relation to organizational aspects and grouping processes identified as influencing the integration projects.

Authority actors/authorities: Refers to the four authorities involved in labor market inclusion in this thesis: the PES, the SIA, the municipality and the region.

Unemployed individuals: Refers to those unemployed individuals from vulnerable groups who have difficulties gaining access or re-entry to the labor market. 


\title{
PROLOGUE
}

\author{
Remember the two benefits of failure. \\ First, if you do fail, you learn what doesn't work; \\ and second, the failure gives you the opportunity to try a new approach.
}

(Roger von Oech)

So here I am, about to reach the end of a very long journey of doctoral studies, characterized by enriching detours, mistakes, and new approaches. My journey began seventeen years ago, in 2003, with a study examining the sick leave processes for women on long-term sick leave. My background as an occupational therapist and further studies in public health contributed to an individual focus, emphasizing the role of work and activity. However, studying these women revealed other perspectives, such as the roles played by employers and the authority actors in their return to work and especially challenges concerning integration between these actors. For various reasons I interrupted these studies in 2006 and chose to change the direction of my professional orientation. The following nine years were devoted to non-academic self-employment within sales and marketing, and later as an employee at the Public Employment Service (PES) dealing with labor market inclusion issues.

My interest in labor market inclusion was aroused by my experiences at the PES. This work had introduced me to a new target group: vulnerable unemployed individuals. This was a group that, for various reasons, was excluded from the labor market and where many had no work experience at all. Nevertheless, they were expected to be "re"-habilitated to work, and my role as a Supported Employment consultant ${ }^{1}$ consisted of helping individuals with disabilities and reduced work capacity to find, get and keep a job. This involved cooperation with three types of actors: unemployed individuals, employers, and other authority actors. The latter included various professionals at the PES and other actors such as representatives from the Swedish Social Insurance Agency (SIA), the municipal labor market services, and social services, as well as health care professionals from the region. It was through this practical work that I became aware of the com-

\footnotetext{
${ }^{1}$ Supported Employment (SE) is a work-oriented rehabilitation method for unemployed individuals with disabilities who are far from the labor market. Central to the method is SE consultants helping these individuals to find, get and keep a job in the open labor market.
} 
plexity of labor market inclusion, and the challenges of different views, organization, and cooperation. How could these challenges be understood? The search for answers led me to the academic world.

In 2015, I resumed my doctoral studies with a new approach. This time, the research questions had arisen from the practice system and the challenges I experienced. This new approach also meant different study arrangements, enabling me to enroll as a doctoral student at Linköping University in combination with employment at the Coordination Association in Central Östergötland. This arrangement facilitated integration between the research system and the practice system, providing access to the practice and the anchoring of my studies in the practice, which had been a challenge during my initial doctoral studies. As a result, I have not only studied labor market inclusion through this thesis, but have also had the opportunity to study the context of labor market inclusion in detail by being involved in the practice for five years.

My hope is that this thesis can provide a piece of the puzzle of this complex phenomenon, contributing an increased understanding of the social dynamics of labor market inclusion.

\section{Acknowledgements}

Before I turn to the actual work, I would like to express my gratitude to all those who have contributed to this thesis in various ways.

Christian Ståhl, my main supervisor, for always being there for me; responsive, stable, and committed. I appreciate your fantastic ability to combine professional and friendly guidance. Thank you for the fantastic sculpture you gave me when I needed it most.

Madeleine Abrandt Dahlgren, my assistant supervisor, for your drive to improve and always contribute new perspectives. I appreciate your positive energy and your encouraging comments. Together, you two have been a fantastic supervisor team, matching my needs for guidance. Thanks to you, these years have been not only educational but also enjoyable.

Kerstin Ekberg, my supervisor during my first $\mathrm{PhD}$ period, for giving me a second chance when I was ready. Thank you for the hazel tree you gave me when I quit in 2006, with the crooked branches symbolizing life's unfathomable detours. It is still with me. 
New and old colleagues from Linköping University who have contributed and supported me in various ways. Ursula Reichenpfader for being my supportive roommate and for showing the way to Nicolini. Isa Moldvik and Elin Karlsson for stimulating conversations and nice travelling memories to Oslo and Copenhagen. Jennie Nyman, for supporting me through the statistics. Anna-Carin Fagerlind Ståhl for encouraging pep talks. Old and new colleagues at RAR, Helix, IBL, and other contexts at LIU, for inspiration in showing the way as well as providing input for the thesis. A special thank you to all A\&A seminar participants who gave valuable comments for the "kappa".

Other national and international colleagues from other universities and networks such as NIVA, SPID, and Nätverket för samverkansforskning. These meetings have contributed inspiration, knowledge, and new approaches. Special thanks to Per Germundsson for making me aware of the theory of social representations during lunch at a network meeting. It helped me put the puzzle together.

Mattias Bergström at Samordningsförbundet Centrala Östergötland (SCÖ) for promoting this employment arrangement and opening doors to the context. Thank you to all the officials and politicians at SCÖ who have supported the arrangement during the period. Also thank you to all SCÖ colleagues who have joined over the years, especially Karin Tjärnlund, for good teamwork, valuable proofreading, and the beautiful embroidery!

All participants in the studies; unemployed youths, project staff members, staff from the authority actors, steering representatives, and employers for sharing your views. Thank you especially to the project staff members who have given access to their practices.

Old and new friends for supporting me and showing interest in my work and for helping me focus on other things, outside the academic world. You know who you are. Special thanks to my beloved 'yayas', Heléne, Anna and Ericka and 'RAR-ingar' Josefin and Maria, for being there throughout the journey and always supporting and believing in me.

My fantastic family, mother Mona and my father Rolf, for your unconditional love. My brother Fredrik and my sister-in-law Tina, for your love and support. 
$P-O$, the love of my life, for your love and humor.

My beloved children, Jasmine, Jack, Nikki, and Dexter, for just being you. You are and always will be my number one priority. I look forward to following you on life's paths and detours.

I am so grateful to have you all in my life! 


\section{INTRODUCTION}

I think that if we don't learn to inhabit other peoples' perspectives, then we're never going to understand why people do what they do.

(Ruth Ozeki)

In this thesis, the focus is on exploring the complex phenomenon of labor market inclusion, with a particular focus on the integration of different actors, and the various social dynamics involved in such processes.

Labor market inclusion is an important societal issue. In Sweden, an increasing number of unemployed individuals from vulnerable groups are on welfare benefits and need help from the authorities to enter the labor market (Arbetsförmedlingen, 2017b). At the same time, the Swedish labor market policy is undergoing changes and the authorities are struggling to find strategies for organizing labor market inclusion (Bengtsson, 2017).

The concept of labor market inclusion refers to the process of getting unemployed individuals from dependency on welfare benefits to self-sufficiency through work, and in this thesis is understood in relation to an interplay between three central actors representing unemployed individuals, employers, and the authorities, as described in greater detail in chapter 2 . This interplay is described in terms of integration, which is used as an overall concept in the thesis describing various forms of collaboration and cooperation between the actors. This integration concerns intraorganizational integration within an organization's units and departments (study III), interorganizational integration between various authority actors (study II), and intrasectoral integration between authority actors and employers (study III). The integration concept is further explored in chapters 3 and 4.

The authority actors face two challenges in relation to integration and labor market inclusion. The first challenge concerns intraorganizational and interorganizational integration. Since no single authority actor has overall responsibility, the actors involved need to integrate and contribute their various skills and resources, for example through integration projects. This area is characterized by a significant knowledge gap, and there is a need for research concerning both intraorganizational and interorganizational integration between authorities in the context of Swedish labor market inclusion. The second challenge concerns intersectoral integration. Despite employers' central role in labor market inclusion, integration between employers and authority actors is limited, and research on the roles and perspectives of employers in labor market inclusion is not sufficiently explored. These challenges are the starting point for this thesis. 
When exploring these challenges through the empirical studies of integration projects within the labor market inclusion context, various tensions have been identified in relation to organizational aspects and grouping processes referred to in this thesis as social dynamics. Understanding these dynamics is central to making sense of integration within labor market inclusion.

\section{Aim and research questions}

The aim of this thesis is to explore the social dynamics of labor market inclusion, with a particular focus on integration, from employers' and authority actors' perspectives.

Three research questions have guided the research process and the focus of the four papers:

I. What are employers' views on labor market inclusion and integration with authority actors, and how can this be theorized? (Papers I and IV.)

II. What are the different authority actors' views on labor market inclusion and integration, and how can this be theorized? (Papers II and IV.)

III. How do the different views impact on the organization and integration in labor market inclusion projects, and how can this be theorized? (Papers II, III and IV.)

\section{Outline of the thesis}

This thesis is a compilation thesis, comprising four papers based on three studies. Each of the papers has a specific aim and research questions, as well as different methodological and theoretical frameworks, contributing to an overall aim and research questions within the framework of this compilation thesis. This following introductory text, consisting of eight chapters, aims to present the context and the research rationale, and to show how the papers contribute to the overall aim of the thesis. The chapters are structured in the following order:

Chapter 1 is a short introduction to the thesis and the rationale, including a presentation of the aim and research questions. Chapter 2 consists of a background, describing the Swedish labor market, labor market policy, and the responsibilities and regulations governing the three main actors involved in labor market inclusion: unemployed individuals, the authorities, and employers. The concept of labor market inclusion is also presented 
in greater depth in this chapter. In chapter 3 , the concept of integration is defined and conceptualized, and various integration forms are presented. Chapter 4 consists of research on interorganizational integration through the theory of collaborative advantage and seven selected collaborative themes, as well as intersectoral research. Chapter 5 presents the theoretical framework by describing the different theories and approaches that have guided the research process and been applied in the specific papers. This is followed by a description of the methodological framework in Chapter 6, where the methodological approaches are presented in relation to a description of the three studies. The chapter ends with ethical considerations. In chapter 7 , the findings from the papers are summarized, including a section on each paper's contribution to the thesis. In chapter 8 , the results are discussed in order to address the aim and overarching research questions through the social dynamics of labor market inclusion. This is followed by methodological considerations, including a section on future research. The chapter ends with conclusions and practical implications 



\section{BACKGROUND}

This chapter provides a background to the topic of labor market inclusion by presenting a brief description of the Swedish labor market and its characteristics. This is followed by a presentation of Swedish labor market policy, highlighting central concepts and significant changes during recent decades that are essential in order to understand labor market inclusion. The chapter ends with a description and definition of the concept of labor market inclusion, including description of the three actors: unemployed individuals, employers, and the authorities.

\section{The Swedish labor market}

A labor market can be described as a system for hiring labor (Furåker, 2017). The main actors in a labor market are those who hire or bye labor (employers) and those who rent out or sell their labor (employees). Apart from these, there are three other actors in a labor market: trade unions, employer organizations, and the state. In the Swedish labor market, unions and employer organizations bargain to determine wages and employment conditions, whereas the state is responsible for the legal regulation of relationships between the labor market actors and general labor market policy (e.g., measures aimed at counteracting and managing unemployment, and producing a sufficient supply of labor with appropriate training)(Furåker, 2017).

Sweden has a very high employment rate from an international perspective, at approximately $75 \%$. This is explained by a high employment rate for women and the elderly (Arbetsförmedlingen, 2019b). For a long time, Sweden had unemployment rates which were among the lowest in the Western world, although that picture has changed since the recession of the 1990 s when unemployment increased, and has remained relatively high ever since (between $6 \%$ and $9 \%)^{2}$.

Swedish working life has undergone extensive structural changes in recent decades. Developments have been driven by new knowledge, digitalization, increased demands for efficiency, increased international competition, and budgetary cuts that have led to new ways of organizing work, as well as a more complex, dynamic, and more insecure working life (Allvin et

\footnotetext{
${ }^{2}$ https://data.oecd.org/unemp/unemployment-rate.htm
} 
al., 2006; Nilsson and Ekberg, 2014). One consequence of these changes is that the demands placed on the workforce have increased in terms of psychological and social abilities such as flexibility, creativity, social competence, and initiative (Garsten and Jacobsson, 2004; Ekberg et al., 2006). These new requirements are responses to broad tendencies of individualization and the deregulation of work organization, which have characterized working life in the 21st century and have meant that employees are expected to be independent, flexible, and responsible in order to manage work (Allvin et al., 2006). At the same time, the increased demands in terms of productivity and profitability have meant that tolerance for mistakes and low productivity have decreased (Nilsson, 2010).

One consequence of the digitalization and automation of work is that many simpler jobs have disappeared from the labor market: during 20062011, almost half a million jobs were automated (Fölster, 2015). These changes have also meant a tougher work climate that places higher demands on levels of education and competence, both in existing professions and in new jobs that did not exist ten years ago (Ahlberg et al., 2018). The high educational requirements, in combination with an increased proportion of jobseekers with a low level of education, create an imbalance in the labor market where employers experience difficulties finding employees with the right skills. This gap between the skills that employers demand and those that the unemployed possess is one of the labor market's biggest challenges for the future (Nordström, 2018).

In line with the individualization trend, the individual is considered responsible for being attractive in the labor market and is expected to continuously promote his or her employability (Nilsson and Ekberg, 2014). In practice, an individual's employability includes everything that is important for getting a job and the individual's ability to actually perform the work. However, in addition to education, competence, and the personal qualities mentioned above, other aspects such as gender, ethnicity, health, and ability to work also affect an individual's ability to get and keep a job (Garavan, Nilsson and Ellström, 2012). Another consequence of the developments within the labor market is that employment arrangements have changed, with permanent employment increasingly being replaced by various forms of temporary employment, or employment through temporary work agencies. These changes in the structure of the labor market have made the labor market more exclusive (Michailakis, 2002). Particularly vulnerable groups, such as individuals with low levels of education, immigrants, and individuals with disabilities, have a harder time entering and remaining in the labor market (Arbetsförmedlingen, 2017a). Various labor market policies and inclusion measures aim to counteract these developments. 


\section{Swedish labor market policy}

The concept of labor market policy lacks a clear common definition and demarcation in relation to other areas and policies. Olofsson and Wadensjö (2009, pp. 7-8) point out that it is not always possible "to distinguish between what is labor market policy and what is other policy, e.g. education policy or social policy". The same applies in international contexts, where labor market policy at EU level is included in social policy, which also includes labor law and labor market relations.

Labor market policy in broad terms can be understood as all kinds of public intervention in the labor market regarding institutions or policies aimed at the functioning of the labor market, such as legislation regarding job security and discrimination, as well as educational and family policy initiatives (Furåker and Blomsterberg, 2009, p. 287). A narrower definition views labor market policy as "actions intended to solve the employers' and employees' main problems - a sufficient supply of labor and a sufficiently large labor demand" (Bengtsson, 2017, p. 270). Calmfors et al. (2002) narrows the meaning even further to measures aimed at improving the individual's opportunities in the labor market.

The aim of labor market policy actions is "to counteract or manage unemployment and to produce a sufficient supply of labor with appropriate education" (Furåker, 2017, p. 67). The means for this are different actions and policies, which can be divided into passive and active policies. Passive policies involve financial support for unemployed individuals, while active policies involve direct intervention in the functioning of the labor market in order to reduce unemployment (Bengtsson, 2017).

As with labor market policy, there is no commonly agreed definition of active labor market policies (ALMPs) (Martin, 2014). The OECD defines activation strategies as aiming "to bring more people into the effective labour force, to counteract the potentially negative effects of unemployment and related benefits on work incentives by enforcing their conditionality on active job search and participation in measures to improve employability, and to manage employment services and other labour market measures so that they effectively promote and assist the return to work" (OECD, 2013, p. 132). ALMPs can be divided into three different categories: search assistance measures, training programs, and subsidized jobs (Crépon and van den Berg, 2016). Search assistance measures aim to make the labor market operate more smoothly by matching vacancies to jobseekers. Training programs aim to increase the market value and employability of the employee through training, internships, or job coaching. Subsidized jobs refer to various forms of employment support or direct job creation. (Bengtsson, 2017)

A related concept to ALMP is activation, which refers to measures targeting people who receive financial support or who risk being excluded in 
the labor market (sometimes referred to as "vulnerable individuals"). The concept has strong attachment within the EU and the OECD, which aim to encourage countries to change from passive to active measures. (Bengtsson, 2017) Activation policy has been described as a Janus face integrating two different approaches (Hedblom, 2004). On one side is the more positive approach, with active measures and generous benefits, representing a view where the unemployed are considered to have the right to receive public support to develop their resources. On the other side is the more negative approach, referring to a control and discipline logic that aims to reinforce the benefits of work through various work incentives. (Bengtsson, 2017)

Another central concept in Swedish labor market policy is the political notion of "the work strategy" or "the line of work". This strategy is based on a strong work norm and a high work ethic, prioritizing work to secure tax revenues in order to be able to finance the welfare system (Johansson and Hornemann Möller, 2009). Even if the emphasis on the work strategy has shifted between being mainly seen as a right, an obligation, and "help to self-help", its general meaning has been that unemployment benefits should have an active character and "should be prepared primarily in the form of work, employment or education and only in exceptional cases of financial/beneficial support" (Junestav, 2007, p. 10).

\section{Changes in Swedish labor market policy}

Historically, Swedish labor market policy has had a strong emphasis on activation and Sweden is often seen as "the cradle of active labor market policy" (Bengtsson, 2017, p. 271). However, in recent decades, this policy has undergone changes affected by political governance and economic changes, whereby the commitment to full employment has been somewhat relaxed, although pressure on the unemployed has intensified (Raffass, 2017). This development can be understood based on the welfare researcher Neil Gilbert's theory (Bengtsson, 2017) as a shift from a welfare state to an enabling state, where the balance in the social contract between state and individual has been shifted toward more individual obligations and fewer rights. The transformation can be understood in relation to four tendencies: a work first approach, a controlling and conditional labor market policy, selective actions, and privatization.

\section{A “work first" approach}

The first tendency is a shift from protecting citizens through a welfare state's safety net to a "work first" approach. This has been seen during the 200os, with reforms reinforcing the "work strategy" through various 
strengthened work incentives such as reduced benefits in unemployment insurance and tax reductions (Bengtsson, 2017).

Based on Junestav's (2004) research on work strategies, this shift can be described as a transition from a rights perspective or a self-help perspective to a line of work with a control and discipline perspective. The three different orientations identified in Swedish labor market policy history differ concerning whether work is viewed as a right or obligation and the perceptions regarding the division of responsibilities between the welfare state and the individual. The development toward a control and discipline perspective is characterized by a perception of the individual's responsibilities and obligations as a provider, and by financial support to the individual having clear requirements for compensation, which in turn is based on activity demands. This perspective is based on the principle of controlling the individual's behavior through threats of financial sanctions and performance demands for individuals receiving financial support, known as workfare (Junestav, 2004). Workfare has been found to be the least effective measure for bringing people closer to regular employment (Raffass, 2017).

Activation is central to the work first approach. The development toward increased demands for compensation in order to receive compensation is usually summarized as a shift from "welfare to workfare", but can more aptly be described as a development from "welfare to activation measures" (Nord 2017). In other words, one has "a right and a duty to activation", not the right and duty to work (van Kersbergen and Hemerijck, 2012, p. 482). The activation strategy has been criticized for not resulting in lower unemployment and for affecting vulnerable groups in negative ways (Rafass 2016). Since employment is not guaranteed as a right and statistically there are not enough jobs for every unemployed individual, the duty to activate means that unemployed individuals are forced to demonstrate "work-readiness" through participation in prescribed activities that are not genuinely expected to result in real jobs. Activation is also considered to drive unemployed individuals into low-skill, low-pay, and precarious jobs. (Rafass 2016)

\section{A controlling and conditional labor market policy}

The second tendency Gilbert refers to is a shift from considering social benefits as a human right to the recipient's obligation and responsibility to behave correctly, contribute to society, and quickly become independent. This shift can be seen through the introduction of the guarantees and individual action plans at the PES, as a way of individualizing and contractualizing labor market policy (Bengtsson, 2017). Also, demanding activation in vari- 
ous measures is seen as a solution for dealing with the difficulty of controlling whether the unemployed really want to work and actively seek work (SOU, 2007).

The political strategy is characterized by reducing labor market absence by increasing the supervision and control of individuals living on welfare allowance. The development of the dual function of the PES to both support and control can be described as "from supporting and controlling to supporting by controlling" (Walter, 2011, p. 61).

One aspect of this shift toward a conditional welfare is reduced benefits. The monitoring of the unemployed is an important controlling element, and suspicions of negligence can lead to financial sanctions (Nord, 2018). The development is based on the assumption that the individual, through financial pressure, will be encouraged to develop work ability and employability (Olofsson, 2011). Unemployment benefits have been gradually reduced, with a sharp drop in the income-related allowance benefit (Bengtsson, 2017).

Research has shown that reduced benefits hit already vulnerable groups especially hard. Kjellberg studied unemployment benefits and found that that restrictions in insurance led to around 500,000 individuals leaving the unemployment insurance system; among these, there was an over-representation of vulnerable groups such as young people, low-educated people, and people with immigrant backgrounds (Kjellberg, 2010b, 2010a).

\section{Selective actions}

The third tendency concerns the transition from universal rights to selective activities. This transition is manifested in Swedish labor market policy by focusing the more extensive program measures on groups that are far from the labor market, while simpler initiatives are offered to regular jobseekers (Bengtsson, 2017).

The development toward selective actions for specific groups means a change in the scope and content of the ALMPs. Since the 1990s, the total expenditure on active measures has decreased, especially for labor market education. Instead, the emphasis has shifted to matching, job search programs, guidance, and coaching. This work is mostly aimed at those who are far from the labor market, and the cost of subsidized employment has increased (Arbetsförmedlingen, 2016). However, in relation to international measures, expenditures during 2009-2013 shows that Sweden has one of the highest costs for ALMPs in Europe (Bengtsson, 2017).

This development toward selective actions for specific groups is criticized by Gallie (2002) due to the efforts being offered when concerns have arisen instead of working preventively before unemployment occurs. 


\section{Privatization}

The fourth tendency mentioned by Gilbert is a transition from a state responsible for public services and demand-oriented measures to a state where welfare is increasingly privatized. This development can be seen in the increased presence of private actors working with labor market inclusion and providing support to jobseekers, so-called complementary actors to the PES (Bengtsson, 2017). This development is confirmed by a recent proposal concerning a new organization of the PES, in which has been suggested that private actors should be given an increased role (SOU, 2019).

The development is also reflected in the unemployment benefit provision system, where the retrenchment of the public system has been combined with an institutionalization of complementary systems by unions and private insurance actors (Lindallee, 2018). A development that Lindallee (2018) concludes benefits those with a very low risk of becoming unemployed and disadvantages those in vulnerable groups, since the majority of those who are actually unemployed do not have access to these earningsrelated benefits.

\section{Labor market inclusion: definition and demarcation}

This section aims to define the concept of labor market inclusion. Since there is no existing common definition, some related concepts will be described that are closely connected before arguing for introducing this new concept.

Firstly, there are the closely related concepts of active inclusion and inclusive labor market. The European Commission defines active inclusion as "enabling every citizen, notably the most disadvantaged, to fully partici-

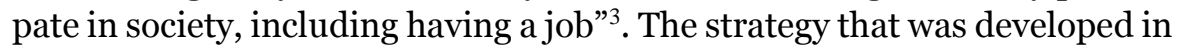
2008 builds on three integrated elements: adequate income support, inclusive labor markets, and access to quality services (European Commission, 2008). Active inclusion emphasizes the importance of helping individuals who are excluded from the labor market to get a job, since many jobs are not accessible for disadvantaged groups. The commission described inclusive labor markets as including personalized pathway support for quality employment. Labor markets are defined as being inclusive "when everyone of working age can participate in paid work, especially vulnerable and disadvantaged people". Promoting inclusive labor markets means "making it easier for people to join (or re-join) the workforce, removing disincentives to work and promoting quality jobs and preventing in-work poverty"

\footnotetext{
${ }^{3}$ https://ec.europa.eu/social/main.jsp?catId=1059\&langId=en
} 
(European Commission, 2008). Active inclusion aims to tackle various challenges such as poverty, social exclusion, in-work poverty, labor market segmentation, long-term unemployment, and gender inequalities ${ }^{4}$. These concepts have a broader meaning than labor market inclusion, since they also cover and focus on social inclusion in society.

Secondly, there are concepts related to rehabilitation, such as workoriented rehabilitation, work rehabilitation, vocational rehabilitation, occupational rehabilitation, and return-to-work. These concepts lack a common definition and are used inconsistently. On an overall level, they describe measures that aim to enable individuals who lack the capacity to work to regain their ability and be given the right conditions to support themselves through employment (Johansson et al., 2011). Measures under these headings are primarily directed at individuals who have had a profession or previous work experience, and the term "return to work" primarily refers to individuals with an existing job, e.g. in the case of sick leave. Ekberg (2010) describes work-oriented rehabilitation as the interplay between an individual's abilities and the requirements of a job. The measures are focused on creating the right conditions for the individual to support themselves through professional work. Measures in the workplace that aim to facilitate a return to work, such as changing work tasks and ergonomic aids, are part of work-oriented rehabilitation. These concepts have a narrower meaning than labor market inclusion, due to their focus on regaining functions and abilities and returning to the labor market.

Neither labor market policy, active inclusion, inclusive labor markets nor the rehabilitation concepts fully describe the process that is the focus of this thesis. Therefore, the concept of labor market inclusion has been chosen, which in this thesis is used to describe the process of helping unemployed individuals to progress from dependency on welfare benefits to self-sufficiency through work. The concept can be understood in relation to an interplay between the three central actors: unemployed individuals, employers, and the authorities. This interplay can be illustrated as a piece of clockwork machinery, where each cog wheel represents an actor (Figure 1). In order to make the machinery work, that is to succeed with labor market inclusion, the actors need to interact with each other. This is where the challenges arise.

\footnotetext{
${ }^{4}$ https://ec.europa.eu/social/main.jsp?catId=1059\&langId=en
} 


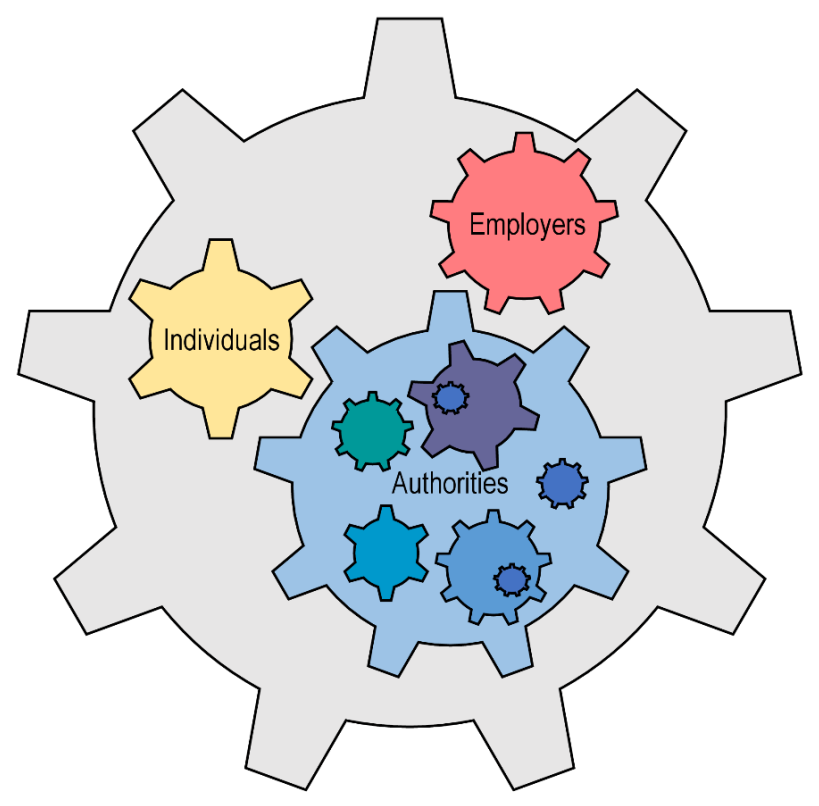

Figure 1: Labor market inclusion: An interplay between three actors; the individuals, the authorities, and the employers, resembling with a piece of clockwork machinery.

In the following sections of this chapter, these three actors and their contexts are described. The integration between the actors is described in chapter 3 , and the integration challenges are addressed in chapter 4.

\section{Unemployed individuals}

The unemployed individuals referred to in this thesis are on welfare benefits, that is, financial support from the social insurance system or municipal financial support. These individuals are therefore not self-sufficient, and require support from the authorities. Many are long-term unemployed, and many have never been able to get a foothold in the labor market. They are often referred to as "standing far away from the labor market" (Forslund et al., 2019). The PES refers to this group as individuals who have "a vulnerable position in the labor market", highlighting individuals with disabilities and reduced work capacity, individuals born outside Europe, individuals with short education, and jobseekers aged 55 or older (Arbetsförmedlingen, 2017a). 
Figure 2: Unemployed individuals aged 16-64, enrolled at the PES during January 2004-December 2016, divided into vulnerable groups and other unemployed.

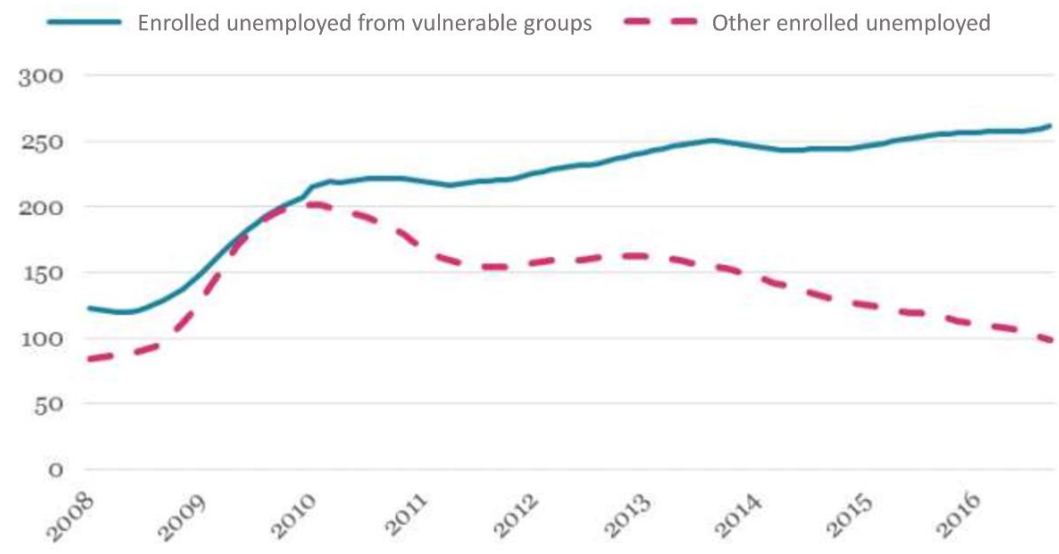

Source: Arbetsförmedlingen 2017 (translated into English by the author).

Since 2006, this group has increased from 50\% to $72 \%$ (approximately 260,000 individuals). At the same time, other groups of registered unemployed people have decreased (Arbetsförmedlingen, 2017a).

A common denominator of unemployed people in a vulnerable position in the labor market is that they run a greater risk than others of ending up in long-term unemployment (i.e., longer that 12 months). There has also been an increase in the proportion of young people who are long-term unemployed, where a large proportion of these individuals have disabilities and a low level of education. However, in an international context, Sweden has the lowest proportion of long-term unemployment (20\%) compared to EU countries as a whole, where the average is around 50\% (Arbetsförmedlingen, 2017b).

The reasons behind this increase among vulnerable groups can be linked to various labor market policy reforms. Changes in the sickness insurance system resulted in an increase in people with health problems, people on long-term sick leave and people with reduced work capacity being enrolled at the PES. An "establishment assignment" was assigned to the 
PES, aiming to assist immigrants to enter the labor market, which significantly increased the proportion of enrolled individuals born outside $\mathrm{Eu}-$ rope. The increase can also be explained by cyclical changes in the economy and the labor market, where cuts have affected individuals with relatively low levels of productivity and have resulted in higher demands being placed on upper secondary education, weakening the position of individuals with a low level of education (Arbetsförmedlingen, 2017b). Statistics from the PES show that approximately 287,000 individuals participated in an ALMP program with activity support during 2019 (Arbetsförmedlingen, 2019a).

Individuals can receive financial support from the social insurance system and from the municipal financial support system. The social insurance system refers to public insurance schemes such as unemployment insurance, sickness insurance, occupational injury insurance, parental insurance, old-age pension and certain forms of unemployment insurance. These schemes provide financial support in the event of loss of income. The level and length of payment are linked to previous labor market participation, and for individuals who do not qualify there is a basic level (Ståhlberg, 2014). For individuals who are not entitled to compensation from social insurance or who are unable to support themselves, there is a means-tested municipal financial support system. The different compensation forms and their conditions are described in greater detail below.

\section{The authorities}

The authorities involved in labor market inclusion in this thesis are the Public Employment Service (PES), the municipalities (the social services and labor market units), the Swedish Social Insurance Agency (SIA) and the regions (health care). These four actors are also connected through a specific integration form called coordination associations, which is one of the arenas in which the empirical studies of this thesis take place. In the following sections, the authority actors are described briefly in relation to their assignments concerning labor market inclusion. The coordination associations are described under "Examples of integration".

\section{The Public Employment Office (PES)}

The PES is the actor with main responsibility for labor market policy and ALMPs. The PES's assignment involves improving the functioning of the labor market by working to create an effective match between employers and jobseekers. The assignment also involves prioritizing and equipping those standing far from the labor market, and contributing to increased inclusion and long-term employment. (SFS, 2007) In total, the Swedish Pub- 
lic Employment Service received SEK 67.2 billion to carry out its assignment in 2019. ${ }^{5}$ The PES's assignment is regulated annually through letters of regulation from the Swedish Government. In the regulations for 2020, the focus includes the establishment of immigrants, work-oriented rehabilitation in cooperation with the SIA, and people with disabilities. Between now and 2022, PES is undergoing a fundamental reform characterized by a privatization trend, where the state will continue to have government responsibility for labor market policy, but where the matching assignment is handed over to private independent actors. (Regeringen, 2019)

The PES is also responsible for providing immigrants with suitable conditions for inclusion in the labor market as quickly as possible, as well as work-oriented rehabilitation. Work-oriented rehabilitation means that jobseekers who need special support are offered investigative, guiding, rehabilitative, or work-preparatory support, with the aim that more people with reduced work capacity due to disability or illness should be able to work. A condition for individuals to get access to these resources is that they have a medical certificate that allows for coding based on various disability codes. ${ }^{6}$

Labor market policy programs are central measures at the PES. The overall purpose of these programs is to strengthen the individual's ability to get and keep a job, and to encourage and enable employers to hire jobseekers standing far away from the labor market. The PES distinguishes between programs with activity support and programs with financial support, or subsidized employment (Bengtsson, 2017). The programs with activity support consist of various types of activation as well as educational and practical activities for unemployed individuals, such as labor education, training, the establishment program (for immigrants), the job and development guarantee (for the long-term unemployed), a job guarantee for young people, support for starting a business, or validation and other preparatory activities. Preparatory activities include a variety of activities such as job search courses, work-oriented rehabilitation, and courses in Swedish for immigrants. The benefits for these programs are administered by the Swedish Social Insurance Agency. Programs with financial support consist of financial support to employers through various forms of subsidized employment for individuals in vulnerable groups. (Bengtsson, 2017; Arbetsförmedlingen, 2019a)

The PES is responsible for ensuring that unemployment insurance functions as a transitional insurance. This includes checking that those

\footnotetext{
${ }^{5}$ https://arbetsformedlingen.se/om-oss/press/nyheter/nyhetsarkiv/2019-10-28-prognos-arbetsformedlingen-lamnar-tillbaka-delar-av-programanslagen

${ }^{6}$ https://arbetsformedlingen.se/om-oss/var-verksamhet/vart-uppdrag
} 
jobseekers who receive or request unemployment benefits meet the regulatory requirements. Unemployment insurance is voluntary, and all employed workers are eligible. It consists of two parts: basic insurance and income-based insurance. The insurance is conditional, with the basic condition concerning the individual's commitment and willingness to get a job. This means that the individual must be enrolled at the PES, and be able to work and to take a job of at least three hours per day (and an average of 17 hours per week) in order to be considered "at the disposal of the labor market”. Moreover, individuals have to actively seek work, participate in establishing individual action plans, and submit monthly activity reports to the PES. Compensation from the insurance requires previous work amounting to approximately half-time employment for six months. The income-based insurance requires membership of an unemployment fund, and is based on previously worked hours and income. Unemployed people without such a membership but who meet the basic conditions are referred to the basic insurance, with a maximum allowance of SEK 365 per day. This insurance covers 300 compensation days, with an additional 150 days for parents of children under 18. Thereafter, a work requirement is applied in order for the individual to qualify for a new compensation period. (SO, 2016)

Individuals participating in labor market policy programs at the PES receive compensation called activity support, development allowance, or establishment allowance. This allowance is also conditional, and the level depends on age, educational level, and whether the individual meets the conditions for unemployment insurance. Entitlement to the allowance is decided on by the PES, but the allowance is administered by the Swedish Social Insurance Agency ${ }^{7}$. Individuals enrolled at the PES who do not participate in labor market policy programs and do not qualify for unemployment insurance are not entitled to any compensation.

\section{The municipalities}

\section{Municipal social services}

Municipal social services are regulated by the municipal social board responsible for the practical and political work regulated by the Social Services Act. Social services work according to the social services act introduced in 2001 (SFS, 2001). Social services have an extensive area of responsibility that aims to promote people's economic and social security, equality of living conditions, and active participation in society.

\footnotetext{
${ }^{7}$ https://www.forsakringskassan.se/privatpers/arbetssokande/om-du-deltar-i-ett-program-hos-arbetsformedlingen
} 
One area concerns financial assistance and labor market measures. The role of the financial support is to provide a safety net for people with temporary livelihood difficulties. Social services decide on and pay financial support to individuals who cannot meet their own needs and cannot have them met in another way. It is intended to provide temporary relief, and the individual is encouraged to primarily seek other solutions, such as employment or sickness benefits. The allowance is conditional and meanstested. A central condition for receiving financial support is the individual's financial situation, where money in the bank or other assets limit the possibilities for compensation. (SFS, 2001)

Social services are strongly influenced by the work principle, and aim to help the individual to become self-sufficient. According to the Social Services Act (SFS, 2001), everyone is primarily obliged to support themselves and their families, meaning that individuals with the capacity to work must "be at the disposal of the labor market" in order to be entitled to welfare benefits. In practice, this means that unemployed individuals can be required to apply for jobs or participate in programs or measures at the municipality or at the PES. Individuals with reduced work capacity due to disability need to prove this with a medical certificate. The work principle is translated into practice through the organization of municipal labor market units.

\section{Labor market policy units}

Since the 1990s, the municipalities have been given increasing responsibility for labor market policy through the development of municipal labor market units (Forslund et al., 2019). One reason for this increased activity is the increase in unemployed individuals standing far from the labor market who receive municipal financial support. The development is thus driven by the need to reduce this expense by helping unemployed individuals to become employable and ultimately employed. The development can be understood as a gradual decentralization of labor market policies and a development of two parallel labor market policy systems, one at municipal level and one at state level (SOU, 2017b).

There are uncertainties regarding the municipalities' role and authority concerning labor market policy initiatives, and the division of roles between the PES and the municipalities is unclear (SOU, 2019). The municipalities are not obliged to provide labor market initiatives. Despite this, 97\% of Swedish municipalities do offer labor market policy activities (SKR, 2011). The municipal labor market policy system handles approximately a fifth of the number of participants enrolled at the PES (Forslund et al., 2019), and the municipalities' net costs for labor market initiatives in 2017 were just under SEK 5 billion (Panican and Ulmestig, 2017). 
The municipal labor market policy activities can be classified into the following categories: job training/testing and preparatory activities, job search/coaching and study guidance, courses, matching, internships, employment support for people with and without disabilities, municipal labor market employment arrangements, holiday jobs/youth internships, language courses in Swedish for immigrants, and validation. These activities vary between municipalities, but the most common activities are job searching activities, internships, and municipal labor market employment (Forslund et al., 2019).

Even though the municipal labor market units mainly work with individuals on financial support who have been referred to them by social services, they also receive individuals referred to them by the PES. In a recent government report (SOU, 2020), it is suggested that the municipal labor market units can be formally considered as complementary actors to the PES in their reorganization, thus further enforcing the role of the municipalities.

Despite the extent of the system, there is a lack of knowledge about the effects on labor market employment and the municipalities' labor market initiatives in general (Vikman and Westerberg, 2017; Lundin, 2018; Forslund et al., 2019). In a knowledge review by Thorén (2012) of various measures for unemployed income support recipients, the available evaluation and effect studies of municipal activation showed few positive results.

\section{The Swedish Social Insurance Agency (SIA)}

The Swedish Social Insurance Agency is responsible for deciding on and paying out a large part of the benefits included in the Swedish social insurance system. This assignment is regulated by the Social Insurance Code (SFB, 2010), which is a coherent and comprehensive social insurance law, and through annual regulation letters to the authority from the Government. The agency has a role in deciding on and paying benefits such as sickness benefits, housing benefits, and parental benefits. In addition to paying sickness insurance benefits, the agency is also responsible for paying other benefits (activity support, development compensation, and establishment compensation) to unemployed individuals enrolled in a labor market policy program at the PES. These benefits are conditional, and the individual needs to fulfil four conditions in order to be entitled to receive them: they cannot look for or take a job, they must be enrolled at the PES, they must have a sickness benefit qualifying income (SGI in Swedish), and they must be insured in Sweden (i.e., fulfilling the work requirements for being covered by the insurance system) ${ }^{8}$

\footnotetext{
${ }^{8}$ https://www.forsakringskassan.se/privatpers/sjuk/arbetssokande/sjukpenning
} 
The sickness benefit qualifying income is calculated based on annual income, and is the basis for compensation for both short-term sickness (sickness benefit) and long-term permanent sickness (disability pension). Individuals who have never worked do not qualify for this income. There are also individuals who have been working, but who - due to their illness or disability - have not been able to protect this income. These individuals fall outside the system and may need to apply for financial support from social services (Lundqvist Medén, 2016). Unemployed young individuals (aged 19-29) with an illness or a disability that renders them unable to work for at least one year can qualify for a special benefit called activity compensation. The level of benefits depends on age and whether the individual has worked before. Unemployed individuals can also apply for insurance schemes that are not dependent on work, such as parental insurance.

The Swedish Social Insurance Agency has a responsibility for coordinating rehabilitation efforts for individuals on sick leave. In this work, the agency cooperates with the municipalities, social services, health care, the PES, and other authorities involved in rehabilitation. The agency is responsible for monitoring that all actors in the rehabilitation process contribute to effective rehabilitation, drawing up a rehabilitation plan, and convening reconciliation meetings for coordination, but does not carry out any rehabilitation efforts of its own (Johansson et al., 2011). ${ }^{9}$

\section{The regions}

Health care is the regions' most important assignment. Swedish health care is regulated by the Health Care Act and the National Board of Health and Welfare's regulations. According to the act: "The goal of health care is good health and care on equal terms for the entire population. Care must be given with respect for the equal value of all human beings and for the dignity of the individual human being. Those who have the greatest need for health and medical care must be given priority for care." (SFS, 2017) Moreover, health care must work to prevent illness. The regions are directed by regional self-government and, as such, the different regions in the country are adapted in line with local conditions. ${ }^{10}$

In relation to labor market inclusion, the regions play a central role for unemployed individuals with illness or disability who need health care or rehabilitation activities in order to be able to work, regardless of income/compensation and/or work capacity.

\footnotetext{
${ }^{9} \mathrm{https} / / / \mathrm{www}$. forsakringskassan.se/press/vart-uppdrag-sjukforsakringen

${ }_{10}$ https://skr.se/demokratiledningstyrning/politiskstyrningfortroendevalda/kommunaltsjalvstyresastyrskommunenochregionen/sastyrsregionerna.1790.html
} 


\section{Employers}

Swedish employers have no legal obligation to participate in or facilitate labor market inclusion by hiring individuals from vulnerable groups or by cooperating with authority actors in ALMPs. In some other countries, the role of employers has been regulated in this sense. For example, in some states in the US, employers with more than 15 employees are forbidden from discriminating against people with disabilities in all aspects of employment, ${ }^{11}$ and in Germany, employers with more than 20 employees are required to fill more than $5 \%$ of their job positions with severely disabled employees (Kock, 2004). Employers' participation in labor market inclusion in Sweden is thus based on voluntary actions.

According to the Work Environment Act (SFS, 1977), employers are responsible for employees being able to perform their work without the risk of illness or accidents. Moreover, employers must ensure that there is an appropriate organization for work adaptation and work-oriented rehabilitation in the workplace. This is regulated in the Swedish Work Environment Authority's Regulations on Work Adaptation and Rehabilitation (AFS, 1994), the Regulations for Systematic Work Environment Management (AFS, 1994), the Regulations on Organizational and Social Work Environment (AFS, 2015), and the Social Insurance Code (SFB, 2010). The work must be organized so that it can be done in collaboration with the employees concerned, and with the Swedish Social Insurance Agency if required. Other laws related to the employer-employee relationship include the Employment Protection Act (SFS, 1982), which regulates laying off staff and temporary jobs. This law states that employers cannot terminate employment without a "factual basis", and in the case of redundancy, a certain turnaround must be followed based on how long the person has been employed - last in, first out.

If an employer chooses to participate in labor market inclusion, various forms of support are available from the PES. The nature of this support depends on which target group the individual belong to: immigrants, young people, long-term unemployed, or people with disabilities. The support consists of three elements: financial support, professional support, and aids and adjustments in the workplace. Financial support consists of support for both training and internships, as well as subsidized employment. Subsidized employment includes employment with support in the form of a financial contribution or a tax reduction for all or part of the wage cost. It is divided into jobs aimed at people with disabilities and those aimed at people from vulnerable groups who, for other reasons, have a weak position, mainly the long-term unemployed and new arrivals. The different

\footnotetext{
${ }^{11}$ https://www.dol.gov/odep/pubs/fact/rights.htm
} 
forms of subsidized employment differ in terms of purpose, target group, compensation period, and degree of subsidization. The financial support varies from SEK 150 per day to full salary compensation. In some cases, if the individual has extensive needs, the employer can be financially compensated in a way that implies a profit. Professional support means that the employer can get support from different professionals at the PES, such as occupational therapists, psychologists, or social consultants. Aids and adjustment in the workplace involve the employer being compensated financially for aids, or if the individual needs assistance from a supervisor or a coworker to perform tasks, or if an interpreter is required ${ }^{12}$.

For employers in the public sector, special funds are set aside to encourage different initiatives such as incentive funds for "extra jobs" within municipalities and regions. In 2017, municipalities received SEK 70,000 per individual employed with extra job employment. For regions, the sum in 2018 was SEK 150,000 (SKR, 2018).

In 2018, 14\% of companies in the labor market had some form of subsidized jobs. Almost half of these employers were small businesses with 14 employees (Arbetsförmedlingen, 2019b).

\section{Summary}

Chapter 2 has focused on labor market inclusion by defining and presenting the concept and the involved actors in relation to the Swedish labor market and labor market policy. Labor market inclusion has been illustrated as a piece of clockwork machinery, conveying an ideal image of the phenomenon as a synchronized integration machine.

The chapter has shown that labor market inclusion is an important and challenging societal issue in the Swedish welfare system, where an increasing number of unemployed individuals from vulnerable groups on welfare benefits need help from the authorities to enter the labor market. At the same time, the Swedish labor market policy is undergoing changes and the authorities are struggling to find strategies for organizing labor market inclusion.

\footnotetext{
${ }^{12}$ https://arbetsformedlingen.se/for-arbetsgivare/anstall-med-stod
} 


\section{INTEGRATION}

This chapter presents integration as a central working method in labor market inclusion. The chapter begins with a section that defines and conceptualizes integration. This is followed by a section on organizing integration, presenting different integration forms with a specific focus on integration projects. Thereafter, a section is devoted to empirical examples of different integration forms, highlighting the coordination associations that play a central role in this thesis.

\section{Definition and conceptualization}

\section{Why integration?}

Labor market inclusion is a complex welfare commitment, involving different actors and professional groups from different organizations and sectors. These actors and groups have different roles and responsibilities in encouraging unemployed individuals on welfare benefits to become selfsufficient workers. This welfare sector has seen increased differentiation and professionalization, both within and between organizations, bring a risk of fragmentation and a lack of a holistic view among the actors involved. (Axelsson and Bihari Axelsson, 2013; SOU, 2017a)

Integration is a more or less structured approach to integrating various professionals and actors, and aims to counteract fragmentation and improve the quality and effectiveness of welfare services by enabling different actors to contribute complementary knowledge, skills, and resources (Axelsson and Bihari Axelsson, 2006; Nylén, 2007). At the end of the $20^{\text {th }}$ century, integration was suggested as "the welfare state's new working form" (Kullberg and Danermark, 1999). More than twenty years later, it can no longer be referred to as "new", but is still a common working form which is strongly recommended by authorities (Huxham and Vangen, 2005), with regard to both interorganizational and intersectoral integration (Tillmar et al., 2018).

The benefits of integration that are usually highlighted are access to resources, shared risks, increased efficiency, co-ordination, and learning. Another argument for integration is the moral imperative, described as there being "no other way". This argument rests on the belief that complex welfare issues, such as labor market inclusion, cannot be tackled by any organization acting alone (Huxham and Vangen, 2005, p. 7). This is a synergy argument which argues that "to gain real advantage from collaboration, 
something has to be achieved that could not have been achieved by any one of the organizations acting alone" (Huxham and Vangen, 2005, p. 60).

\section{Definitions and dimensions}

There is no commonly accepted definition of integration, either internationally or in Sweden, which has led to a varied nomenclature for describing different forms of integration. This is also true for similar concepts, where there is no consensus regarding the specific meaning of terms such as cooperation, collaboration, or coordination (O'Leary and Vij, 2012). These concepts are often used synonymously without specifying differences in terms of complexity and formalization, contributing to conceptual confusion (Huxham, 1996).

Danermark defines integration as "conscious goal-oriented actions performed together with others in a clearly defined group regarding a defined problem and purpose" (Danermark, 2000, p. 15). Axelsson and Bihari Axelsson describe it as "working together, i.e., to accomplish or achieve something common", meaning something that presupposes that the collaborating actors cross different disciplinary, professional, organizational, and sectoral boundaries (Axelsson and Bihari Axelsson, 2013, p. 18).

In order to sort out the terminology, the concept of integration - meaning bringing different parts together into a larger unit - has been suggested by Axelsson and Bihari Axelsson (2006) as an umbrella term. They have also put together a conceptual scheme differentiating between the different integration concepts in relation to horizontal and vertical integration. Horizontal level refers to integration between authority officials or similar, whereas vertical level refers to integration between hierarchical levels. The categorization results in four different types of integration depending on the amount of integration: contracting (little integration on both axes), coordination (high on the vertical axis and low on the horizontal axis), collaboration (high on the horizontal axis and low on the vertical axis), and cooperation (high on both axes). In practice, integration can be a combination of vertical and horizontal integration along a sliding scale of different forms of coordination and collaboration (Axelsson and Bihari Axelsson, 2006). This can be described as a matrix organization where the vertical integration takes place through leaders at different hierarchical levels from the integrative organizations, and the horizontal integration takes place through network organization across professional and organizations boundaries, i.e. in teams (Bihari Axelsson and Axelsson, 2009). 
Figure 3: Conceptual scheme of different forms of integration

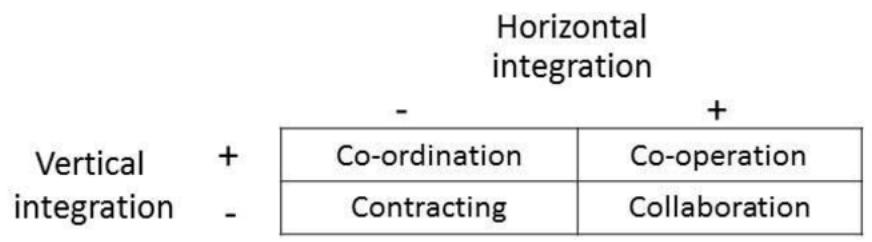

Source: Axelsson \& Bihari Axelsson 2006.

One way of approaching the complexity of integration is to use the analytical model for integration presented by Danermark and Germundsson (2007), which focuses on three basic dimensions of central importance to the integration process: regulatory framework, organization, and views. Regulatory framework concerns the rules that govern the integrative actors, i.e. laws, ordinances and regulations, instructions, and internal rules. Organization applies to both the organization of each integrative actor and the organization of integration as such. Views are about the collaborators' cultures and perspectives, in terms of both integration and those with whom they integrate. These dimensions should not be considered autonomous and independent, but as interacting in complex relationships with each other (Danermark and Germundsson, 2007).

The conditions can be divided into structural and cultural dimensions, where the structural dimension concerns economic restrictions, rules, political directives, control systems, administrative boundaries, etc., while the cultural dimension affects professional and organizational cultures such as views, language, attitudes, values, and communication patterns. This very distinction between cultural and structural dimensions is a common division, and means that the first two conditions (regulatory framework and organization) can be said to be more structural, while the third (views) is more cultural (SOU, 2018).

\section{Organizing integration}

The relationship between organizing and organization can be described as organization being a result of organizing and organizing taking place in organizations (Czarniawska and Joerges, 1996). The focus in this thesis is on the organizing rather than the form itself. 


\section{Integration forms}

The different forms or models for organizing integration can be categorized into seven models and placed on a continuum, depending on complexity and formalization, and ranging from autonomy to fusion (Andersson et al., 2011; Axelsson and Bihari Axelsson, 2013)(Figure 4). The forms can be divided into structure-oriented and process-oriented models. Structure-oriented models concern integration between different organizations (i.e. interorganizational integration) and sectors (i.e. intersectoral integration), and consist of case coordination, partnership, co-location, and pooling of budgets. Process-oriented models are more about integration and working forms between different professions (i.e. interprofessional integration), and consist of information exchange, interprofessional meetings, and multidisciplinary teams). According to Andersson et al. (2011), the seven models often occur in different combinations.

Figure 4: Different models for organization of integration on a continuum.

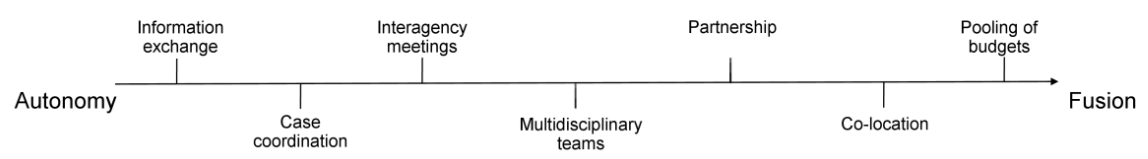

Source: Andersson et al. 2011.

The simplest form is the information exchange between independent organizations, often via informal contacts between professionals in the different organizations. Case coordination is another simple form of integration, consisting of an appointed representative of the authorities coordinating efforts and support for an individual. Interagency meetings are a common form of integration, with various frequencies, systematizations and formalizations. A more intensive form of integration is multidisciplinary teams, where different professions and organizations work together over a longer period. The teams can be multidisciplinary, interdisciplinary, or transdisciplinary, depending on how intense the contacts are between the participants and how dependent they are on each other (see Thylefors, Persson and Hellström, 2005). Partnership is a formalized integration form between two or more organizations, based on formal agreements or arrangements. The partnership can include everything from the focus, scope, financing of the activities, and the responsibilities and obligations of 
the involved actors, to structures for communication and information exchange. Co-location is not really a form of integration but a model for physical placement, where different organizations are placed nearby or at the same premises, creating conditions for cooperation across professional and organizational boundaries. The most far-reaching form of integration, pooling of budgets, is a model where the partners combine their resources into a common budget for joint activities.

\section{Integration projects}

A common form of organizing collaboration is through integration projects. Depending on formalization, integration projects can consist of all seven integration models mentioned above, organized separately or in different combinations. Projects as a form of organization are typically characterized by the fact that they are clearly delimited in time and task, have defined goals, and consist of a specific project organization, separating the project organizationally and financially from regular operations within the organizations (Löfström, 2010).

Integration projects often mean that representatives from different organizations come together to carry out a joint activity, enabling employees from different organizations with different professions and experiences to meet and try out different forms of integration. They can be used to create awareness of collaboration issues, create meeting places, or gather expertise and funding to develop new forms of work and routines (Torfing, 2016). The purpose of integration projects is often to pass on experience from projects to the home organizations and regular operations. In integration projects, each actor has boundaries in the form of competencies, regulations, administrative systems, and management structures from their home organizations. These boundaries need to be addressed when organizing collaboration, and are often a challenge when considering implementation. (Löfström, 2010)

Integration projects have become such a common form of organizing in the public sector that the "projectification of integration" is referred to (Löfström, 2010). Projectification means an increasing belief in projects as a temporary form of organization in order to bring about change, development, renewal, and a culture which perceive projects as the organizational solution. There are a large number of projects, and the European Social Fund (ESF) alone has funded over 90,000 projects in Sweden since 1995 (Fred, 2018).

One argument for using integrative projects as a form of organization in a collaborative context is the difficulty of carrying out developmental work in the ordinary organizational structure. The idea is to circumvent 
these difficulties by organizing integration projects as temporary organizations. (Löfström, 2010) The project form is also often a prerequisite for receiving funds (e.g., from international, national, or regional authorities such as the ESF, the coordination associations, etc.), where it is a common requirement that the financed activity is unique and separate from ordinary operations (Fred, 2018; Mc Glinn, 2018).

\section{Examples of integration}

\section{The coordination associations}

A coordination association (CA) is an example of pooling of budgets. The CAs are organized as local integration associations, with representatives from the PES, the Swedish Social Insurance Agency, the municipalities, and the region aiming at cooperating financially within labor market inclusion. They are regulated by the Law on Financial Cooperation, FINSAM (SFS, 2003). The intention of FINSAM is based on the assumption that complex problems require complex solutions.

The CAs are voluntary structures, but the Swedish Social Insurance Agency and the PES have regulations that require them to conduct financial coordination of rehabilitation efforts according to FINSAM. The majority of Sweden's municipalities (260 of 290 municipalities) are part of a CA, and there are about 80 CAs in total. The CAs are jointly funded by the municipality, the region and the state authorities, where the state accounts for half of the funding, while the municipality and the region each account for a quarter. In total, the CAs have a budget of about SEK 670 million. The CAs operate locally and are governed by representatives of the involved actors, enabling collaboration based on local conditions and needs. (ISF, 2019b)

The primary mission of the CAs is to meet the needs for efforts in the welfare area that are not met by the four organizations themselves. The CAs aim to carry out rehabilitation and labor market inclusion efforts that encourage unemployed individuals to achieve or improve their work ability in order to become self-sufficient. The target group is unemployed individuals with medical, mental, social, and labor market-related problems who need coordinated support from several actors. The individual-oriented interventions consist of activating and motivating interventions, such as individual counseling, various types of individual treatment, and preventive interventions. The CAs also work with cross-structural initiatives that aim to strengthen cooperation between the authorities involved by creating good contacts among the actors and increasing knowledge of issues related to the target group and labor market inclusion. The CAs' efforts provide support for individuals approaching the labor market and self-sufficiency, and for getting the "right" form of compensation (ISF, 2019a). These efforts reach 
about $10 \%$ of the 280,000 individuals who are assumed to be in need of coordinated efforts (ISF, 2019b). ${ }^{13}$

\section{Other empirical examples of welfare integration}

One example of two-part integration, and an example of partnership between organizations, is the statuary enhanced cooperation between the PES and the Swedish Social Insurance Agency. This integration form aims to encourage individuals to leave sickness insurance in order to work, study, or participate in other active initiatives at the PES. The target group is individuals, regardless of income, who have a reduced work ability due to illness or disability, or the risk of illness or disability, and who need rehabilitation to develop or regain their work ability. This includes both employed and unemployed individuals, with compensation from sickness insurance (individuals on sick leave and young people with activity compensation) and other benefits, such as municipal financial support. The collaboration is allocated over SEK 700 million annually, and involves approximately 10,000 individuals per year. The goal of this cooperation is to offer early and active activities based on the individuals' needs in order to stimulate labor market inclusion, or - for individuals with jobs or work experience - to facilitate a return to their workplace or another job at the labor market. Other actors such as employers, the municipalities, and health care providers from the region may be involved in the enhanced cooperation, and it should be possible to conduct the initiatives in parallel. (Bengtsson, Ornstein and Rödin, 2018) $)^{14}$

Another regulated integration form, and an example of interagency meetings, is the Coordinated Individual Plan (Samordnad Individuell Planering, SIP). This integration tool has had legal support since 2010 via the Social Services Act and the Health Care Act, and aims to facilitate interaction between health care providers and the municipalities concerning individuals with needs from both social services and health care, and where different activities need to be coordinated. Through this tool, other actors such as the PES and the Swedish Social Insurance Agency may also be included in the work, even if their participation is not required by law. (SFS, 2001, 2017a)

A less regulated example of integration is so-called local agreements between the municipalities and the PES, the Swedish Social Insurance Agency, or the region. This enables the parties to design the integration according to their needs and local conditions, and often concerns a specific

\footnotetext{
${ }^{13}$ https://www.finsam.se/

${ }^{14}$ https://www.forsakringskassan.se/myndigheter_old/arbetsformedlingen/samverkan/forsakringskas- 
issue or target group. Examples of effective forms of collaboration with descriptions of organization and success factors learned from local initiatives between the PES and municipalities regarding people with financial assistance have been compiled in a report (Socialstyrelsen and Arbetsförmedlingen, 2015). The Delegation for the Employment of Young People and Newly Arrived Migrants (DUA) supports local agreements, and aims to promote collaboration between the PES and municipalities and the development of new forms of collaboration (SOU, 2018).

\section{Summary}

Chapter 3 has presented integration as a central working form in labor market inclusion contexts. The chapter includes sections with definitions of the concept and descriptions of various dimensions, explaining the choice of the concept of integration instead of the more common concepts of collaboration and cooperation. The chapter has also addressed organizing integration by presenting various integration forms and, in particular, integration projects which are central in this thesis, as well as various empirical examples of different integration forms. 


\section{RESEARCH ON INTEGRATION}

This chapter introduce previous research on interorganizational integration, using Huxham and Vangen's theory of collaborative advantage (2005) as a structure for the presentation. This theory is a framework of concepts which constitute a frame of reference for the thesis. The presentation is based on seven collaborative themes from the theory that have been selected due to their relevance to the thesis. This is followed by a section addressing research on intersectoral integration.

\section{Research on interorganizational integration}

Research on interorganizational integration is characterized by a wide variety of disciplines, research paradigms, theoretical perspectives, and sectoral focuses (Huxham, 2003). The research that has been carried out has focused extensively on problems and difficulties in collaboration (Huxham and Vangen, 2005). The research carried out over the last three decades has concluded that "collaborations are complex, slow to produce outputs and by no means guaranteed to deliver synergies and advantages" (Vangen, 2016, p. 263). However, there is also research that highlights the advantages. Typically, research is compiled into barriers and facilitators for integration, and many of these tend to be seen as two sides of the same coin (Andersson et al., 2011).

Leading proponents of a more critical approach include the British researchers Huxham and Vangen, (see e.g. Huxham and Vangen, 2005) who have studied interorganizational collaboration for several decades. The conclusion from their research is that there are no easy routes to success, and that seeking collaborative advantage is a seriously resource-consuming activity which should only be considered when it is really worth pursuing. Their message to practitioners and policymakers is therefore "don't do it unless you have to" (Huxham and Vangen, 2005, p. 13). In Sweden, Andersson's (2016) research is an example of a growing critical stream of collaboration research, problematizing the rationalized myth of collaboration as a taken-for-granted solution in CAs.

\section{The theory of collaborative advantage}

Huxham and Vangen acknowledge and conceptualize the difficulties of integration in a complex and multifaceted model, the theory of collaborative 
advantage (Huxham and Vangen, 2005). This model describes collaborative advantage as the energizing state that arises when the actors involved feel inspired and succeed with their efforts. In these situations, collaboration is associated with real gains, and is perceived as rewarding and worthwhile. Collaborative inertia is the opposite condition, describing the pain and frustration that can be associated with collaboration. This demanding state is associated with the collaboration process being slow-paced and the output being negligible. (Huxham and Vangen, 2005)

The model derives from a practitioner perspective, building on perceived issues that bring about advantages or inertia in collaboration (Huxham and Vangen, 2005). These perceptions are grouped into practitioner-generated themes. The most common themes are shared aims, communication, commitment and determination, compromise, working processes, accountability, democracy and equality, trust, and power (Huxham and Vangen, 2005). The model has gradually developed to include crosscutting themes, referring to identified issues that impact on all the other themes, represented by the theme of membership structures. Other themes include policy-generated themes, which consist of leadership, learning, and success. Finally, there are the researcher-generated themes, referring to issues raised by researchers as being applicable to collaboration. Examples of these types of themes include identity and social capital.

Figure 5 illustrates the diversity of themes and also how they relate to each other, aiming to convey the complex and multifaceted picture of collaborative practice. The themes are highly interrelated and are built up of underlying interrelated issues, without clear delineations between themes or issues. Not all themes are relevant to all collaboration practices. The themes are part of a holistic picture and cannot be enacted in isolation. By studying each theme, the theory can help to unpack the practice in "manageable chunks". Issues, contradictions, tensions, and dilemmas that underpin each theme can thus be identified and clarified. Huxham and Vangen (2005) stress that the themes and labels are not fixed or sacrosanct, and the blank figures indicate that the themes are constantly evolving and expanding, and that the theory will never be completed.

\section{Central themes for integration}

There is a high degree of correlation between Huxham and Vangen's themes (2005) and other research. A tendency among integration research has been to present lists of aspects with hampering and facilitating factors for collaboration. For example, in a review of literature on collaboration within vocational rehabilitation, Andersson et al. (2011) describe these factors as two sides of the same coin, where each factor can facilitate collaboration as much as it can hinder it. The review agrees well with factors that 
other researchers address (see e.g. Danermark and Germundsson, 2007; Ståhl C., 2010; O'Leary and Vij, 2012; Axelsson and Bihari Axelsson, 2013).

In the following sections, selected themes are presented based on Huxham and Vangen's theory (2005), in order to represent the different types of themes (practitioner-generated themes, cross-cutting themes, policygenerated themes, and research-generated themes). Each theme is illustrated with examples from other studies, strengthening the relevance of the selection for the thesis.

Figure 5: Types of themes in collaborative practice, with the selected themes for this thesis highlighted in yellow.

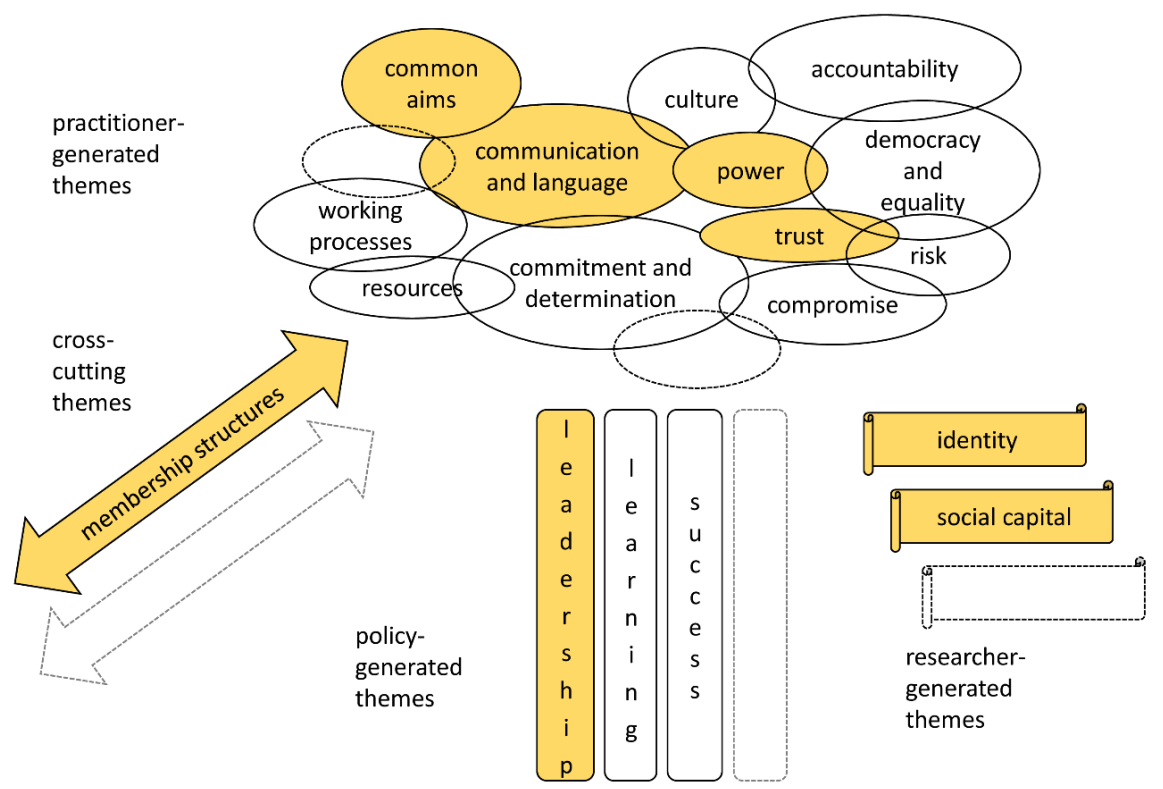

Source: Huxham \& Vangen 2005, adapted by the author.

\section{Common aims}

The first selected practitioner-generated theme is common aims or, in other words, vision, aim, goals, objectives, and purposes (Huxham and Vangen, 2005). Regardless of how this theme is referred to, it is commonly argued that common or at least compatible aims are important starting points for collaboration. However, common practice shows that the variety of organizational and individual agendas makes it difficult for actors to 
agree on this. Huxham and Vangen have put together a framework for understanding aims in collaboration, distinguishing between the goals of the collaboration, the related goals of each participating organization, and the individual participants' personal goals. These goals can be explicit, taken for granted by some, and not recognized by others, as well as being deliberately hidden. Based on this complex goal framework, Huxham and Vangen conclude that it is challenging to achieve common aims, and suggest that collaboration on an action can begin without fully agreeing on the aims. (Huxham and Vangen, 2005)

Issues related to common aims are common in the integration literature (Andersson et al., 2011; O'Leary and Vij, 2012; SOU, 2018). Some researchers conclude that consensus among involved actors may facilitate integration, but should not be considered a prerequisite (Andersson, 2010; Ståhl, 2010). Others conclude the opposite. O'Leary and Vij (2012) found numerous studies emphasizing that clear and mutually agreed aims are a success factor. Andersson et al. (2011) found common aims and goals to be related to cooperative actors and organizations establishing a common ground. Several researchers highlight the interrelationship between common aim and culture, problematizing the challenge of collaborating actors representing different organizations, professions, and views, and thus the scope and variety of aims and reasons for being involved in collaborative practices. Examples of this variation are aims addressing cross-sector failure, resources and knowledge, efficiency in delivering services, legitimacy, or building collaborative relationships (O'Leary and Vij, 2012; SOU, 2018). O'Leary and Vij (2012) conclude that the interests of collaborative actors may come into conflict, but emphasize that the actors must agree on the overall aim of the collaboration and consider whether the different organizations' aims are compatible with the aim of the collaboration. A lack of focus on common aims is assumed to stimulate territoriality, which hampers integration (Andersson et al., 2011).

\section{Trust}

The second selected practitioner-generated theme is trust (Huxham and Vangen, 2005). Huxham and Vangen describe the theme of trust as collaborative actors' expectations and faith about the collaboration, and the other actors' future behaviors in relation to meeting these expectations. They found that trust was often mentioned by practitioners on their wish lists, but was a rare commodity in practice and suspicion rather than trust was often the starting point, expressed as follows: "Trust is necessary for successful collaboration but we are suspicious of each other" (Huxham and Vangen, 2005, p. 66). Collaboration can mean more or less forced partnership due to government policies or pragmatics. In order to accomplish 
trust, Huxham and Vangen emphasize trust building. Their research is summarized as a trust building loop based on two conditions. The first forms expectations about the future of the collaboration, based on reputation, past behavior, or contracts and agreements. The second concerns risk taking, and argues for the need to trust enough to be willing to initiate the collaboration. Aiming for initially modest and realistic positive outcomes forms the basis for trust development, with reinforced trusting attitudes and underpinnings for more ambitious collaboration. In order to sustain the trust-building loop, they emphasize the importance of managing the dynamics and power imbalances as well as nurturing the collaborative relationships. (Huxham and Vangen, 2005)

Trust as a central theme for integration is confirmed in integration research (see e.g. Andersson, 2010; Ståhl C., 2010; O’Leary and Vij, 2012). Andersson et al. (2011) found that trust was mainly a facilitator for integration and highlighted the time factor, concerning both long-term commitment and the continuity of actors over a longer period, stating that trust takes time to build but can be destroyed in very short time. This fragility of trust has been highlighted in a study of local agreements between the PES and municipalities (SOU, 2018). Ståhl (Ståhl, 2010) found a connection between trust in integration and payback on invested money (related to membership structures), where if payback is modest or delayed, cooperation will be valued low. Other studies relate trust to communication, confirming the underlying and interrelated connection between the themes (Andersson et al., 2011; O'Leary and Vij, 2012). In line with the trust loop, O'Leary \& Vij (2012, p. 514) emphasize that trust does not arise by itself but demands "clear communication, reciprocity, goal alignment, transparency, information and knowledge sharing and by demonstrating competency, good intentions and follow-through".

\section{Power}

The third selected practice-generated theme is power (Huxham and Vangen, 2005). This theme is closely interrelated with trust, and Huxham and Vangen suggest that the two themes are in some respects seen as opposite sides of the same coin, since perceptions of power imbalance inevitably lead to feelings of mistrust. They found that the common wisdom is that "the power is in the purse strings", implying that the actors who are not in control of finances are automatically deprived of power. However, in reality, most actors at least have the power to leave. According to the researchers, the power theme consists of different points of power at different levels, referred to as a power infrastructure. By unpacking the theme, different points of power can be identified. Power at the macro level concerns sources of power, and deals with organizational issues related to resources 
and whether actors have something that others need (e.g. skills, knowledge, or information). Moreover, it involves structural variations in positions among actors and different perceptions of the importance of the collaboration and the relationship. Another point is that power balances tend to change over time, both between actors as the collaboration develops and individuals, and in terms of the type of power. Power at the micro level concerns how power is enacted in the daily life of the collaboration, from the individual perspective. Examples of points at this level include practical issues such as the naming of the collaboration, the invitation, choosing participants, meeting management and meeting agendas, and format. Thus, managing the power infrastructure is central for managing collaboration. (Huxham and Vangen, 2005).

The perception of power as an essential aspect for understanding integration is confirmed by other researchers (e.g. Danermark, 2004; O'Leary and Vij, 2012). O'Leary and Vij (2012) conclude that power imbalances within collaborations may result in conflict and co-optation, and may affect the success of the integration. They see structure and leadership issues as both a source of and a remedy for power balances. They conclude that collaborations work more easily when there are no major disparities of power, and that a legal mandate for increased authority and power will increase the likelihood of successful integration. Danermark and Germundsson (2010) present a theoretical approach of power relations in relation to the theory of social representations. Central to this approach are unequal interpersonal power relations, categorizing actors as being powerful and nonpowerful.

\section{Communication and language}

The fourth selected practice-generated theme identified by Huxham and Vangen (2005) is communication and language. They found that good communication was a common requirement from practitioners, in the same way that poor communication was associated with frustration. Huxham and Vangen make a distinction regarding communication between actors in the collaboration group, between the collaboration and the involved organizations, and between the organizations and society as a whole. In terms of communication within the collaboration group, the issue of language is central, with problems related to professional jargon and different interpretations of the same words. Good communication between the actors in the collaboration and the involved organizations is considered essential, but is highly time-consuming. Huxham and Vangen describe how this communication enables the practitioners to spot early signs of disagreements and to gain trust, commitment, support, and resources from the 
organizations. The third communication channel, between the collaboration and society, is mentioned as essential in collaborations dealing with societal problems in order to keep up to date and maintain good relations. (Huxham and Vangen, 2005).

Many integration researchers highlight communication as an essential theme in integration, being related to both barriers and facilitators (e.g. Andersson et al., 2011; O'Leary and Vij, 2012; SOU, 2018). O'Leary and Vij (2012, p. 513) found the following communicative factors to be important: information exchange, dialogue, sharing ideas, articulating and asserting views, negotiations, bargaining, deliberations, problem solving, conflict management, and conflict resolutions. They further stated how deliberate communication allows collaborators to brainstorm, critically examine each other's arguments, identify common interests, and build a base of shared knowledge and social capital. The communication channels need to be inclusive, transparent, and regular. (O'Leary and Vij, 2012) Andersson et al. (2011) pointed out the connection between lack of communication and ambiguity regarding roles and responsibilities, and how an absence of communication was related to different views among the actors on the aims and goals of the collaboration. They also found studies pointing out how sufficient communication was associated with increased knowledge, and with mutual understanding and respect for each other.

\section{Leadership}

The leadership theme is one of the policy-generated themes aiming to explain the role of leadership, focusing on "the mechanisms that make things happen in a collaboration" (Huxham and Vangen, 2005). Huxham and Vangen argue that the formation and implementation of collaborative agendas is led by three interrelated media: leadership through structure, leadership through process, and leadership through participants. Leadership activities are described from two perspectives: facilitative activities undertaken in the spirit of collaboration and manipulative activities labeled collaborative thuggery (Huxham and Vangen, 2005, p. 213). Facilitative activities consist of embracing the "right" kind of members, empowering members to enable participation, involving and supporting all members, and mobilizing members to make things happen Manipulative activities, on the other hand, involve manipulating the collaborative agenda and playing politics. Huxham and Vangen's research has shown the need to combine the two perspectives and operate from both modes in order to make progress. (Huxham and Vangen, 2005)

Leadership and management issues are central themes in integration research, and are perceived to be obstacles as well as success factors (Andersson et al., 2011; O'Leary and Vij, 2012; Axelsson and Bihari 
Axelsson, 2013). Examples of obstacles include leaders who defend the territory of their organization (Andersson et al., 2011), and who do not prioritize and demand integration (SOU, 2018). Examples of success factors include altruistic leaders who are able to transcend organizational boundaries and give support to the professionals involved in the form of time, resources for collaboration, and a mandate to represent their organization (Andersson et al., 2011). Axelsson and Bihari Axelsson (2013, p. 30) (2013) emphasize the importance of leadership in horizontal integration constellations, and describe the leadership's tasks and focus in relation to a development process of four phases: facilitating communication (forming phase), managing conflicts (storming phase), creating trust (norming phase), and facilitating work and contacts (performing phase) (p. 30).

\section{Memberships structures}

This cross-cutting theme is concerned with the collaborative form and relates to all other themes (Huxham and Vangen, 2005). The issues underlying this theme pertain to the members of the collaboration, both concerning who is involved and how they are involved. The theme is characterized by ambiguity and complexity related to the structure of collaboration and the dynamics of the way the membership structure changes over time. Huxham and Vangen state that ambiguity concerns both membership and status, as well as representativeness. This means that members have different perceptions of who is participating in the collaboration, their own and others' roles or membership status, what they are representing (an organization or an individual profession or competence), and to what degree. In addition, many collaborations have complex structures, with "pluralism of partnership" addressing organizations' membership in many different collaborative contexts. The structures of these different collaborations can also be unclear and poorly coordinated. With the dynamics of collaboration, Huxham and Vangen refer to the constant change that characterizes many collaborations with shifting membership, shifting purpose, and shifting pace of change. Taken together, this theme underlines the structural complexity in practice. (Huxham and Vangen, 2005)

Research concerning projects as an organizational form criticize "the project society" or "projectification", referring to a system of governance where projects that are intended as a method for organizing and managing societal problems very seldom lead to real changes on a structural or a societal level. The project-based governance of societal problems has been compared to putting an adhesive bandage on a broken arm, implying that rather than solving complex problems, projects have a tendency to give rise to more projects and the project machinery becomes a self-reinforcing operation.(Fred, 2018; Mc Glinn, 2018) 
Structure is a recurrent theme in integration research, and is perceived as both an enabling and a hampering factor (Andersson et al., 2011; O'Leary and Vij, 2012). Löfström (2010) found that the organizational structure of integration projects as demarcated appendages and the boundary problems between the project and the home organizations hampers implementation and means that the results tend to be limited to the integration project and not spread further. Thus, this confirms the challenge that projects risk being temporary solutions to long-term problems. Ståhl et al. (2017) reported similar challenges, stating that organizational problems combined with different approaches between the project and regular practice obscured implementation, and that authorities are not interested in implementing methodologies that require organizational restructuring. In another study by Ståhl (Ståhl, 2010), it is suggested that sustainable cooperation structures need to incorporate and coordinate the involved actors' priorities into a long-term cooperation strategy rather that basing the coordination on vulnerable collaboration projects.

Related challenges have been identified in research on other integration forms. Andersson (2016) points out a dilemma with the CAs, where collaboration is locked into project-like organizations which are demarcated from ordinary practice. She also concludes that the FINSAM Act (SFS, 2003) and specifically allocated resources in pooled budgets strengthen this lock-in. The challenges involved in CAs' organizing have also been studied by Ståhl (Ståhl, 2010), who found that rather than the coordination of existing practices, cooperation within the CAs tends to be organized as collaborative work forms based on an idea of consensus, where all organizations were expected to participate on equal terms and find common work forms, which tended to obscure the existing conflicts between the participating organizations.

The structure of the constellation of members in integration practices is important. The integration literature presents repeated findings about difficulties and challenges involved among the individuals who represent the organizations (O'Leary and Vij, 2012). A collaborating group's "representativeness" can suffer if participants lack sufficient competences to participate effectively (O'Leary and Vij, 2012) , or if important actors are missing (Andersson et al., 2011).

O'Leary and Vij (2012) conclude that structure delineates authority and responsibilities within integration practices, and highlight a paradox of flexibility-stability. On the one hand, integration is often preferred over bureaucratic structures because it is more flexible, but it can also be unstable and make accountability difficult (O'Leary and Vij, 2012). The cooperative actors' organization-specific rules and regulations are mostly considered a hampering factor for integration, complicating the integration between the professionals concerning e.g. confidentiality and employment conditions 
(Andersson et al., 2011; SOU, 2018). Another hampering factor is that these rules and regulations tend to change over time due to new legislation and political initiatives (Andersson et al., 2011). However, structure in terms of formal procedures and systematic planning can facilitate integration (Andersson et al., 2011), and an awareness of pacing activities can increase opportunities to implement activities in the "right" order, time, and place (Mörndal, 2018).

\section{Identity and social capital}

Identity and social capital are examples of themes that have been derived from researcher-generated concepts rather than directly from policy or practice (Huxham and Vangen, 2005). Huxham and Vangen emphasize the relevance of identity forming issues in relation to the theory of collaborative advantage. They conclude that collaborations has a paradoxical nature requiring "simultaneous protection and integration of the partners' uniquely different resources, experiences, and expertise in complex, dynamic organizing contexts" (Huxham and Vangen, 2005; Vangen, 2016, p. 263). Moreover, they highlight two perspectives in relation to identity forming processes. One is concerned with the nature of group membership and the categorization of individuals, for example in-group members focusing on the collaboration as a whole. The other perspective concerns the dynamics of identity, focusing on mutual identity building taking place when parties interact and form relationships with each other.

Huxham and Vangen (2005) describe the identity forming process as a complex, interwoven, tangled mix of interaction cycles, which is difficult to grasp but important to be aware of in order to manage collaboration. The identity issues and how the parties look at each other interrelate to all the previously selected themes (common aims, trust, power, communication and language, leadership, and membership structures), and can cause tensions and inertia in collaboration practices. One specific challenge mentioned by Huxham and Vangen is the tension between the need for participants to identify with their organization and the need for them to identify with the collaboration. The identity issues are closely related to social capital, which is described as a resource based on a person's membership of social networks and groups, and the gains this can bring in terms of recognition and social benefits (Bourdieu, 1986).

These themes have been suggested by researchers to be applicable to collaboration and relevant to collaboration practice. Despite this, there is surprisingly little research on identity and collaboration, as well as social capital and collaboration. Andersson et al. (2011) do not mention identity issues explicitly, but do so in relation to most of the identified barriers and facilitators in their review. Walsh et al. (1999) conclude that stereotypical 
views about members of partnerships and organizations are endemic and affect collaborations, while Luo (1998) emphases partner characteristics as an essential issue when considering collaboration partners. O'Leary and Vij (2012) conclude that as individuals collaborate, they will learn from other individuals and build a base of shared knowledge which can lead to the development of social capital. Social capital can also be stimulated by the storming phase in the collaboration development process (Axelsson and Bihari Axelsson, 2013).

\section{Research on intersectoral integration}

Research on intersectoral organizing - that is, between authority actors and other actors, such as employers, and how such organizing works in practice - is scarce, especially in a Swedish context (Tillmar et al., 2018). More specifically, there are limited studies focusing on integration between authorities and employers in labor market inclusion. Despite employers' central role in the labor market and their opportunities to influence labor market inclusion, research indicates that there is a power imbalance between employers and authorities in integration related to labor market inclusion. Nord (Nord, 2018) concludes that Swedish labor market policy has been characterized by an overemphasis on the role of the PES in tackling unemployment, while Ståhl (Ståhl, 2010) highlights employers' limited role, which indicates that integration between authorities and employers tends not to be organized from the perspective of employers.

Employers' views on integration with authorities have been studied in the research field of labor market inclusion, particularly in relation to individuals with disabilities. One specific research field concerns the Individual Placement and Support (IPS) vocational rehabilitation approach for people with serious mental illness and Supported Employment (SE) for people with disabilities. These methods are dependent on intersectoral cooperation, but studies are generally focused on their outcomes rather than the integration aspects (see e.g. Andersson et al., 2011; Bejerholm et al., 2015; Lexén, Emmelin and Bejerholm, 2016). In line with the research on interorganizational integration, this research on intersectoral integration has identified factors that can be either facilitating or hampering. Some of the factors are individual-related, for example concerning the character of the disability, the individual's work ability, or specific individual characteristics (Ju, Roberts and Zhang, 2013; Shaw et al., 2014; Andersson et al., 2015). Other factors are employer-related, and concern for example the employer's knowledge about disabilities and accommodation strategies (Erickson, Schrader and Bruyère, 2014; Shaw et al., 2014; Houtenville and Kalargyrou, 2015) and previous experiences of working with people with 
disabilities (Hernandez, Keys and Balcazar, 2000; Ju, Roberts and Zhang, 2013; Andersson et al., 2015).

Factors concerning the authorities and the integration between employers and the authorities are mainly about support and the structure of the integration. A lack of integrated services and accessible resources is perceived as a hampering factor (Shaw et al., 2014; SKR, 2018). Studies have shown that employers can perceive difficulties in terms of knowing what support is available and how to access it. This perception of the welfare system as impenetrable and difficult to understand or get an overview of can strengthen barriers to integration and labor market inclusion (Karlsson and Nilsson, 2017).

Other studies have emphasized the importance of consultation and assistance from the authorities or disability employment services as facilitating factors (e.g. Graffam et al., 2002; Gilbride et al., 2003; Kaye and Jones, 2011; Gustavsson, 2014; Lexén, Emmelin and Bejerholm, 2016; Karlsson and Nilsson, 2017). In her research on supported employment, Gustavsson (2014) found that the support given by the supported employment representative could reduce the individual's perceived transactional costs, that is costs related to contact, contract, and control during the recruitment and employment process. Concerns about costs relating to hiring have been identified in several studies as a barrier (Hernandez, Keys and Balcazar, 2000; Kaye and Jones, 2011; Erickson, Schrader and Bruyère, 2014), while other studies have highlighted financial support from the authorities as a facilitating factor (Domzal, Houtenville and Sharma, 2008; Gustavsson, 2014). Gustavsson (2014) found that, in addition to financial support, other risk-reducing factors for hiring, such as probationary periods and "open purchase", reduce perceived risks when employers experienced uncertainty about individuals' work ability and productivity.

Other identified factors include the character and organization of the integration. A lack of established partnerships between employers and authorities is considered to be a hampering factor (Shaw et al., 2014). Certain studies have identified that existing integrations (between employers and the PES) are not working effectively, and ensuring that these are functional and long-term is seen to be difficult (SOU, 2018). Employers ask the authorities to represent flexibility, continuity, and proactivity, and have a more service-oriented approach (Gustavsson, 2014; SOU, 2018). Based on the research carried out by Gustavsson (2014) on integration through supported employment, integration is affected by employers' views of the authorities. Trustful relationships are built by employers perceiving that the authority actors have adequate knowledge about the labor market and that they offer various support measures with the employers' best interests in 
mind (Gustavsson, 2014). The authority actors' understanding of the employers' perspective seems to be essential for successful integration (SOU, 2018).

\section{Summary}

Chapter 4 has presented research on interorganizational integration based on the theory of collaborative advantage (Huxham and Vangen, 2005). Seven collaborative themes have been presented, which have been seen as central for the empirical studies in this thesis. The chapter also presented research on intersectoral integration.

The literature review confirmed the two challenges mentioned in the introduction concerning integration in labor market inclusion contexts. The first concerns intraorganizational and interorganizational integration, where the actors involved - due to the fact that no single authority actor has overall responsibility - need to integrate and contribute their various skills and resources, for example through integration projects. The review confirmed that this area is characterized by a significant knowledge gap, and that there is a need for research concerning both intraorganizational and interorganizational integration between welfare actors in the context of Swedish labor market inclusion. The second challenge concerns intersectoral integration between employers and authorities, which - despite employers' central role in labor market inclusion - is limited. The review confirmed that research on the roles and perspectives of employers in labor market inclusion has not been sufficiently explored.

The previous chapters have aimed to place the thesis and the empirical studies in a context, and to present a background to the integration challenges mentioned in the introduction. In summary, it can be concluded that research on integration and organizing labor market inclusion in a Swedish context is scarce. There is a need for qualitative studies that contribute a deeper understanding of the phenomenon concerning the social dynamics of integration, and how different perspectives influence the integration and the organizing. This is the focus of this thesis. 



\section{THEORETICAL FRAMEWORK}

This chapter presents the different theoretical approaches that have guided the research process. The overall research process has been inspired by a theorizing approach (Swedberg, 2012), which has guided the research process through the three empirical studies and encouraged the use of a several theoretical approaches, resulting in a broad and multifaceted theoretical framework.

The theory of collaborative advantage and the central themes for integration described in chapter 4 form a theoretical basis for the thesis (Huxham and Vangen, 2005). Based on their relevance for the thesis, seven collaborative themes have been selected: common aims, trust, power, communication and language, leadership, membership structures, and identity and social capital. These have been supplemented with different theoretical approaches in the various papers, functioning as analytical tools for zooming in on the studied phenomena. Each theory has contributed unique terminology and perspectives on understandings of labor market inclusion. These theoretical approaches are described below.

\section{Theorizing (thesis and paper III)}

Theorizing can be described as "finding a perspective or lens through which a problem can be viewed and an invitation to see the problem in a new or revised way" (Hammond, 2018, p. 2). The word "theorize" comes from the Greek, and means to see, to observe, and to contemplate. It is a mixture of several activities: observing something, penetrating something, and finding something out. These activities are closely related and iterative, building on each other. Together, they capture the theorizing process going from observation to explanation. Heidegger (1977) suggested that theorizing means to concentrate on a phenomenon and stay with it, trying to understand it in this way. Swedberg (2012) emphasizes that theorizing focuses on the "context of discovery", defined as the form in which thinking processes are subjectively performed, in contrast to the "context of justification", which is defined as the form in which thinking processes are communicated to other people. Swedberg suggests four rules or steps for a successful theorizing process.

The first rule is to observe and choose something interesting. In order to theorize a phenomenon, one needs to observe and see it for oneself, preferably through field studies. The recommendations for data collection are 
to observe and stay in the context of discovery to see for oneself and to develop tacit knowledge of the phenomenon by collecting strong and nuanced descriptions from various sources. Anything that provides knowledge, information, associations, and ideas about what something is like is acceptable at this stage. The general strategy is that empirical data should drive the theorizing process and encourage the researcher not to force research findings into existing theories (Swedberg, 2012). Weber concluded that "theory must follow the facts, not vice versa" (Weber, 2001, p. 36), while Durkheim suggested that the researcher should process "from things to ideas", not from "ideas to things" (Durkheim, 1895, p. 15).

The second rule in the theorizing process is to name and formulate the central concept. The key to this rule is abduction, defined as "observing a fact and then processing to say what idea it was that gave rise to that fact" (Swedberg, 2012). Abduction has both a logical and an innovative character, and the quality lies in its "means of inferencing". It is a sensible and scientific form of interference intended to help researchers to be able to make new discoveries in a logically and methodologically ordered way. (Reichertz, 2007).

The third rule is to build out the theory. This rule aims to give form to the central concepts by outlining the structure, pattern, and organization of the phenomenon. It is a reflexive and iterative process, driven by the theoretical concepts and the empirical study. The use of metaphors, analogies, and comparisons is recommended as a thinking tool, leading to new perspectives. (Swedberg, 2012)

The fourth rule in the theorizing process is to complete the tentative theory, including the explanation. This rule emphases providing an explanation for the phenomenon, and constitutes the natural end point of the theorizing process. In contrast to a theory, theorizing is characterized by being "impermanent, imperfect, and incomplete". (Swedberg, 2012, p. 35)

In addition to guiding the research process for the dissertation, the theorizing process was used explicitly in paper III as an inspiration for the methodological process.

\section{Practice theory (paper II)}

Practice theory is not one theory, but a range of theories, and is used to understand and explain social and organizational phenomena, constituting several theoretical approaches with different conceptual and historical similarities (Schatzki, Knorr-Cetina and von Savigny, 2001; Gherardi, 2012; Nicolini, 2012). 
The theoretical approach used in this thesis is the one outlined by Nicolini, called a theory-method package (2012). The package has a toolkit approach, aiming to encourage the use of several practice theories and methods to enrich our understanding of everything social and organizational. Nicolini emphasizes the need for an internally coherent approach in which the ontological assumptions and methodological choices work together. The multifaceted package responds to the principle that "the aim of social science is to provide a richer and more nuanced understanding of the world, and not to offer simplified answers to complex questions" (Nicolini, 2012, p. 215). Nicolini argues that in order to understand practices we need thick descriptions, enabling new and enlightening connections, thus providing opportunities to act in a more informed way. In other words, adding - not abstracting or deconstructing - is the crucial point (Stengers, 1997).

The theory-method package follows three movements: zooming in on the accomplishments of practice, zooming out to discern the relationships in space and time, and producing textual material that enriches the understanding of the studied phenomenon. Nicolini emphasizes that the study of practices always starts in the middle of action, and thus recommends beginning with zooming in. The toolkit suggests eight focus areas related to different practice-theoretical resources to zoom in on: sayings and doings; interactional order; timing and tempo; bodily choreography; tools, artefacts and mediation work; practical concerns; tension between creativity and normativity; and processes of legitimation and stabilization (Nicolini 2012). Connected to each focus area are examples of sensitizing research questions, which together serve as examples of analytical foci and can be used in different combinations. Depending on the focus area, different methods are recommended in order to take the recommended internally coherent approach. A recommended strategy is different forms of ethnographical methods (e.g., Czarniawska, 2007).

The zooming in and out are iterative processes, and are achieved by switching theoretical lenses. The process ends when it is possible to "provide a convincing and defensible account of both the practice and its effects on the dynamics of organizing, showing how that which is local contributes to the generation of broader effects" (Nicolini, 2012, p. 219).

The approach was used in paper II, where it contributed to illuminating the complex dynamics of integration projects.

\section{Shadow organizing (paper III)}

Shadow organizing is a metaphor that enables an exploration of organizing as intrarelating processes and a focus on what happens in the interstices 
between intentional and unintentional organizing actions (Gherardi, Jensen and Nerland, 2017). The metaphor brings out the dynamic and liminal aspects of organizations, outlining organizations in terms of activity and process rather than in terms of stable entities. The shadow is a symbol of what is obscured, and can only be seen by looking past the obvious and focusing on what is hidden (Buch, 2019).

Buch (2019) recommends the use of this metaphor as a methodological approach and a conceptual tool, enabling certain aspects and phenomena in organizations to be understood as they are played out in practice. The metaphor can be understood based on three concepts: productivity, liminality, and secrecy. Productivity is illustrated "through the image of the forest and its sheltered spaces in penumbra". Liminality is seen "through the image of a liminal, grey zone between canonical and non-canonical practices". Secrecy captures "the organizational secrecy kept in-between the sayable and the unsayable". (Gherardi, Jensen and Nerland 2017, p. 7)

The approach was used in paper III as an analytical tool focusing on negative organizational dynamics in the context of an interorganizational project.

\section{Social capital (paper III)}

Social capital has multiple definitions and interpretations across a variety of disciplines and research fields (Rostila 2010; Woolcock 2010). Bourdieu (1986) describes social capital as a resource based on membership of social networks and groups, and the benefits this can bring in terms of recognition and social benefits. Most commonly, however, it is interpreted as a positive characteristic of social groups. Rostila (2010) presents a model of social capital comprising both individual and collective dimensions, where social capital fundamentally consists of formal or informal social networks, social trust, and social resources, which are derived from the previous two aspects. Networks represent the structural dimension of social capital, while trust represents the cognitive dimension. Social resources, which are products of networks and trust, and hence the actual "capital", may be collective or individual, and can be expected to lead to different returns, either instrumental (such as economic, political, or social gains) or expressive (such as physical or mental health benefits, based on the emotional support social capital may bring). Szreter and Woolcock (2004) present another typology featuring three different forms of social capital: bonding (horizontal relationships of trust and reciprocity between individuals with similar social identities at the same hierarchical level), bridging (horizontal relationships between people at the same hierarchical level from different backgrounds), and linking (vertical relationships between people interacting across gradients within society). 
One tendency among research studies is that social capital is operationalized in exclusively positive terms, for example being positively related to health outcomes, leaving little room for exploring potentially negative effects (Szreter and Woolcock, 2004; Kouvonen et al., 2006). However, there is empirical evidence of negative effects of social capital across a variety of settings; not only in social contexts, which have obvious negative consequences such as mafia families, prostitution rings, and youth gangs (Portes, 1998), but also in organizations and management (Pillai et al. 2017). Pillai et al. (2017) reviewed research on negative effects of social capital in organizations and management, focusing on the context of firms and how social capital relates to several organizational outcomes, such as innovation, organizational cultures, and the creation and transfer of knowledge. They identified six types of negative effects of social capital, which are all based on dysfunctional social identification processes: "(1) dilution of the dialectical process; (2) inhibition of individual learning; (3) groupthink; (4) postponement of structural adjustments; (5) non-rational escalation of commitment; and (6) blurring of firms' boundaries" (10, p. 98)(Pillai et al., 2017, p. 98).

The theory of social capital with a focus on the negative effects was used in paper III as an analytical tool to describe dysfunctional group processes in an interorganizational integration project.

\section{Social representations (paper IV)}

The theory of social representations is a social psychological orientation based on the idea that our conceptions of the world around us are shaped through social interaction with other people, in the form of intragroup and intergroup relationships. These conceptions are called representations, and according to the theory they develop into a form of common-sense knowledge that holds groups together and gives them a social orientation (Chaib \& Orfali 1995). Jodelet (1995, p. 32) defines social representations as constituting "a specially produced and shared form of knowledge that has a practical objective and influences the conception of reality that is constructed by a certain social group". Social representations function as interpretation systems that affect how we relate to our surroundings. They give us guidance on how to name and define different phenomena in our everyday reality, how to interpret them, how to make decisions about them, and how to defend our position. (Chaib \& Orfali 1995)

The theory is useful for studies of social objects (Guimelli \& Jacobi 1995). Studies of social representations concern not only the product of our social conceptions, but also the process behind the formation of these conceptions (Chaib \& Orfali 1995). Jodelet (1995) describes social representations as complex multifaceted phenomena, pointing out that research on 
social representations must be studied in parallel with emotional, cognitive, and social aspects in the social contexts that surround them. The theory emphasizes the context of representation and focuses on the dynamic social process of continual change, concluding that representations evolve in different social groups over time. (Jodelet 1995)

The theory of social representations can be applied through various approaches and orientations "from ethnography to experimentation, of data sources from pictures to attitude scales, and analytic procedures from qualitative interpretation to multi-dimensional scaling" (Bauer \& Gaskell 1999, p. 163). Bauer and Gaskell (1999) suggest several combinable implications of social representations which form a paradigm for research into this subject, making it possible to capture the content, the structure, and the central core of the representation. Examples of implications include content and process, time structures and longitudinal data, and crossovers of cultural projects and trajectories.

The theory of social representations suggests that people develop and stabilize representations in concert with others, and that "it is through the contrast of divergent perspectives that we become aware of representations, particularly when the contrast challenges our presumed reality and is resisted" (Bauer \& Gaskell 1999, p. 169). Danermark concludes that different social representations are considered to be a source of conflict in integration (Danermark et al. 2014), while Voelklein and Howarth (2005) emphasize that social representations are never neutral but are constantly permeated by power relations. Danermark and Germundsson (2010) present a theoretical approach of power relations in the process of shaping and transforming social representations in interprofessional integration. This approach highlights the concept of unequal interpersonal power relations, which characterizes actors as being powerful (model strong) and non-powerful (model weak), based on the degree of development and difference. The outcome of the interactions between the actors with different models can be stability (the social representation does not change) or a transformation of the representation where the process may or may not involve conflicts. (Danermark \& Germundsson 2010)

The theory of social representations was applied in paper IV, together with a power relation perspective as an analytical tool, focusing on how different social representations among professional groups played out within an intraorganizational labor market inclusion project. 


\section{METHODOLOGICAL FRAMEWORK}

This chapter describes the methodological framework, presenting the three empirical studies in the thesis and the four papers, the various data sources, the data collection, and the analysis procedures that have been conducted. The chapter ends with ethical considerations.

In this thesis, the overall ambition is to explore labor market inclusion from the perspectives of authority actors and employers, and the methodological framework has been chosen in relation to this ambition, in line with recommendations for qualitative research (Patton, 2015). In order to be able to respond to the aim, three empirical studies have been conducted with various forms of qualitative methods and theoretical approaches. The methodological process has also been influenced by an interactive research approach. In the following sections, this research approach is described, followed by descriptions of the three studies regarding background information, empirical sources, and data analysis.

\begin{tabular}{|c|c|c|c|}
\hline & Study I & Study II & Study III \\
\hline $\begin{array}{l}\text { Study } \\
\text { design }\end{array}$ & Qualitative interview study & $\begin{array}{l}\text { Qualitative longitudinal } \\
\text { case study }\end{array}$ & $\begin{array}{l}\text { Qualitative longitudinal } \\
\text { case study }\end{array}$ \\
\hline $\begin{array}{l}\text { Data } \\
\text { collection }\end{array}$ & Semi-structured interviews & $\begin{array}{l}\text { Observation } \\
\text { Informal interviews } \\
\text { Semi-structured interviews } \\
\text { Focus groups } \\
\text { Shadowing } \\
\text { Document studies }\end{array}$ & $\begin{array}{l}\text { Observation } \\
\text { Informal interviews } \\
\text { Semi-structured interviews } \\
\text { Focus groups } \\
\text { Document studies }\end{array}$ \\
\hline Time frame & $2015-2016$ & $2015-2017$ & $2017-2018$ \\
\hline $\begin{array}{l}\text { Empirical } \\
\text { source }\end{array}$ & Employers & $\begin{array}{l}\text { Authority actors in the } \\
\text { project organization }\end{array}$ & $\begin{array}{l}\text { Authority actors in the } \\
\text { project organization and } \\
\text { employers }\end{array}$ \\
\hline $\begin{array}{l}\text { Data } \\
\text { analysis and } \\
\text { theoretical } \\
\text { approach }\end{array}$ & $\begin{array}{l}\text { Phenomenographic } \\
\text { analysis following the } \\
\text { approach by Sjöström and } \\
\text { Dahlgren (2002). }\end{array}$ & $\begin{array}{l}\text { Paper II: Thematic analysis } \\
\text { using Nicolini's (2012) } \\
\text { practice-theory toolkit as } \\
\text { an analytical tool. } \\
\text { Paper III: Thematic analysis } \\
\text { using Hammond's (2018) } \\
\text { and Swedberg's (2012) } \\
\text { perspectives on theorizing } \\
\text { and negative effects of } \\
\text { social capital (Pillai et al. } \\
\text { 2007) as an analytical tool. }\end{array}$ & $\begin{array}{l}\text { Thematic analysis using } \\
\text { Danermark and } \\
\text { Germundsson's (2010) } \\
\text { theory of social } \\
\text { representations and power } \\
\text { approach as an analytical } \\
\text { tool. }\end{array}$ \\
\hline
\end{tabular}

Table 1: A summary of the theoretical and empirical framework. 


\section{An interactive research approach}

The methodological process has been inspired by an interactive research approach (Svensson, Brulin and Sjöberg, 2009). The approach involves an interaction between the research system and the practice system driven by problems and issues originating in research or practice, enabling joint learning (Ellström, 2008). By creating a collaborative inquiry where researchers and practitioners together investigate problematic situations in the practice, both parties seek explanations and understanding with the aim of creating new knowledge that is both practically useful and theoretically interesting (Johannisson, Gunnarsson and Stjernberg, 2008). The interactive research approach provides the researcher with access to the practice, which enables understanding from the participants' perspective, and which contributes to theory development. The approach presupposes close collaboration between the researcher and the practitioners throughout the entire research process in order to focus the research on issues of the greatest practical and scientific relevance. (Svensson et al., 2007) By creating conditions for reflection and learning, the research system can provide continuous feedback to the practice system about the studied phenomenon (Brulin and Svensson, 2011).

The interactive research process constituted a starting point for both study II and study III, with various influence and results. In study II, the researchers had a more pronounced role throughout the process, from the starting up to the closing down of the studied project, where the researchers continuously wrote reports and held seminars concerning the project development. In study III, the interactive research design consisted of an evaluation with limited interaction with the project management, resulting in a report at the end of the project.

\section{Study 1}

\section{Description of the study}

This study was based on qualitative interviews, aiming to map employers' perceptions of unemployed individuals from vulnerable groups, employability, and labor market inclusion. The goal of the study was to increase knowledge about employers' perspectives in order to find out what makes them willing to include these individuals at their workplaces. The study was carried out as project between 2015-2017, with the PES as project owner and the Coordination Association of Central Östergötland providing financial backing. 


\section{Data collection}

The sample consisted of 27 employer representatives working as chief executive officers, managers, or human resource consultants. The informants were eighteen women and nine men. Strategic sampling was used, in line with a phenomenographic approach, to maximize variation in the choice of interviewees and to capture possible ways in which the phenomenon is understood across different professional areas, in the private and public sectors and in companies of different sizes. The employers were selected based on their varied experience of working with labor market inclusion strategies and people with disabilities.

Data were collected through semi-structured interviews, a recommended data method in phenomenography (Marton, 1981). The interviews followed a semi-structured interview guide with questions concerning the employers' experiences and their views of the employability of unemployed individuals from vulnerable groups (e.g., individuals with disabilities and reduced work capacity, individuals born outside Europe, individuals with short education, and jobseekers aged 55 or older). The employers were asked to describe the characteristics of their workplace and work tasks, their need for labor, their recruitment routines, their views on corporate social responsibility, work ability, and facilitating factors influencing their desire and ability to initiate or increase cooperation with authority actors concerning labor market inclusion. Prompting questions were used in order to exhaust the phenomenon and capture the diversity of different perceptions. The interviews were audio-recorded and transcribed verbatim.

\section{Phenomenography}

Phenomenography is a research method for mapping the qualitatively different ways in which people experience, conceptualize, perceive, and understand various phenomena in the world around them and how these ways of understanding are related to one another (Marton, 1981; StenforsHayes, Hult and Abrandt Dahlgren, 2013). Phenomenography fits within the interpretivist paradigm, which acknowledges that there are multiple and diverse interpretations of reality. It is a research approach with epistemological and ontological assumptions that emphasize change and complexity (Stenfors-Hayes, Hult and Abrandt Dahlgren, 2013). Phenomenography builds on a non-dualistic ontology, which means that ways of experiencing a phenomenon represent a relationship between the phenomenon and that which is being experienced (Marton, 1988).

Interviewing is the primary data collection method within phenomenography, and the sampling is commonly maximized to capture the range of possible ways the phenomenon is understood. The phenomenographic interview is characterized by open-ended questions and probing follow-up 
questions aiming to exhaust the range of possible ways the phenomenon is understood (Marton, 1988). The role of the researcher is to hold back his or her own prejudices and theories, and fully focus on how the phenomenon is understood by the interviewees. In the phenomenographic analysis, which often follows a specific procedure e.g., that described by StenforsHayes, Hult and Abrandt Dahlgren (2013), the categories are constructed by the researcher in relation to the data. The main result of a phenomenographic analysis is the outcome space, comprising a set of descriptive categories that display the variation in how the conceptions are structured through their internal relationships. The identifying relationships among the categories is the unique aspect of the phenomenographic analysis. (Stenfors-Hayes, Hult and Abrandt Dahlgren, 2013)

Phenomenography provides a way to investigate people's different perceptions of a phenomenon, and can facilitate improved understanding. It can help "to bring to the surface and define our different perspectives so that these can be compared, contrasted and scrutinized" (Stenfors-Hayes, Hult and Abrandt Dahlgren, 2013, p. 267). The approach was used in paper I, with the aim of capturing employers' perspectives on labor market inclusion, and was delimited to mapping the qualitative different ways in which employers understand the phenomenon of the employability of people with disabilities.

\section{Data analysis}

The interviews were analyzed with a phenomenographic approach, inspired by the seven-step procedure proposed by Sjöström and Dahlgren (2002). The first step is familiarizing, which meant that the interview transcripts was read through in their entirety to obtain an overall impression. In the second step, condensation, significant passages in the material were identified, and were marked out and summarized into a text document. In the third step, comparing, the significant passages were re-read and compared in a search for similarities and variations, and different aspects of the phenomenon were identified. The fourth step, grouping, involved searching for patterns, and data excerpts with similarities were grouped together. This step meant going back to the material and re-grouping until saturation was reached. The result of this analysis was three exclusive but internally related descriptive categories, forming the outcome space. In the fifth step, articulating, the focus was on capturing the essential meaning of the three categories, and in the next step, labeling, the categories were labeled: employability as constrained by disability, employability as independent of disability, and employability as conditional. Steps 3-6 followed an iterative procedure to ensure that the similarities and differences between the categories were distinguished and explicit. In the last step, contrasting, an 
analysis of the outcome space was carried out by investigating internal relationships across the categories. This analysis resulted in identifying three cross-cutting themes across the descriptive categories, namely trust, contribution and authority support.

\section{Study II}

\section{Description of the study}

The second study was an evaluation of an interorganizational integration project, aiming to develop cooperation services for unemployed young people with a need for coordinated labor market inclusion support to achieve self-sufficiency. The participating actors in the project were the municipal labor market unit, social services, the PES, the Swedish Social Insurance Agency, and the region. The project was financed by the local coordination association, and the municipal labor market was project owner. The project was organized with co-location and a multi-professional team of one or two representatives from involved actors. The management was organized with a steering group of managers from involved organizations and the project leader. More than 20 goals were set at different levels. At the organizational level, the project aimed to achieve faster and easier handling of cases as well as promoting knowledge exchange between involved actors. At the individual level, the project aimed to improve participants' life situations through shortened processes and measures tailored to the needs and resources of the individuals. It also aimed for 50 per cent of participants to reach self-sufficiency through work or studies. The project was initiated in 2015 and ended prematurely in 2017. It was evaluated by learning evaluation with an interactive approach, which meant a dialogue with the management through feedback on observed changes during the project's development via written reports (Svensson, Brulin and Sjöberg, 2009).

\section{Data collection}

The empirical sources consisted of project staff members, steering group members, staff members in the home organizations, and project participants (see Table 2).

Data were collected though ethnographical field work (Czarniawska, 2007, 2008; Aspers, 2011), and consisted of multiple methods including various forms of observations over time, interviews, and document studies. This methodology seeks to ensure in-depth comprehension, and is ideally used to scrutinize a specific social phenomenon through small samples with narrative descriptions (Higginbottom, Pillay, \& Boadu 2013). Ethnographic fieldwork allows the researcher to get close to the studied practice, and is sensitive to its material and embodied nature. While ethnographers 
originally studied entire communities or cultures, there is now wide agreement that the methodology is also suitable for exploring sub-cultures or groups within complex pluralistic contexts (Hammersley, 2018), such as interorganizational integration projects. The project was closely followed throughout the whole process, from initiation to closing down, from autumn 2015 to spring 2017. The different methods and how they were used in the project are described briefly below.

\section{Observations}

Observation is used to understand what is happening and what is being said, enabling the study of what people actually do, not what they say they do (Czarniawska, 2007; Aspers, 2011). It is also useful for capturing situations that are difficult to put into words, such as tacitly embodied and implicit knowledge. In sum, observations give rise to thick descriptions of the studied phenomenon (Aspers, 2011). The method was used in observations of weekly meetings and steering group meetings, as well as in more informal meetings in everyday practice such as coffee breaks. In total, more than 70 observation occasions were documented using field notes.

\section{Shadowing}

Shadowing is a form of participative observation, allowing the researcher to follow a studied object in practice (Czarniawska, 2007). In this study, one project staff member was shadowed in relation to four participants. The method provided access to participation in different meetings with the participants and other cooperative actors, and to dialogue with the project staff member concerning his thoughts and actions in relation to these participants. The material from the shadowing was documented in field notes. The four participants were also part of a group that was interviewed during the closing down phase.

\section{Interviews}

Interviews can be used to supplement observations of what has been observed or said. The degree of structure can vary, as can the length and situation (Aspers, 2011; Kvale and Brinkmann, 2014). In this study, three different forms of interview were conducted: qualitative research interviews, informal interviews, and focus group interviews. Qualitative research interviews aim to understand the world from the interviewee's point of view. The method allows variety of perceptions of a topic to be captured, and provides a multifaceted image of a phenomenon. (Kvale and Brinkmann, 2014) In total, 34 research interviews were performed with project staff members, project organization actors, and participants (youths) in the project during 
the closing down phase. The interviews followed the seven principles proposed by Kvale and Brinkmann (2014), and followed a semi-structured interview guide with different themes and questions for each group (see Table 2). All interviews were audio-recorded and transcribed verbatim.

The informal interviews were characterized by low structure and were performed outside the official meetings in everyday practice. They involved everything from comments in the queue for the coffee machine to longer informal dialogues. They often provided valuable information, contributing to an increased understanding of the various project actors' perspectives. In total, more than 50 informal interviews were conducted with project staff and management representatives, and data from these interviews were documented in field notes in a Word document.

\section{Focus group interviews}

This method enables data collection through observing group interaction on a topic determined by the researcher. The method is used to study people's perceptions, knowledge, attitudes, and values in connection with a phenomenon, and can be used on its own or as a complement to other data collection methods (Wibeck, 2010). In this study, nine focus groups with 42 informants were held with project staff members and staff members in the home organizations, with different topics and at different stages of the project (see Table 2). The procedure followed the principles recommended by Wibeck (2010), and all interviews were recorded and transcribed verbatim.

\section{Document studies}

Document studies consist of records, documents, artifacts, and archives, and constitute a particularly rich source of information in many organizations (Patton, 2015). The method enables an "oft-intriguing form of analysis" (Patton, 2015, p. 376), comparing official statements found in public documents with documentation from the field work. In this study, the document studies consisted of approximately 40 written documents from various sources and of different characters (see Table 2).

A compilation of the data collection for study II concerning strategy and source, focus, and time aspect and numbers is presented in Table 2. 


\begin{tabular}{|c|c|c|}
\hline Data collection and source & Focus & Time aspect and numbers \\
\hline $\begin{array}{l}\text { Weekly observations of project } \\
\text { staff meetings and monthly } \\
\text { observations of steering group } \\
\text { meetings. }\end{array}$ & $\begin{array}{l}\text { Documenting meetings and } \\
\text { developments in the project, } \\
\text { who is doing and saying what, } \\
\text { which questions are raised, } \\
\text { group processes, etc. }\end{array}$ & $\begin{array}{l}\text { In total, more than } 70 \\
\text { occasions during all phases. }\end{array}$ \\
\hline $\begin{array}{l}\text { Shadowing of project staff } \\
\text { member in relation to } \\
\text { participants and their process } \\
\text { through the project. }\end{array}$ & $\begin{array}{l}\text { What the work looked like in } \\
\text { practice, tensions between } \\
\text { what is being said and what is } \\
\text { being done. }\end{array}$ & $\begin{array}{l}\text { One project staff member and } \\
\text { four participants (autumn } \\
\text { 2016). }\end{array}$ \\
\hline $\begin{array}{l}\text { Semi-structured interviews with } \\
\text { actors in the project } \\
\text { organization (project team } \\
\text { members and steering group } \\
\text { members). }\end{array}$ & $\begin{array}{l}\text { The project actors' perceptions } \\
\text { of the project and reasons for } \\
\text { closing down. }\end{array}$ & $\begin{array}{l}17 \text { interviews with nine project } \\
\text { team members and eight } \\
\text { steering group members } \\
\text { (April-June 2017). }\end{array}$ \\
\hline $\begin{array}{l}\text { Semi-structured interviews with } \\
\text { participants (youths). }\end{array}$ & $\begin{array}{l}\text { The youths' perceptions of the } \\
\text { project and the support they } \\
\text { had received. }\end{array}$ & 17 interviews (April-June 2017). \\
\hline $\begin{array}{l}\text { Informal interviews with actors } \\
\text { in the project organization. }\end{array}$ & $\begin{array}{l}\text { Everything related to the } \\
\text { project, from smaller to bigger } \\
\text { issues. }\end{array}$ & $\begin{array}{l}\text { In total, more than } 50 \\
\text { occasions during all phases. }\end{array}$ \\
\hline $\begin{array}{l}\text { Focus group interviews with } \\
\text { project staff members on two } \\
\text { occasions. }\end{array}$ & $\begin{array}{l}\text { No. 1: Expectations of the } \\
\text { project and perceptions of the } \\
\text { project's aim and goal and their } \\
\text { own role. } \\
\text { No. 2: Describing their } \\
\text { perception of the program } \\
\text { theory of the project. }\end{array}$ & $\begin{array}{l}\text { Four focus groups. } \\
\text { No. 1: Two focus groups with } \\
\text { nine informants (Jan. 2016). } \\
\text { No. 2: Two focus groups with } \\
11 \text { informants (Jan. 2017). }\end{array}$ \\
\hline $\begin{array}{l}\text { Focus group interviews with } \\
\text { staff members external to the } \\
\text { project. }\end{array}$ & $\begin{array}{l}\text { Expectations and perceptions } \\
\text { of the project and how integra- } \\
\text { tion and communication be- } \\
\text { tween the actors work. }\end{array}$ & $\begin{array}{l}\text { Five focus groups with } 22 \\
\text { informants } \\
\text { (September-October 2016). }\end{array}$ \\
\hline $\begin{array}{l}\text { Document studies of various } \\
\text { written documents, such as } \\
\text { project plan, project } \\
\text { application, email } \\
\text { conversations, etc. }\end{array}$ & $\begin{array}{l}\text { Communication and language } \\
\text { in different documents, } \\
\text { tensions between what is } \\
\text { written and what is said and } \\
\text { done, how tensions are played } \\
\text { out, etc. }\end{array}$ & More than 40 documents. \\
\hline
\end{tabular}

Table 2: Characteristics for the data sources and data collection in study II. 


\section{Data analysis}

The extensive data material from study II enabled two separate data analyses to be carried out with different theoretical approaches, one using practice theory and the other using social capital theory and theorizing, resulting in two scientific papers.

\section{Paper II}

In the first analysis of the data material, the focus was on practice theory, contextualized in relation to previous research on integration. The methodological process followed the iterative zooming in and zooming out movements in the Nicolini practice-theory toolkit (Nicolini, 2012) (described under Theoretical framework). The analysis began with a review of all the collected data (field notes, written reflections, documents, and transcriptions from interviews and focus groups). The next step consisted of mapping data in relation to Nicolini's eight focus areas, using the research questions as a guiding tool for which data to search for. In the next step, data were condensed into codes. Three focus areas stood out, all of which concerned the number of matching examples in the material and their explanatory value for highlighting relational dynamics in the project, namely: tensions between creativity and normativity, processes of legitimation and stabilization, and interactional order. These focus areas, together with the sensitizing questions, helped to focus the analysis. Examples of questions included: How are breakdowns addressed? Where are the main tensions? Do the practitioners use the practice to identify themselves as a community? What sort of interactional order is performed by this specific practice? The last step of the analysis consisted of zooming out in relation to previous integration research.

\section{Paper III}

In the second analysis of the same material, the focus was on social capital and shadow organizing in relation to the dysfunctional group processes identified in the analysis for paper II. The methodological process was inspired by Hammond's (2018) and Swedberg's (2012) perspectives on theorizing (described under Theoretical framework). In this process, the analysis began with the second rule, name and formulate the central concept, where existing concepts from Pillai et al. (2017) describing negative effects of social capital were used, namely: dilution of the dialectical process, inhibition of individual learning, groupthink, postponement of structural adjustments, non-rational escalation of commitment, and blurring of firms' boundaries. These concepts were used to obtain an entry point for analyzing the material, and the data (field notes, written reflections, documents, and transcriptions from interviews and focus groups) were mapped 
in relation to these concepts. In the next phase, the material was rearranged in relation to and cross-tabulated with the concepts of bonding, bridging, and linking social capital (Szreter \& Woolcock 2004), contributing to a further analytical step. The third rule, build out the theory, was followed by analyzing how the negative effects of social capital unfolded through three distinct social dynamics, namely insulation, homogenization, and escalating commitment. An additional aspect, and a strategy recommended by Swedberg (2012) which contributed to the analysis and building out of the theory, was the use of Gherardi et al.'s (2017) metaphor of shadow organizing. This methodological approach makes it possible to explore organizing as intrarelating processes and to focus on what happens in the interstices between intentional and unintentional organizing actions. The approach guided the discussion through three central concepts: liminality, secrecy and productivity. (Gherardi et al. 2017)

\section{Study III}

\section{Description of the study}

The third project was an interorganizational project within municipal labor market services, involving a municipality's labor market unit and a municipality's human resources (HR) department. The other actors involved were municipal employers, an actor within vocational training, and the PES. The organization of the project was based on steering documents stating three different aims of the project: to stimulate increased labor market inclusion of unemployed individuals on welfare benefits, to contribute to the municipality's future skills supply, and to develop a structure for the management of workplace-oriented interventions. The management was organized as a joint organization with a steering group consisting of representatives from the involved actors, and the ownership was shared between the two municipal units. The project team consisted of a project leader and three HR consultants employed within the HR unit, and seven labor market consultants employed within the labor market unit.

The initiative started as a project in 2017, and transitioned into regular operations in 2018. During this period, the project was evaluated with a focus on different views of the project among the actors involved and how this affected the organizing of the project.

\section{Data collection}

The empirical source in study III consisted of project staff members, steering representatives, and municipal employers (see Table 3). 
Similar to study II, data were collected through ethnographic field work (Czarniawska, 2007; Aspers, 2011), but in a less comprehensive way, concerning sample, methods, number of occasions, and the time aspect. The methods consisted of observations, interviews, focus groups, and document studies, and were inspired by the same references as described for study II under Data collection. The data collection resulted in 20 observations of project staff meetings, five focus groups with staff members, six interviews with management representatives, and nine interviews with municipal employers. The focus of the data collection varied in relation to the different methods and the data sources and time period (see Table 3). Data from observations were documented in field notes, and all interviews were audio-recorded and transcribed verbatim.

A compilation of the data collection in study III concerning strategy, source, focus, and time aspect and numbers is presented in Table 3.

\begin{tabular}{|c|c|c|}
\hline Data collection and source & Focus & Time period and number \\
\hline $\begin{array}{l}\text { Observations of project staff } \\
\text { meetings. }\end{array}$ & $\begin{array}{l}\text { What are the social } \\
\text { representations of the project } \\
\text { and how do they play out? } \\
\text { Who is doing and saying what? } \\
\text { What tensions arise? }\end{array}$ & More than 20 occasions in total \\
\hline $\begin{array}{l}\text { Focus groups with HR } \\
\text { consultants and labor market } \\
\text { consultant. }\end{array}$ & $\begin{array}{l}\text { No 1: Perceptions of the } \\
\text { structures of the project } \\
\text { concerning aim, goal, target } \\
\text { group, and working methods. } \\
\text { No 2: Experiences of the } \\
\text { project related to aim, target } \\
\text { group, and working methods, } \\
\text { as well as integration issues. }\end{array}$ & $\begin{array}{l}\text { Five focus groups } \\
\text { No. 1: three occasions with ten } \\
\text { informants (Nov. 2017). } \\
\text { No. 2: two occasions with ten } \\
\text { informants (Oct. 2018). }\end{array}$ \\
\hline $\begin{array}{l}\text { Semi-structured interviews with } \\
\text { steering representatives } \\
\text { (project leader, project } \\
\text { manager, HR unit manager, } \\
\text { and labor market unit } \\
\text { manager). }\end{array}$ & $\begin{array}{l}\text { Perceptions and experiences of } \\
\text { the project related to aim, } \\
\text { target group, and working } \\
\text { methods, as well as integration } \\
\text { issues. }\end{array}$ & $\begin{array}{l}\text { Six interviews: two occasions in } \\
\text { Nov. } 2017 \text { and four occasions } \\
\text { in Nov. } 2018 .\end{array}$ \\
\hline $\begin{array}{l}\text { Semi-structured interviews with } \\
\text { municipal employers. }\end{array}$ & $\begin{array}{l}\text { Perceptions of the target } \\
\text { group, the project, the } \\
\text { structure of the cooperation, } \\
\text { and the content of the } \\
\text { employer-oriented support. }\end{array}$ & $\begin{array}{l}\text { Nine interviews } \\
\text { (spring and autumn 2018). }\end{array}$ \\
\hline $\begin{array}{l}\text { Document studies of various } \\
\text { written documents, e.g. the } \\
\text { project plan, political } \\
\text { governance documents, } \\
\text { PowerPoint presentations, and } \\
\text { email conversations. }\end{array}$ & $\begin{array}{l}\text { What does the written } \\
\text { communication concerning the } \\
\text { project look like? Are there } \\
\text { different social representations } \\
\text { and how is this } \\
\text { communicated? }\end{array}$ & More than 20 documents. \\
\hline
\end{tabular}

Table 3: Characteristics of the data sources and data collection in study III. 


\section{Data analysis}

The focus of the analysis was on the theory of social representations, with a power perspective. Data analysis was inspired by Braun and Clarke's (2006) thematic analysis, which is a theoretically flexible method for analyzing qualitative data, focusing on examining themes or patterns of meaning within the data. Analysis was performed in relation to three of Bauer and Gaskell's (1999) implications concerning research on social representation, namely: content and process, time structures and longitudinal data, and crossovers of cultural projects and trajectories. The content and process approach of the analysis involved a focus on capturing the content and changes of the representations and identifying the central core elements of the different representations of the project as views on the aim, target group, and working methods of the project. Through the time structures and longitudinal data approach, the data analysis focused on the changing structures and functions of the representations by analyzing repeated interviews and focus groups, observational data, and documentary analysis over several time points. The crossovers of cultural projects and trajectories approach focused on societal fault lines and illuminated tensions due to the conflicting representations and the power relations between the involved actors.

As a complement to these implications, the material was analyzed in relation to Danermark and Germundsson's (2010) power approach, identifying three different power relations: model weak vs model weak, model weak vs model strong, and model strong vs model strong.

\section{Ethical considerations}

The studies fulfilled the basic ethical principles for research in social sciences by informing participants about the purpose of the study, receiving informed consent, not causing harm to participants, and maintaining confidentiality (Patton, 2015).

Study I followed the Swedish Research Council's Good Research Practice (2017). However, the character of the study, whereby the interviews were voluntary and independent of the employers' relationship to the welfare system, and no sensitive personal data were collected, meant that no specific ethical permission was considered necessary. The employers were contacted by email with a request to participate in the study and information about the intentions of the study. One reminder was sent to those who did not respond.

For the two ethnographic case studies (II and III), permission was given by the Regional Research and Ethics Committee in Linköping. In these studies, the participating professional actors (project staff members, 
steering representatives, staff from the home organizations, and municipal employers) were informed about the research design and the intentions of the studies, and about their voluntary participation in interviews, focus groups, and observations occasions. The employers were contacted with requests by email, and one reminder was sent. The youths involved in the interviews in study II were contacted by email and text message, and were only asked once to participate in order to avoid pressure. The youths involved in the shadowing of a staff member were invited to participate by the same staff member. The youths' requests regarding the format of the interviews were met. For example, two youths preferred to be interviewed by telephone and one chose to have a friend present during the interview. 



\section{FINDINGS}

The three empirical studies in this thesis have investigated labor market inclusion from different actors' perspectives, and with various theoretical and methodological approaches. The studies have resulted in four scientific papers. The chapter begins with a summary of the appended papers, followed by a presentation of each paper concerning the aim, the main results, and how the paper contributes to the aim and research questions of the thesis.

Table 4: Summary of the appended papers and their different characteristics.

\begin{tabular}{|l|l|l|l|l|}
\hline & Paper I & Paper II & Paper III & Paper IV \\
\hline Study & I & II & II & III \\
\hline $\begin{array}{l}\text { Empirical } \\
\text { method }\end{array}$ & Interview study & $\begin{array}{l}\text { Longitudinal case } \\
\text { study }\end{array}$ & $\begin{array}{l}\text { Longitudinal case } \\
\text { study }\end{array}$ & $\begin{array}{l}\text { Longitudinal case } \\
\text { study }\end{array}$ \\
\hline $\begin{array}{l}\text { Perspec- } \\
\text { tive }\end{array}$ & Employer & Authority actors & Authority actors & $\begin{array}{l}\text { Authority actors } \\
\text { and employers }\end{array}$ \\
\hline $\begin{array}{l}\text { Integration } \\
\text { focus }\end{array}$ & $\begin{array}{l}\text { Intersectoral } \\
\text { integration }\end{array}$ & $\begin{array}{l}\text { Interorganizational } \\
\text { integration }\end{array}$ & $\begin{array}{l}\text { Interorganizational } \\
\text { integration }\end{array}$ & $\begin{array}{l}\text { Mainly } \\
\text { intraorganizational } \\
\text { (and intersectoral) } \\
\text { integration }\end{array}$ \\
\hline $\begin{array}{l}\text { Theoretical } \\
\text { approach }\end{array}$ & Phenomenography & Practice theory & $\begin{array}{l}\text { Social capital and } \\
\text { shadow organizing }\end{array}$ & $\begin{array}{l}\text { Social } \\
\text { representations }\end{array}$ \\
\hline $\begin{array}{l}\text { Research } \\
\text { questions }\end{array}$ & I & II and III & III & I, II and III \\
\hline
\end{tabular}

\section{Paper I: Employers' views on disability, employability, and labor market inclusion: a phenomenographic study}

\section{Aim and research focus}

Previous research on employers' views on employability of people with disabilities shows a tendency to dichotomize and oversimplify employers' views as being either positive or negative. The aim of this study was to improve the understanding of these variations by mapping employers' different perceptions of disability and employability and the aspects that build up their views. The research focus was on variations through a phenomenographic approach, i.e., capturing the variation of views among employers 
from different contexts and with varied experiences of working with people with disabilities.

\section{Main findings}

The results suggest that employers' views on the employability of people with disabilities can be described as multifaceted, rather than just being categorized as positive or negative. Through a phenomenographic analysis, three categories portraying different views were identified: employability as constrained by disability, employability as independent of disability, and employability as conditional. The categories are understood through several individual-, workplace-, and authority-related aspects, which promote or obstruct and build up the different views in various ways.

\begin{tabular}{|c|c|c|c|}
\hline $\begin{array}{l}\text { Employability } \\
\text { as: }\end{array}$ & Constrained & Independent & Conditional \\
\hline $\begin{array}{l}\text { Individual-related } \\
\text { aspects }\end{array}$ & $\begin{array}{l}\text { I have to be sure that if it } \\
\text { is decided that you will } \\
\text { begin at seven this week, } \\
\text { you won't come in at nine } \\
\text { and say that you couldn't } \\
\text { get up. That wouldn't } \\
\text { work. It would be hard for } \\
\text { the rest of us who are } \\
\text { working. }\end{array}$ & $\begin{array}{l}\text { When we recruit, we use } \\
\text { a skill-based method, and } \\
\text { it is the person who has } \\
\text { the best competence for } \\
\text { the job who gets it. If it } \\
\text { happens to be a person } \\
\text { with a disability, we get } \\
\text { the support that the per- } \\
\text { son needs. }\end{array}$ & $\begin{array}{l}\text { We have employees tak- } \\
\text { ing care of mentally ill } \\
\text { people. We cannot hire } \\
\text { someone who is mentally } \\
\text { ill. }\end{array}$ \\
\hline $\begin{array}{l}\text { Workplace- } \\
\text { related aspects }\end{array}$ & $\begin{array}{l}\text { When we recruit, we } \\
\text { want someone who } \\
\text { works } 100 \% \text { from day } \\
\text { one. A trainee is someone } \\
\text { who comes in as an addi- } \\
\text { tion to that - but who I } \\
\text { don't want as an ordinary } \\
\text { laborer. As long as I can } \\
\text { choose the most capable } \\
\text { worker, I will. }\end{array}$ & $\begin{array}{l}\text { This is not an obstacle for } \\
\text { us, because we know that } \\
\text { it's worth it. }\end{array}$ & $\begin{array}{l}\text { A limitation does not } \\
\text { have to be an obstacle to } \\
\text { their work. You can't look } \\
\text { at an individual's diagno- } \\
\text { sis. You have to look at } \\
\text { what they can do. }\end{array}$ \\
\hline $\begin{array}{l}\text { Authority-related } \\
\text { aspects }\end{array}$ & $\begin{array}{l}\text { The wage subsidy can } \\
\text { suddenly disappear, you } \\
\text { never know... You can be } \\
\text { left standing there with } \\
\text { an employee with a disa- } \\
\text { bility who doesn't work } \\
\text { well and they (the PES) } \\
\text { don't want to pay any- } \\
\text { more. }\end{array}$ & $\begin{array}{l}\text { The size of the financial } \\
\text { support doesn't matter. I } \\
\text { need my employees to be } \\
\text { present. }\end{array}$ & $\begin{array}{l}\text { It seems like they work in } \\
\text { periods, because some- } \\
\text { times I get requests for } \\
30 \text { interns in a week and } \\
\text { then it's quiet for } \\
\text { months. }\end{array}$ \\
\hline
\end{tabular}

Table 5. Overview of the categories of views among the employers and selected quotations. 
Three common themes were identified through a contrastive analysis, affecting these views in different ways, and representing dimensions that cut across all categories, namely: trust, contribution, and support. The results present a framework for understanding employers' different views of employability for people with disabilities, as a complex internal relationship between conceived individual-, workplace-, and authority-related aspects in relation to trust, contribution, and support. Knowledge of the variation in conceptions of employability for people with disabilities may make it easier for authority actors involved in labor market inclusion to tailor employer-oriented support and integration. This can foster long-term trustful partnerships between the actors. It may also enhance the employers' perception of people with disabilities as being able to contribute and thereby increase their labor market inclusion.

Figure 6: The outcome space describing the interplay between different individual-, workplace-, and authority-related aspects, the themes from the contrasting analysis, and the employer's views on employability.

\section{CONTRIBUTION}

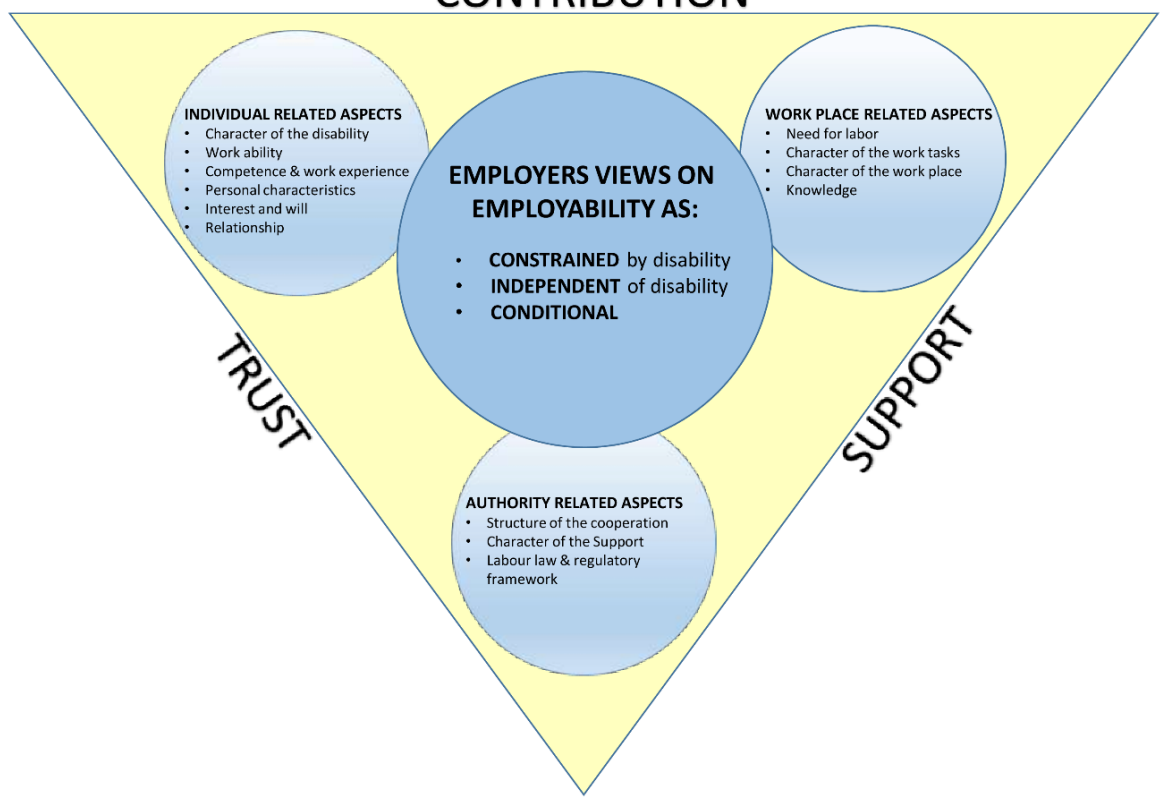

Source: Strindlund et al. 2018. 


\title{
Contribution to the thesis
}

The paper addresses the first research question concerning the employers' views on labor market inclusion and integration with authority actors, and how their perspective can be understood. The paper concludes that employers' views on employability for people with disabilities vary, and suggests that in understanding these variations, the interrelated functions of different individual-, workplace-, and authority-related aspects need to be accounted for. Even though the model in the paper is developed in relation to people with disabilities, it is assumed to be transferable to other vulnerable groups and contributes a framework for understanding labor market inclusion. This is due to the focus on the interrelated aspects and their different facilitating and aggravating functions, affecting the employers' views in different ways. Regardless of whether an individual has a disability or other challenges that complicate labor market inclusion, such aspects needs to be accounted for in relation to both the workplace and the authorities.

This emphasis on interrelationships and the contextual importance implies that labor market inclusion is a highly complex integrative phenomenon. In order to increase labor market inclusion, the authority actors need to take into account the employers' perspective to a greater extent than is currently the case. Rather than organizing labor market inclusion as integration activities between the individual and the authority actors, the measures need to be organized to include integration between the individuals, the authority actors, and the employers, stressing the importance of involving all three actors' perspectives.

The results led to a desire to investigate how the authority actors organized integration with the employers concerning labor market inclusion measures, and how the employers' needs were taken into account. This guided the research process toward studies II and III.

\section{Paper II: Zooming in on labor market cooperation: A study of a failed project to support unemployed young people}

\author{
Aim and research focus \\ This study addresses the lack of research on organizing and the actual prac- \\ tice within integrative services. The aim was to study the relational dynam- \\ ics of interorganizational cooperation over the life of a labor market inclu-
}


sion project. More specifically, the research focus was on how these relational dynamics emerged and were enacted during the initiation, development, and closing down of a cooperative project.

\section{Main findings}

Using a practice-theory approach, the study illuminated the complex dynamics of cooperative projects. The results visualized the consequences of a lack of consensus by identifying two different rationalities within the project organization: a coordinating rationality and an empowerment rationality. These represented two divergent logics that contrasted in most respects and divided the project organization into two groups, each following and acting in accordance with its own logic.

Briefly, the coordinating rationality, represented by the steering group and the financial backer, was characterized by the idea that the project would develop a coordination model. The perception was that the project would have a coordination function, supporting both unemployed individuals and staff with clients in need of support outside their own organization. The goal was to guide long-term unemployed individuals receiving financial welfare benefits through the system in order to achieve self-efficiency through work or studies (50\%), or to the right support (50\%). According to this rationality, the project was expected to include hundreds of individuals during the project time. The other actors (the project owner, project leader, and project teams) adhered to the empowerment rationality, which was characterized by the idea that the project would develop an empowerment aspect whereby unemployed individuals who had been circulating in the welfare system could be strengthened and empowered. By contrast, this rationality implied long treatment periods with fewer participants, and the staff were expected to work with personal treatment rather than coordination.

The results showed how these divergent rationalities had a major influence on the initiation, development, and closing down of the project. This was illustrated through three descriptive situations from three different phases in relation to Nicolini's (2012) focus areas. From the initiation phase, the "education day" situation - describing an education event in empowerment methodology - highlighted how the rationalities caused tensions between creativity and normativity concerning the choice of working method. From the development phase, the "brochure" situation - referring to a project team meeting where the content and design of information material was discussed - showed how the rationalities affected processes of legitimation and stabilization. The "revelation day" situation from the closing down phase - describing a planning day where the two rationalities caused tensions - illustrated the rationalities' importance for interactional order. 
In order to understand the dynamics behind the initiation, development, and closing down of the project, the article point out four conditions, identified in previous literature, namely communication, structure, trust and steering. It is concluded that these relational conditions are central when organizing cooperative projects, and the paper presents four recommendations: (a) to enable open and clear communication, (b) to create an adequate structure for the project and clarify assignments and roles within the project organization, (c) to build trustful relationships within the project organization and toward cooperative actors, and (d) to prioritize steering and monitoring in cooperative projects in order to avoid the project deviating from its purpose.

\section{Contributions to the thesis}

The paper contributed knowledge for answering research questions II and III, concerning the authority actors' views of labor market inclusion and integration, how this affected the organizing of labor market initiatives, and how this could be understood. As the results showed, the rationalities represented different views on the aim of the project, and the methodology also highlighted two different standpoints concerning labor market inclusion and integration.

The coordinating rationality was based on the idea of labor market inclusion as an integration or coordination strategy. The representatives perceived that there were unemployed individuals circulating in the welfare system who were actually ready to work. In order to increase labor market inclusion for these individuals, the idea was to organize the project by offering navigation support within the welfare system, both directly to the individuals but also to staff in remitting organizations searching for solutions for their clients, thereby encouraging the individuals to achieve selfsufficiency through work or studies with the right support, or to receive adequate societal services from existing resources. However, this rationality was overshadowed by the empowerment rationality which came to dominate the project.

For the representatives of the empowerment rationality, labor market inclusion was not an issue on the agenda. They perceived the unemployed individuals to be far from ready to work, instead needing empowerment before they would be ready for working life. Accordingly, the focus was on organizing personal development activities within the project. The view also influenced integration and how this was organized. The representatives directed their focus toward themselves and the integration within the group, and toward the participants, rather than toward cooperative organizations or employers. 
Unlike research that raises challenges with cooperation between authority actors, our results show that problems with integration were not related to which authorities the staff represented. Rather than following their respective organizations' goals and cultures, the people in the project organization adhered to the two rationalities. The results highlighted how the organizing of the integration involved tensions between the different perspectives, resulting in dysfunctional legitimation processes and power struggles. This meant that instead of focusing on labor market inclusion and encouraging integration with cooperative actors and employers, the project's focus was on internal issues. The central concepts of communication, structure, trust, and steering that were pointed out in the results help to answer the research questions concerning how the views can be understood, how this affected the development, and thus the organizing of the measure and integration. However, to gain a greater understanding of the group dynamics in the project, especially the dysfunctional internal group processes, further analysis with other theoretical and methodological approaches was needed. This insight resulted in a second analysis of the same material using a different theoretical lens, where a social capital and shadow organizing perspective was applied. This analysis is presented in paper III.

\title{
Paper III: When cooperation turns ugly: Exploring the dark side of social capital
}

\begin{abstract}
Aim and research focus
This paper is the result of a further analysis of the data material from study II, focusing on dysfunctional group processes. The aim was to contribute to the understanding of negative consequences of social capital in interorganizational cooperation between public organizations by exploring theoretical assumptions in the empirical case of a failed cooperation project, and how these consequences were related to processes involving people, structures, and environments. The conceptualization of the analysis was inspired and framed by the idea of shadow organizing (Gherardi, Jensen and Nerland 2017; Buch 2019).
\end{abstract}

\section{Main findings}

The dominance of the empowerment rationality in the project, as identified in paper II, involved a closed group process with a distancing from cooperating organizations and project organization actors. Through the theory of negative effects of social capital (Pillai et al. 2017) and by studying the social processes within the project, three relational social dynamics were 
identified in relation to three distinct phases, namely insulation, homogenization and escalating commitment. The three social dynamics were further studied in light of the "shadow organizing" metaphor (Gherardi, Jensen and Nerland, 2017) through the aspects of secrecy, liminality and performativity, contributing to new understandings and perspectives of the negative consequences of social capital. An illustration of the dynamics is presented in Figure 7.

Firstly, the social dynamic of insulation visualized the negative effects of group isolation by showing how the project team distanced themselves from their organizational environment, focusing on internal cohesion and the team's identification process. This insulation also hampered communication from the project team to the cooperative organizations and prevented external information and influences from reaching the project. The dynamic can be understood as a process of secrecy. The project team's inward focus and distancing from cooperative actors was described as the "creation of a bubble", and the limiting of transparency in the project relates to the use of the organizational shadow as a secluded environment enabling processes to develop unnoticed and without being questioned. A relatively absent steering group and strong team members provided opportunities for the team to act without insight, which made it possible for the project to develop for a relatively long time before anyone noticed any deviation from the original idea.

Secondly, the social dynamic of homogenization focused on the negative effects of group identification processes by showing how the project team members lost their affiliation identities and assimilated into a new common project identity. This homogenization resulted in a culture striving for conformity and common views, leading to closed-mindedness and the inhibition of critical thinking. This dynamic can be understood through the concept of liminality, which describes the grey zone between canonical and non-canonical practices, capturing the discrepancy between what is prescribed and what is actually practiced. This is enabled through professional discretion, leaving room for professionals to maneuver the organizing, such as the way in which the project team was given free rein to design its own roles and assignments, and to create "a world of its own".

Thirdly, the social dynamic of escalating commitment highlighted the negative consequences of the strong group processes in terms of overestimating the group and a magnified sense of self-importance which led to a polarization between the two parties in the project. This dynamic can be understood through the perspective of performativity. Operating under the shadow of group seclusion, the group created a productive and protective space. This penumbra, or the half-lit environment of the project, enabled unintentionally favorable growth for strong social identification processes, which resulted in overestimating the group, the group viewing itself 
as "superior", and the development of downward leveling norms. Building on this self-perceived strength, the group tried to use its social capital to act against external impulses to make the project change direction through various actions, such as turning to the media. The penumbra of the project organization hence created a specific "ecology" for the group, where the shady organizational undergrowth bred a specific performativity.

Figure 7: Illustration of the social dynamics in the project. In the first phase, insulation, the circle and the one-directional arrow illustrate the lack of communication from the project. In the second phase, homogenization, the circles in the project merge which illustrates how project members assimilate a new common identity. In the third phase, escalating commitment, the expanded circle illustrates the overestimation of the group and the breakdown in communication between the parties.

The social dynamics of:

1. Insulation

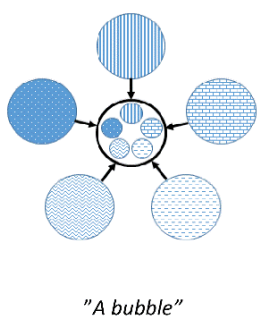

2. Homogenization

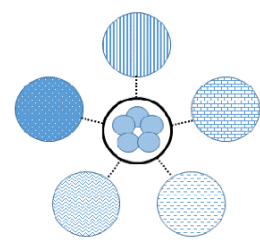

"A world of its own"
3. Escalating commitment

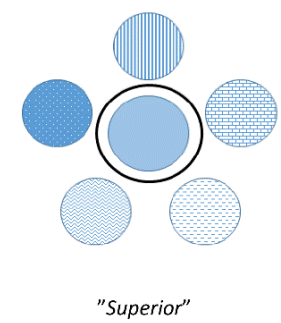

Source: Strindlund et al. 2020

\section{Contribution to the thesis}

The paper mainly contributed knowledge toward research question III concerning how different views of labor market inclusion impact on the organizing of labor market measures and integration, and how this can be understood. The combination of the social capital theory and the shadow organizing approach can offer explanatory value, showing how organizational dynamics can influence the development of social capital to produce negative effects.

The results showed how the different views (identified in paper II) resulted in negative social capital in the project, which can be understood 
through three relational social dynamics. These social dynamics (insulation, homogenization, and escalating commitment) influenced the organizing of the project and the integration in negative ways. The insulation and homogenization dynamics led to interactional integration within the project team between the representatives, rather than fostering links toward involved organizations. The inward directed focus and the homogenized group identity, in combination with a lack of communication and transparency, made the boundaries of the project increasingly non-permeable. This organizing hampered external influence and hindered integration with the participating organizations. The results showed how the different perspectives were not visualized and communicated, and how this contributed to creating conflicts and polarized relationships between the parties, which in turn contributed to the project team's escalating commitment.

The shadow organizing metaphor contributed new ways of understanding the different views of the project and how this influenced the organizing and interaction. By using a tree to represent the original idea of the project as a cooperative arena and its shadow as a symbol of the actual development of the project, the metaphor was used to look beyond the obvious and focus on the hidden, thereby capturing the social dynamics appearing within the project.

The results highlight the importance of focusing on the shadow, that is, studying organizing practices outside explicit structures, in order to identify the development of non-canonical practices and their consequences. When organizing cooperation projects that aim to bridge professional competencies or organizational boundaries, the authority actors have to be attentive to the processes within an organization that take place beyond the canonical and illuminated practices and designs. In this project, protective spaces were created in the penumbra which became a breeding ground for unexpected practices. If such practices are allowed to grow without insight, they may end up deviating from the original intentions and organizational goals.

The results show how knowledge of negative effects of social capital and the risk of letting projects become isolated from and insulated against their environment can increase the understanding of the involved actors' different perspectives and driving forces in interorganizational cooperation, and emphasize the importance of prioritizing communication, structure and steering, and building trustful relationships between involved actors when organizing new interorganizational projects, in order to avoid cooperation turning ugly. 


\title{
Paper IV: Social representations and tensions in organizing a labor market inclusion project
}

\begin{abstract}
Aim and research focus
The aim was to study the organizing of a municipal labor market inclusion project, with a specific focus on how different social representations among professional groups played out and conflicted over time. More specifically, the research focus was on social representations and power imbalances between different involved actors.
\end{abstract}

\section{Main findings}

The results identified three different social representations of the project: 1. an individual-oriented representation (as a means of supporting unemployed individuals), 2. an employer-oriented representation (as a means of supporting employers), and 3. a political representation (as a means of reaching political goals). These representations were identified concerning their central core, i.e. the aim, target group, and working methods. The individual-oriented representation was identified among the labor market consultants and the labor market managers employed at the labor market unit. The representation was characterized by a perception that the aim of the project was to help individuals standing "far from the labor market" to become employable by offering various time-limited workplace initiatives, such as internships and temporary employment at municipal workplaces. The employer-oriented representation was identified among the HR consultants and the HR managers employed at the HR unit. By contrast, this representation was characterized by the perception that the project aimed to support employers in need of labor by broadening recruitment to individuals standing closer to the labor market who were considered to be able to be employed after the project measures. The political representation was connected to municipal politicians, and its central core differed from the other two representations. This representation was denoted by political agendas, using the project as a means to reach specific targets. Thus, working methods were not seen as important as long as the project worked with the target group on the political agenda at the time in a way that contributed to reaching the political goals.

The results showed how the co-existence of these social representations played out and contributed to different tensions during three consecutive phases in the project: the making sense phase, the directed phase and the withdrawal phase. The project was organized as an integration project, with an explicit aim to combine individual and employer perspectives on 
labor market inclusion. However, it was unclear how this would be organized, and there were few thoughts about whether this might involve any difficulties.

During the making sense phase, the ambiguity resulted in an identification process where the project team tried to agree on a common social representation of the project, that is, what they were supposed to do, for whom and how. The group did not manage to agree, and instead two perspectives emerged into the individual- and the employer-oriented representations. These representations were not communicated, and contributed to the first tension - incomprehension about each other's representations - which split the project team in relation to the representations.

The second tension, power struggle, was related to management and power issues. The lack of project structure also applied to the steering, which resulted in a power struggle between the individual and employer perspectives at all levels within the project organization. This tension meant a tug-of-war between the parties in trying to dominate the project and influence the organizing in accordance with their social representation.

The third tension, gap of expectations, was a consequence of the presence of the different representations, resulting in various expectations of the project and making the project appear unclear. This tension emerged after the directed phase, in which the politicians influenced the project through a short-term political directive, conflicting with both individual and employer representations. Not having clear expectations met meant frustrations and disappointments concerning the aim, target group, and working methods, both within the project organization and among the employers.

The fourth tension, distrust, was a consequence of the discrepancies between what was said and what was actually being done in relation to the representations. This tension was seen during the withdrawal phase and meant that intensified separate grouping processes with decreased integrational activities in the project finally resulting in a collapse in integration.

This development can be understood by analyzing the power relations between the representatives of different social representations (Danermark \& Germundsson 2010). The results show that power among the actors was relational and conditional on the other representations, and that it changed over time. In particular, the results highlighted how a political directive introduced a new "model strong" representation of the project which, due to a strong political mandate and hierarchical structures, came to dominate the project and led to a short-term power shift, turning the other two representations into "model weak". This political representation, which was not in line with either the individual or employer representations, had ma- 
jor consequences for the further development of the project. When the political input was over, the two representations resumed the struggle for power over the project, leading to the growth of two "model strong" actors who were unwilling to compromise on their representations, and resulting in the withdrawal of the employer representation from the project.

\section{Contribution to the thesis}

This paper responds to all three research questions in the thesis.

Firstly, the results contributed new aspects relating to the research question concerning employers' views on labor market inclusion and how this can be understood. The results showed that the employers' views on the aim of the project, the target group, and the character of the support and integration depended on what information they had perceived and from whom, i.e. the social representation of the project. This meant that there were employers who expected the project to act in accordance with the employer representation and others who expected it to act in accordance with the individual representation. Depending on whether or not their expectations were fulfilled, they developed different views of the project and labor market inclusion. Those employers who aligned themselves with the individual representation seemed to consider the measure as a way to take social responsibility by enabling individuals to break their unemployment for a shorter period of time and add work experience to their CV. If the individual were to make a contribution, this represented added value but was not a requirement. On the contrary, those employers who aligned themselves with the employer representation seemed to feel that the project had not delivered what had been promised. The individuals that they had received at the workplaces did not match their actual labor needs, and the support from the project was neither sufficient in relation to the target group nor employer-oriented. These gaps in expectations seemed to generate feelings of distrust and unwillingness to continue the cooperation and to be involved in future integrative labor market inclusion measures.

Secondly, the paper contributes to the research question concerning authority actors' perspectives on labor market inclusion and integration by presenting how attribution to different social representations can have a major influence on different professionals' views on these issues. Unlike study II, where a common view of the project (empowerment rationality) united an interorganizational project team, this result shows how the development of two different views divided an intraorganizational group. The results point out the importance of understanding the strong mechanisms influencing these group identification processes in order to avoid tensions and power imbalances between the different perspectives. 
Thirdly, the results add knowledge to the research question concerning how different views impact on the organizing of labor market measures and integration. This study highlights the risks of organizing an integrative project with different social representations among involved actors. By not addressing and communicating these differences, an incomprehension of each other's representations can develop. In combination with lack of structure, such as a program theory, this situation can lead to a power struggle between the professionals in an attempt to dominate the project according to their own interpretation. If the project develops in the opposite direction to the involved actors' expectations, this can result in distrust and an unwillingness to integrate. 


\section{DISCUSSION: THE SOCIAL DYNAMICS OF LABOR MARKET INCLUSION}

In this chapter, the main findings are discussed in relation to the aim of the thesis and the three research questions. The chapter begins with a synthesis of the results and continues with a discussion of recurrent themes in the thesis, described in terms of social dynamics and their relationship to previous research. This is followed by methodological considerations and recommendations for future research. The chapter ends with a conclusion and practical implications.

\section{Synthesis of results}

The aim of this thesis was to explore the social dynamics of labor market inclusion with a particular focus on integration, from employers' and welfare actors' perspectives. The three empirical studies have contributed an increased understanding of employers' and authority actors' views and their relationships to the organizing and integration in labor market projects.

Below is a brief summary of the main results, highlighting the different views and central conditions for understanding these views and the organizing and integration, as well as the different theoretical approaches used.

In study I, a phenomenographic approach helped to highlight variations in employers' views on people with disabilities, employability, and labor market inclusion. The different views were categorized as constrained by disability, independent of disability, and conditional, and could be understood in relation to a complex interplay between different individual-, workplace-, and authority-related aspects and three themes: trust, contribution, and support.

In study II, a practice-theory approach helped to zoom in on social dynamics in integration, specifically tensions between creativity and normativity, processes of legitimation and stabilization, and interactional order. This contributed to the identification of two divergent views of the studied project among the actors: an empowerment rationality and a coordinating rationality. Four central concepts were highlighted in relation to understanding the views and the organizing and integration: communication, trust, structure, and steering. 
In the second analysis of study II (paper III), theories of negative effects of social capital and shadow organizing helped highlight the dysfunctional group processes in the project team. The results emphasized three social dynamics in understanding the development of the views and influences on the organizing and integration in the project: insulation, homogenization, and escalating commitment.

Study III applied the theory of social representations in order to identify three different representations of the studied project among different professional groups: an individual-oriented representation, an employeroriented representation, and a political representation. Four tensions were found, influencing the views and the organizing and integration: incomprehension, power struggles, gap of expectations, and distrust.

These results, taken together, have shown that the integration projects have been influenced by various dysfunctional tensions and social processes, hampering integration and thus also labor market inclusion. These tensions and processes can be described as social dynamics, and can be understood in relation to the selected collaborative themes from the theory of collaborative advantage (Huxham \& Vangen 2005). Three social dynamics emerged from the results: multiple and conflicting views, grouping processes, and power struggles.

\section{Multiple and conflicting views}

One of the main results, answering research questions I and II concerning employers' and authority actors' views on labor market inclusion, was the identification of multiple views among the different actors. Through various methodological and theoretical approaches, the studies have highlighted a diversity of views both among employers and authority actors. The papers have identified how these views are built on different rationalities and social representations. Apart from being multiple, the results have shown that the views are complex, multifaceted, and nuanced, and often conflict with other actors' views. Moreover, the results have found that the views are affected by a variety of themes (paper I), concepts (paper II), social dynamics (paper III), and tensions (paper IV), contributing to additional dimensions.

As for employers, the results from paper I suggest that their views are multifaceted and not as dichotomic as previous research has shown (e.g. Gilbride et al., 2003; Ju, Roberts and Zhang, 2013; Shaw et al., 2014). The results present a framework for interpreting their views in relation to various individual-, employer-, and authority-related aspects that can have both hampering and facilitating effects, emphasizing the need to consider 
the context and the specific situation, rather than the general and the predetermined. Paper IV contributed further knowledge about employers' views, by showing the impact of their views on the integration between employers and authority actors. The results showed that employers' views were conditional and not predetermined. What seemed crucial was the description they had received about the project and whether the project had delivered in line with that description, emphasizing the importance of clear communication.

As for authority actors, paper II identified two views of the project, described as an empowerment rationality and a coordinating rationality. These rationalities meant contrasting views on most aspects of the project, including aim, target group, and working methods. Unlike other research on interorganizational integration (e.g. Huxham and Vangen, 2005), the results showed that the views were not dependent on organizational or professional affiliation. Instead, they could be traced to what rationality the professionals in the project organization considered themselves to belong to, resulting in a division within the project organization based on these rationalities. Paper IV showed that underlying social representations build up the actors' views. The results identified three different rationalities among the various professional groups in the project: individual, employer and political rationalities. These views were contrasting in relation to perceptions of the project's aim, target group, and working methods. Unlike in study II, these rationalities were closely related to the professionals' affiliations, that is the HR unit, the labor market unit and municipal politics.

The multiple and conflicting views can be interpreted based on Huxham and Vangen's theme of common aims (2005). In theory, common or at least compatible aims or visions of the object of the integration are important as a starting point for integration. In reality, as seen in study II and III, the variety of organizational and individual agendas makes it difficult for actors to agree. O'Leary and Vij (2012) conclude that the interests of collaborative actors may conflict, but they emphasize that the actors must agree on the overall aim of the integration and consider whether the different organizations' aims are compatible with the aim of the integration. Huxham and Vangen (2005) state that differences in perspectives are inevitable in multi-party situations, and are not limited to the aim of the integration, but relate to other themes and issues such as power, trust, and integration structures, which the following dynamics will address. They conclude that collaborations have a paradoxical nature requiring "simultaneous protection and integration of the partners' uniquely different resources, experiences, and expertise in complex, dynamic organizing contexts" (Huxham and Vangen, 2005; Vangen, 2016, p. 263). 
However, the results showed that this paradox was unknown among the actors, and that there was widespread incomprehension about the presence of multiple and conflicting views. The results from the studies focusing on employers' perspectives (papers I and IV) show that employers do not think that the authority actors understand their views of labor market inclusion, with the result that workplace-related measures and integration around the unemployed individual are organized from the perspective of the authorities rather than the employer. Concerning the authority actors' perspective, the results show shortcomings in understanding the presence of multiple views and how they interact and conflict. This led to difficulties understanding integrative actors' perspectives concerning their assignments, needs, and contributions in relation to labor market inclusion.

The incomprehension about multiple and conflicting views can also be understood in relation to Huxham and Vangen's theme of communication and language (Huxham and Vangen, 2005). Both study II and study III were characterized by ambiguity and vagueness. The projects lacked program theories stating the aim, target group, and working methods. Instead, they were built on unclear project plans, with obscure goals and objectives. The lack of clarity contributed to an inward directed focus, where the project actors spent a lot of time during the start-up phase trying to interpret what they were supposed to do, for whom, and how, rather than being directing toward collaborative actors outside the project. In study II, this incomprehension was identified through the practice-theory focus area of "tensions between creativity and normativity", where the project team interpreted their assignment in a different way to the original project assignment. In study III, the incomprehension was identified during the "making sense phase", where the lack of communication and language addressing the differences between the perspectives and how these needed to be integrated enforced the incomprehension among the professionals. This social dynamic relates to the paradox of integration, where each actor embarks on integration with different images of what is to be achieved, and a failure to communicate these differences and a failure to compromise underlies dysfunctional adverse effects (Huxham and Vangen, 2005).

Finally, the social dynamic can be understood in relation to Huxham and Vangen's theme of membership structures (Huxham and Vangen, 2005). The projects in the studies were characterized by ambiguity concerning both membership and status, as well as representativeness. The actors had different perceptions of who was participating in the projects, their own and others' role or membership status, and what they were representing and to what degree, helping to enforce the incomprehension about the multiple and conflicting views. 
The following two dynamics (grouping processes and power struggles) address research question III, concerning how the different views impact on the organizing and integration in the labor market inclusion projects.

\section{Grouping processes}

The social dynamic grouping processes describes the dysfunctional group identification processes seen in the integration projects within the project team, as a consequence of the incomprehension about the multiple and conflicting views. The processes were characterized by an inward directed focus where, in order to make sense of the assignment, the project actors grouped themselves with like-minded people, resulting in different divisions within the project organizations. The process was seen as a reaction to the incomprehension about each other's views and how they conflicted, and instead led them to prioritize their own perspectives. The processes can also be seen as a consequence of the vagueness characterizing the structure of the projects, with the lack of program theories leading the project actors to search for answers on their own.

The dynamic can be understood in relation to the researcher-developed themes of identity and social capital in the theory of collaborative advantage (Huxham and Vangen, 2005). Huxham and Vangen (2005) describe identity-forming processes as a complex, interwoven, tangled mix of interaction cycles, taking place within and around interorganizational integration. They conclude that actors often enter integration situations with a predisposition about themselves and the collaborative actors, which is continuously influenced by actions and interpretations. They point out the challenge involving the tension between the need for participants to identify with their organization and with the integration.

In study II, the grouping processes meant that the project team went through a strong identification process, identifying themselves with the project. In paper II, this process was described through the practice theory as "processes of identification and stabilization", where the project members distanced themselves from their home organizations and went through an extensive identification-forming process with the project, for example by designing a project logo for use on project workers' clothing and marketing materials. In paper III, social capital theory highlighted how the grouping developed into dysfunctional processes through the three dynamics of insulation, homogenizing, and escalating commitment. Insulation described how the project team withdrew and isolated themselves from the environment outside the project. Homogenizing described the process whereby the group members began to resemble each other rather 
than highlighting their differences and complementary competencies. Escalating commitment described how the grouping led to an overestimation of the group and a magnified sense of self-importance, resulting in a polarization between the two parties in the project.

In study III, this social dynamic implied a division within the project team in relation to the various social representations of the project. This meant that the project team was split into an HR consultant group and a labor market consultant group. Huxham and Vangen (2005) point out the importance of employment structures for understanding the identification processes, where the professionals in study III followed their managers' representations, enforcing the identification with their respective unit rather than with the project.

The grouping processes played out in different ways in the two projects, with the experiences from project II showing how this social dynamic can help to unite project members (and form a basis for dysfunctional grouping processes), whereas the experiences from project III were an example of how the same dynamic can split a project team. In both examples, the dynamic had hampering effects on the organizing and the integration, and contributed to a collapse in integration, which shows the importance of being aware of the tension between the need for actors to identify with their organization and with the integration, as emphasized by Huxham and Vangen (2005).

\section{Power struggles}

The social dynamic of power struggles was identified in the integration projects, capturing the dysfunctional processes between actors with different views of the same project. This social dynamic followed the grouping process, which meant that the integration projects resulted in subgroups with conflicting views about the core of the project, that is, the aim, the target group, and working methods. This lack of consensus was related to the lack of structure characterizing the projects and the lack of communication concerning the different views and how this affected the organizing of the project and the integration. The lack of structure also concerned the steering of the projects, with the studies showing that both projects had issues with steering structure and engagement, resulting in questions concerning who decides and whose perspective dominates. The power struggles can be seen as a consequence of these malfunctions, where the failure to address the differences led the actors to influence the project in line with their interpretations. This meant a focus on power struggles rather than integration, driving the project actors to dominate the project in line with their interpretation. 
This social dynamic has a clear connection to the collaboration themes of leadership and power (Huxham and Vangen, 2005). In study II, a power struggle was identified between the representatives of the empowerment rationality and the coordinating rationality through the practice-theory focus area of "interactional order" (paper II) and the negative effect of social capital "escalating commitment" (paper III). In study III, a power struggle was identified between the three social representations, and was studied through a power perspective and Danermark and Germundsson's (2010) theory of social representations. The power approach visualized unequal interpersonal power relations between the three groups, categorized as powerful and non-powerful actors, and showed how this imbalance generated conflicts and tensions, effectively resulting in a collapse in integration. One essential aspect visualized in the study was how a political directive with a conflicting view changed the whole direction of the project, contributing to negative effects on the internal integration between the professional groups as well as the integration with employers.

The negative consequences of the power struggles on integration, as noted in both study II and study III, have also been seen in previous research. Power imbalances within integration situations may result in conflicts which can hamper the success of the integration (Sawa, 2005; O'Leary and Vij, 2012). Structure and leadership issues are both sources of and remedies for power struggles. O'Leary and Vij (2012) conclude that collaborations work more easily when there are no major disparities of power, and that a legal mandate for increased authority and power will increase the likelihood of integration succeeding. The power struggles have meant a focus on the steering representatives defending the territory of their own organization rather than prioritizing integration, a condition that has been perceived in previous research as hampering conditions for integration (Andersson et al., 2011; SOU, 2018).

The power struggles in the project can be interpreted in relation to theories on the importance of leadership in horizontal collaboration contexts (Axelsson and Bihari Axelsson, 2013). Axelsson and Bihar Axelsson (2013) describe the leadership's tasks and focus in relation to a development process with four phases: facilitating communication (forming phase), managing conflicts (storming phase), creating trust (norming phase), and facilitating work and contacts (performing phase). The steering representatives failed to facilitate communication between the rationalities during the forming phase, and did not manage the conflicts during the storming phase. Nor did they contribute to creating trust between the parties during the norming phase, or to facilitating work and contacts during the performing phase. Instead, the power struggle was given too much space, contributing to polarization and distrustful relationships between the parties. 
Huxham and Vangen (2005) conclude that collaboration leadership consists of balancing facilitative activities undertaken in the "spirit of collaboration" and manipulative activities labeled "collaborative thuggery", where the power struggles in the projects can be understood as a failure to strike this balance.

The power struggles and the previous social dynamics led to distrustful relationships, both within the projects and in relation to integrative actors outside the projects. Distrustful relationships between actors with conflicting views were related to gaps in expectations among the actors, that is, the perception that the project and the integration had developed in an unexpected direction. These deviations contributed to distrust between the representatives of the different views. The distrustful relationships were characterized by feelings of disappointment and frustration among those actors whose views were not taken into account.

This can be understood through the collaboration theme of trust (Huxham and Vangen, 2005), described as collaborative actors' expectations of and faith in the integration, and the other actors' future behaviors in relation to meeting these expectations. Huxham and Vangen (2005) point out that trust is closely related to power, and see the two themes as opposite sides of the same coin, since perceptions of power imbalance inevitably lead to feelings of mistrust.

In study II, distrustful relationships developed between the representatives of the rationalities. Trust was one of the conditions highlighted in paper II in terms of understanding the negative development of the project, related to deficiencies in communication, structure, and steering. When the steering representatives understood that the project team had developed the project in a conflicting direction, they lost faith in the project team and chose to end the project prematurely. The lack of trust led to a total collapse in integration. In study III, this social dynamic was described as a tension, following on from power struggles and a gap of expectations, resulting in distrust and an unwillingness to collaborate. The tension was seen as a consequence of the actors adhering to the employer representation, concluding that their perspectives were not taken into account. The employers were critical that the project did not deliver support and integration organized from their perspective, according to the themes from study I (trust, contribution, and support). Their distrust toward the authority actors and their failure to deliver what was promised resulted in a deterioration in relations, hampering future integration within labor market inclusion. For the representatives from the HR unit, the social dynamic led to an unwillingness to collaborate and their withdrawal from the project.

The results show the interrelated connections between distrust and communication found in previous integration research (Andersson et al., 2011; O'Leary and Vij, 2012). They also confirm research highlighting that 
trust is essential in integration (Ståhl, 2010; Andersson et al., 2011; O'Leary and Vij, 2012). The experiences demonstrate the fragility of trust, and serve as examples of how trust takes time to build but can be destroyed in a very short time (Andersson et al., 2011; SOU, 2018).

\section{Methodological considerations}

The research process in this thesis has been influenced by continuous methodological considerations, contributing to both strengths and limitations that need to be considered when interpreting the findings. A more detailed description of the methodological issues is provided in the summary of the studies (studies I-III) and in the appended papers (I-IV).

One consideration concerns the research role and the employment arrangement enabling practical work to be combined with research. The combination employment meant that I represented both the university and the coordination association. One benefit of this arrangement was that it facilitated access to the practice. A disadvantage was that it was sometimes difficult to separate the research studies from the regular practice. Another aspect of the research role concerns my pre-understanding of the studied phenomenon. Through my previous experience of practical work at the PES I had some prior knowledge of the practice, which was an asset throughout the research process, from staging the studies to the data analysis. However, this also involved a risk of preconceptions about the data, and in order to prevent distortions from such biases and to increase awareness of preconceptions and interpretations, continuous peer debriefing with my supervisors and co-writers took place.

Another consideration concerns the research design, where the three empirical studies were designed in order to explore labor market inclusion from the perspectives of authority actors and employers. The studies involved material from all three interactive actors, with a focus on authorities and employers. In total, the sample consisted of more than 100 informants, providing a wide variation of experiences and perspectives on the studied phenomenon. In study I, this variation was considered to be one of the strengths of the study, addressing the problem of self-selection from previous studies. In both study II and study III, the variation of informants (project staff members, management representatives, unemployed individuals, professionals representing the home-organizations, and employers) contributed insights into how various perspectives influence the organizing and integration of labor market inclusion. One of the limits of study I was that the phenomenological approach allowed for a focus on employers' views and sayings, and not on their actual doings. This argument was addressed in studies II and III, where the various ethnographical methods such as observations, shadowing, and document studies complemented the 
interviews, all contributing to a deeper and more nuanced understanding of the phenomenon, concerning both doings and saying. The longitudinal study design also proved to be a valuable approach for understanding the different perspectives and how they changed over time.

Another aspect of the research design concerns the interactive approach. The interactive research in combination with the employment arrangement gave me the opportunity to "stay in the context of discovery" (Swedberg, 2012) for five years. This resulted in extensive data collection with thick descriptions of the studied phenomenon. One challenge with this approach has been to distinguish between what constitutes the research study and what constitutes general knowledge about the context and labor market inclusion. Another challenge with this approach concerns the continuous feedback given to the project, which was sometimes seen as criticism by some actors. This hampered the interactive approach, and made access more difficult in some situations where the researchers were considered a threat rather than offering a contribution to the project development. The approach called for constant reflection about the balance between proximity to and distance from the field. Here, my supervisors and co-authors have had a significant role, reminding me to keep track of the specific studies and not the whole context, as well as highlighting the importance of keeping my distance in order to not be included in what is studied.

Moreover, the interactive approach has involved challenges that relate to the role of the researcher concerning feedback on negative aspects of the organizing and interaction. In study II, highlighting shortcomings contributed to the closure of the project, where the results were in line with the management's agenda. In study III, the management had a different approach, resulting in hampering an interactive approach and the feedback of results. These experiences show the challenges of the researcher's role in balancing pointing out shortcomings and building trustful relationships for continuing integration and opportunities for access.

Moreover, the research process has involved theoretical considerations. Following the theorizing process, the theoretical approaches were not stated from the beginning but emerged during the process. The interactive approach has also influenced the data analysis, which has been a continuous iterative zooming in and out process between practice and theory. This has meant gradually building on the pre-understanding with new insights through the studies and the theoretical analysis. Another asset was that the data analysis involved the supervisors and co-writers in all four papers, contributing their specific experiences and perspectives in different ways. Also, the use of various theoretically approaches has provided differ- 
ent lenses, which has contributed to exploring the phenomenon and enriching the data as a whole. One limitation of this varied approach is that I have not developed a deeper experience of using the different theories.

The main strength of the research approach is that it has facilitated a close study of labor market inclusion, not only on the surface, but also the fluid and intangible parts. The ethnographical approach has contributed to new insights and knowledge of the phenomenon and the social dynamics of labor market inclusion, where the four papers only form a limited part of all the material. This approach can be related to Malcom Gladwell's (2014) 10,00o hour rule, suggesting that in order to master something one needs to devote 10,000 hours, and writing a thesis at least meets the time demands.

The trustworthiness of a qualitative study depends on four criteria: credibility, transferability, dependability, and confirmability (Lincoln and Guba, 1985). These aspects have been addressed by the findings of the studies having been systematically presented to project participants, professionals, and politicians, representing different local and national contexts within labor market inclusion. The findings have been continuously discussed among the co-authors and with colleagues at seminars (local, national, and international), as well as in informal discussions. Moreover, concerning transferability, the findings emphasize the importance of context-specific conditions.

\section{Future research}

This thesis points to a need for future research.

- Further ethnographical research studies of various integration contexts are recommended, in relation to both integration projects and integration within ordinary structures, in order to enrich the data and the understanding of labor market inclusion.

- Further studies of employers' perspectives and roles in labor market inclusion projects and measures are also requested, ideally in contexts where the employers are really involved and also with employers outside the public sector.

- Moreover, the political perspective on labor market inclusion, which has only been touched upon in this thesis, but which turned out to play a central role in study III, needs to be explored in more depth.

- Finally, future research studies applying an interactive research approach are encouraged, to ensure that the research design is anchored and requested by the practice system, given its potential impact on the practice. 


\section{Conclusions}

This thesis contributes to the knowledge of integration inertia (Huxham and Vangen, 2005) within the labor market inclusion context by pointing out shortcomings and challenges in the organizing of integration projects, relating to both the challenges of intraorganizational and interorganizational integration between the authorities and the intersectoral integration between authorities and employers. Thus, it can be concluded that labor market inclusion does not function like a piece of clockwork machinery. Rather, this thesis has revealed - through the close study of two labor market inclusion integration projects - a complex and dynamic interplay between the involved actors' various views, and social processes in the project organizations and organizational aspects, referred to as social dynamics. These social dynamics constitute the key concepts in this thesis, contributing understanding about how integration and organizing within labor market inclusion projects work, or rather, what makes them fail. Three social dynamics were identified: multiple and conflicting views, grouping processes, and power struggles.

The social dynamics can be understood through the metaphor of shadow organizing, exploring organizing as intrarelating processes focusing on what happens in the interstices between intentional and unintentional organizing actions (Gherardi, Jensen and Nerland, 2017). This metaphor brings out the dynamic and liminal aspects of organizations, outlining organizations in terms of activity and process rather than in terms of stable entities. The different perceptions of the projects can be seen as trees and their shadows. By zooming in on the shadows and those parts that are not obvious, the social dynamics can be identified and illuminated. The social dynamics can be understood through the concept of liminality, capturing the grey zone between canonical and non-canonical practices. This addresses the discrepancy and tensions between the multiple views, between what was prescribed in the projects and what actually came to be practiced, i.e. the gaps of expectations. The social dynamics can also be understood in relation to the concept of secrecy, which captures the secluded environment and limited transparency in the projects. This secrecy was found to be a result of vagueness and a lack of steering, structure, and communication characterizing the organizing within the projects, which allowed the dynamics to develop unnoticed and without being questioned. Moreover, the social dynamics can be understood through the concept of productivity, illustrated as sheltered half-lit spaces in the shadows. This shady organizational undergrowth bred a specific performativity and facilitated an unintentional but favorable growth of dysfunctional grouping processes and power struggles. 
Increased knowledge and awareness of this complexity and the social dynamics of labor market inclusion may contribute to increased preparedness when organizing integration projects. The results suggest that by identifying and addressing the multiple views characterizing integration projects and not letting incomprehension dominate, destructive social dynamics may not be given as much space, or may even be avoided, which can stimulate a willingness to integrate rather than the opposite.

\section{Practical implications}

This thesis has highlighted challenges involved with integration and organizing in labor market inclusion projects. Given the risk of collaborative inertia, the recommendations follow Huxham and Vangen's advice: "Don't do it unless you have to" (Huxham and Vangen, 2005, p. 13). However, since labor market inclusion is a fragmented and complex assignment shared by several authority actors in relation to the unemployed individual and the employers, integration is often demanded, or requested. In those cases, integration competence is needed to avoid integration failure. One excellent source of integration competence is Huxham and Vangen's theory of collaborative advantage.

This thesis may also contribute to integration competence by highlighting some recommendations based on the lessons from the failures in the projects:

- Organize integration projects based on program theories with clearly stated aims, target groups, and working methods.

- Organize and clarify the project organizations, concerning roles, mandates, and assignments.

- Prioritize the management of the integration projects and ensure that these representatives possess good communication skills.

- Be sure to include the employers' perspectives when organizing labor market inclusion projects and measures.

- Prioritize evaluation and create conditions for a learning environment. 



\section{REFERENCES}

AFS (1994) 'Arbetsanpassning och rehabilitering AFS 1994:1'. Available at: https://www.av.se/globalassets/filer/publikationer/foreskrifter/arbetsanpassningoch-rehabilitering-foreskrifter-afs 1994-1.pdf.

AFS (2015) 'Organisational and social work environment AFS 2015:4'. Available at: https://www.av.se/en/work-environment-work-and-

inspections/publications/foreskrifter/organisatorisk-och-social-arbetsmiljo-afs20154-foreskrifter/.

Ahlberg, O. et al. (2018) 'Var finns jobben? Bedömning för 2018 och på fem års sikt'. Arbetsförmedlingen.

Allvin, M. et al. (2006) Gränslöst arbete - Socialpsykologiska perspektiv på det nya arbetslivet. Liber.

Andersson, J. et al. (2011) 'Organizational approaches to collaboration in vocational rehabilitation-an international literature review.', International Journal of Integrated Care doi: 10.5334/ijic.670.

Andersson, J. et al. (2015) 'Employer attitudes toward hiring persons with disabilities: A vignette study in Sweden', Journal of Vocational Rehabilitation, 43(1), pp. 41-50. doi: 10.3233/JVR-150753.

Andersson J. (2016) Locked-in collaboration. Förvaltningshögskolan Göteborg. Available at:

https://gupea.ub.gu.se/bitstream/2077/49531/1/gupea_2077_49531_1.pdf.

Andersson, L. (2010) När strävan efter samsyn blir en kamp: Meningsskapande och meningsgivande i mångtydiga sammanhang. Linköpings universitet. Available at: http://liu.diva-portal.org/smash/get/diva2:282640/FULLTEXT01.pdf.

Arbetsförmedlingen (2016) Subventionerade anställningar. Kartläggning ur ett bransch-och företagsperspektiv.

Arbetsförmedlingen (2017a) Perspektiv på arbetslösheten i olika grupper.

Arbetsförmedlingen (2017b) Perspektiv på långtidsarbetslösheten.

Arbetsförmedlingen (2019a) Arbetsförmedlingens återrapportering 2019. Arbetsmarknadspolitiska program.

Arbetsförmedlingen (2019b) Arbetsmarknadsrapport.

Aspers, P. (2011) Etnografiska metoder. Liber.

Axelsson, R. and Bihari Axelsson, S. (2006) 'Integration and collaboration in public health- a conceptual framework'. The international Journal of Health Planning and Management. 21(1), pp. 75-88. doi: 10.1002/hpm.826.

Axelsson, R. and Bihari Axelsson, S. (2013) 'Samverkan som samhällsfenomennågra centrala frågeställningar', in Axelsson, R. and Bihari Axelsson, S. (eds) Om samverkan-för utveckling av hälsa och välfärd. Lund: Studentlitteratur, pp. 17-38.

Bauer, W. M. and Gaskell, G. (1999) 'Towards a Paradigm for Research on Social Representations', Journal for the Theory of Social Behaviour, 29(2), pp. 163186. 
Bejerholm, U. et al. (2015) 'Individual placement and support in Sweden - a randomized controlled trial', Nord J Psychiatry, 69(1), pp. 57-66. doi: 10.3109/08039488.2014.929739.

Bengtsson, M. (2017) 'Arbetsmarknadspolitik', in Bengtsson, M. and Berglund, T. (eds) Arbetslivet. Lund: Studentlitteratur.

Bengtsson, P., Ornstein, P. and Rödin, M. (2018) Analys av det förstärkta samarbetet för sjukskrivna. Arbetsförmedlingen analys 2018:13. Available at: https://arbetsformedlingen.se/download/18.75a5a30116b93f40a3f60e6/analysdet-forstarkta-samarbetet-sjukskrivna.pdf.

Bihari Axelsson, S. and Axelsson, R. (2009) 'From territoriality to altruism in interprofessional collaboration and leadership', Journal of Interprofessional Care, 23, pp. 320-330.

Bourdieu, P. (1986) 'The Forms of Capital', in John, G. (ed.) Handbook of Theory and Research for the Sociology of Education. New Work: Greenwood.

Brulin, G. and Svensson, L. (2011) Att äga, styra och utvärdera stora projekt. Lund: Studentlitteratur.

Buch, A. C. (2019) 'When does the owl of Minerva spread its wings? Shadow organizing and modes of inquiry', Qualitative Research in Organizations and Management: An International Journal. doi: 10.1108/QROM-10-2018-1691.

Calmfors, L., Forslund, A. and Hemström, M. (2002) Does active labour market policy work? Lessons from the Swedish experiences. 2002:4. The Institute for Evaluation of Labour Market and Education Policy.

Chaib, M. and Orfali, B. (1995) 'Introduktion till teorier och metoder kring sociala representationer', in Chaib, M. and Orfali, B. (eds) Sociala representationer-Om vardagsvetandets sociala fundament. Göteborg: Daidalos.

Crépon, B. and van den Berg, G. (2016) Active labor market policies. Working paper 2016:17. The Institute for Evaluation of Labour Market and Education Policy (IFAU).

Czarniawska, B. (2007) Shadowing - and Other Techniques for Doing Fieldwork in Modern Societies. Liber.

Czarniawska, B. (2008) 'Organizing: How to study it and how to write about it', Qualitative Research in Organizations and Management: An International Journal, 3(1), pp. 4-20. doi: 10.1108/17465640810870364.

Czarniawska, B. and Joerges, B. (1996) 'Organizing, process of.', in Warner, M. (ed.) InternationalEncyclopedia of Business \& Management. Berlin, New York: Walter de Gruyter, pp. 39966-3981.

Danermark, B. (2000) Samverkan - himmel eller helvete? : en bok om den svåra konsten att samverka. Gothia.

Danermark, B. (2004) Samverkan- en fråga om makt. LäroMedia Örebro AB.

Danermark, B. et al. (2014) 'French and Swedish teachers' social representations of social workers', European Journal of Social Work, 17(4), pp. 491-507.

Danermark, B. and Germundsson, P. (2007) Nya vägar till arbetsmarknadenkvalitetssäkring av samverkan. Sundsvall: Liber.

Danermark, B. and Germundsson, P. (2010) 'Social Representations and Power', in Chaib, M. et al (ed.) Education, Professionalization and Social Representations: On the Transformation of Social Knowledge. Routledge, pp. 33-43. 
Domzal, C., Houtenville, A. and Sharma, R. (2008) Survey of Employer Perspectives on the Employment of People with Disabilities. Technical Report November 2008. Available at:

https://www.dol.gov/sites/dolgov/files/odep/research/surveyemployerperspective semploymentpeopledisabilities.pdf.

Durkheim, E. (1895) The rules of sociological method. New York: The Free Press.

Ekberg, K. et al. (2006) Tid för utveckling? Lund: Studentlitteratur.

Ekberg, K. (2010) 'Arbetslivsinriktad rehabilitering', in Edling, C. (ed.) Arbets- och miljömedicin- en lärobok om hälsa och miljö. Lund: Studentlitteratur.

Ellström, P. E. (2008) 'Knowledge Creation through Interactive Research: A Learning Perspective'. Available at: http://center.hj.se/download/18.7b2d1d971365d15588680006296/PerErik+Ellström.pdf.

Erickson, W. A., Schrader, S. von and Bruyère, S. M. (2014) 'The Employment Environment: Employer Perspectives, Policies, and Practices Regarding the Employment of Persons With Disabilities', Rehabilitation Counseling Bulletin, 57, pp. 195-208. doi: 10.1177/0034355213509841.

European Commission (2008) 'Commission recommendation on the active inclusion of people excluded from the labour market', Official Journal of the European Union. The Commission of the European Communities. Available at: https://eurlex.europa.eu/legal-content/EN/ALL/?uri=CELEX\%3A32008H0867.

Fölster, S. (2015) De nya jobben i automatiseringens tidevarv. Stiftelsen för strategisk forskning (Swedish Foundation for Strategic Research. Available at: https://strategiska.se/app/uploads/de-nya-jobben-i-automatiseringenstidevarv.pdf.

Forslund, A. et al. (2019) Kommunal arbetsmarknadspolitik. Vad och för vem? En beskrivning utifrån ett unikt datamaterial. RAPPORT 2019:5. IFAU (Institutet för arbetsmarknads- och utbildningspolitisk utvärdering). Available at: https://www.ifau.se/globalassets/pdf/se/2019/r-2019-05-kommunalarbetsmarknadspolitik-vad-och-for-vem.pdf.

Fred, M. (2018) Projectification : the Trojan horse of local government. Malmö Universitet.

Furåker, B. (2017) ‘Arbetsmarknaden', in Arbetslivet. Lund: Studentlitteratur, pp. 61-84.

Furåker, B. and Blomsterberg, M. (2009) 'Arbetsmarknadspolitik', in Berglund, T. and Schedin, S. (eds) Arbetslivet. Lund: Studentlitteratur.

Gallie, D. (2002) 'The Quality of Working Life in Welfare Strategy', in EspingAndersen, G. (ed.) Why we need a New Welfare State. Oxford: Oxford University Press, pp. 96-129.

Garavan, T. N., Nilsson, S. and Ellström, P. E. (2012) 'Employability and talent management: Challenges for HRD practices', European Journal of Training and Development, 36(1), pp. 26-45.

Garsten, C. and Jacobsson, K. (2004) Learning to be employable: new agendas on work, responsibility and learning in a globalizing world. New York: Palgrave Macmillan.

Gherardi, S. (2012) How to Conduct a Practice-Based Study. Problems and methods. 
Edward Elgar Publishing.

Gherardi, S., Jensen, K. and Nerland, M. (2017) 'Shadow organizing: a metaphor to explore organizing as intra-relating', Qualitative Research in Organizations and Management: An International Journal, 12(1), pp. 2-17. doi: 10.1108/QROM06-2016-1385.

Gilbride, D. et al. (2003) 'Identification of the Characteristics of Work Environments and Employers Open to Hiring and Accommodating People with Disabilities', Rehabilitation Counseling Bulletin, 46(130-137). doi: https://doi.org/10.1177/00343552030460030101.

Gladwell, M. (2014) Outliers:10 000-timmarsregeln och andra framgångsfaktorer. Volante.

Graffam, J. et al. (2002) 'Employer benefits and costs of employing a person with disability', Journal of vocational rehabilitation, 17(4), pp. 251-63.

Guimelli, C. and Jacobi, D. (1995) 'Nya praktiker och förändringar av sociala representationer- om sjuksköterskors representationer om sin arbetssituation', in Chaib, M. and Orfali, B. (eds) Sociala representationer-Om vardagsvetandets sociala fundament1. Göteborg: Daidalos, pp. 153-177.

Gustavsson, J. (2014) Supported employment $i$ en svensk kontext : förutsättningarnär personer med funktionsnedsättning når,får och behåller ett arbete. Örebro universitet.

Hammersley, M. (2018) 'What is ethnography? Can it survive ? Should it?', Ethnography and Education. Taylor \& Francis, 13(1), pp. 1-17. doi: 10.1080/17457823.2017.1298458.

Hammond, M. (2018) 'An interesting paper but not sufficiently theoretical: What does theorising in social research look like?', Methodological Innovations, MayAugust, pp. 1-10. doi: 10.1177/2059799118787756.

Hedblom, A. (2004) Aktiveringspolitikens Janusansikte - en studie av differentiering, inklusion och marginalisering. Lund University. Available at: http://lup.lub.lu.se/record/21605.

Heidegger, M. (1977) 'Science and reflection', in The question concerning technology and other essays. New York: Harper, pp. 154-182.

Hernandez, B., Keys, C. B. and Balcazar, F. E. (2000) 'Employer attitudes toward workers with disabilities and their ADA employment rights: A literature review', Journal of rehabilitation, 66(4), pp. 4-16.

Higginbottom, G. M. A., Pillay, J. J. and Boadu, N. Y. (2013) 'Guidance on Performing Focused Ethnographies with an Emphasis on Healthcare Research', The Qualitative Report, 18(9), pp. 1-6. Available at: https://nsuworks.nova.edu/tqr/vol18/iss9/1.

Houtenville, A. and Kalargyrou, V. (2015) 'Employers' Perspectives about Employing People with Disabilities: A Comparative Study across Industries', Cornell Hospitality Quarterly, 56, pp. 168-179. doi: https://doi.org/10.1177\%2F1938965514551633.

Huxham, C. (1996) Creating Collaborative Advantage. Edited by C. Huxham. London: Sage.

Huxham, C. (2003) 'Theorizing collaboration practice', Public Management Review, 5(3). doi: 10.1080/1471903032000146964. 
Huxham, C. and Vangen, S. (2005) Managing to Collaborate. The theory and practice of collaborative advantage. New York: Routledge.

ISF (2019a) Gör samordningsförbund någon skillnad? ISF Granskar och analyserar. Rapport 2019:4. En analys av samordningsförbund under perioden 2005-2010. Available at: https://inspsf.se/download/18.6e75aae16a591304896b37/1565330423268/Gör samordningsförbund någon skillnad-ISF-Rapport 2019-04.pdf.

ISF (2019b) Samordningsförbundens organisering och verksamhet En granskning av förbund för finansiell samordning av rehabiliteringsinsatser. ISF Granskar och analyserar. Rapport 2019:1. Available at: https://inspsf.se/publikationer/rapporter/2019/2019-02-19samordningsforbundens-organisering-och-verksamhet.

Jodelet, D. (1995) 'Sociala representationer: ett forskningsområde under utveckling', in Chaib, M. and Orfali, B. (eds) Sociala representationer-Om vardagsvetandets sociala fundament. Göteborg: Daidalos, pp. 27-57.

Johannisson, B., Gunnarsson, E. and Stjernberg, T. (2008) Gemensamt kunskapande - den interaktiva forskningens praktik. Edited by B. Johannisson, E. Gunnarsson, and T. Stjernberg. Acta Wexionensia.

Johansson, H. and Hornemann Möller, I. (2009) Aktivering - Arbetsmarknadspolitik och socialt arbete i förändring. Liber.

Johansson, P. et al. (2011) Arbetslivsinriktad rehabilitering. Underlagsrapport till den parlamentariska socialförsäkringsutredningen. Inspektionen för socialförsäkringen.

Ju, S., Roberts, E. and Zhang, D. (2013) 'Employer attitudes toward workers with disabilities: A review of research in the past decade', Journal of Vocational Rehabilitation, 38(2), pp. 113-123. doi: DOI: 10.3233/JVR-130625.

Junestav, M. (2004) Arbetslinjer i svensk socialpolitisk debatt och lagstiftning 19302001 (The Principle of the Work strategy in Swedish Social Policy and Legislation 1930-2001). Uppsala University.

Junestav, M. (2007) Socialförsäkringssystemet och arbetsmarknaden - politiska idéer, sociala normer och institutionell förändring - en historik. Available at: https://www.ifau.se/globalassets/pdf/se/2007/r07-04.pdf.

Karlsson, T. and Nilsson, V. (2017) Bristande samordning och liten förståelse: En studie av arbetsgivares behov av stöd vid anställning av individer i långvarigt utanförskap. KFi-rapport nr 143. Available at: https://www.researchgate.net/publication/331907077_Bristande_samordning_oc h_liten_forstaelse_En_studie_av_arbetsgivares_behov_av_stod_vid_anstallning_ av_individer_i_langvarigt_utanforskap_KFi-rappor_t_nr_143.

Kaye, S. and Jones, E. C. (2011) 'Why Don't Employers Hire and Retain Workers with Disabilities?', Journal of Occupational Rehabilitation, 21(4), pp. 526-36. doi: 10.1007/s10926-011-9302-8.

van Kersbergen, C. J. and Hemerijck, A. C. (2012) 'Two decades of change in Europe: The emergence of the social investment state', Journal of Social Policy, 41(3), pp. 475-492. doi: 10.1017/S0047279412000050.

Kjellberg, A. (2010a) Växande avgiftsskillnader i a-kassan - och utvecklingen därefter. Studies in Social Policy, Industrial Relations, Working Life and 
Mobility. Research Reports Volym 2014:1 (ny upplaga).

Kjellberg, A. (2010b) Vilka 'hoppade av' a-kassan eller avstod från att gå med? En studie av a-kassornas medlemsras. Studies in Social Policy, Industrial Relations, Working Life and Mobility. Research Reports Volume 2014:2 (ny upplaga).

Kock, M. (2004) 'Disability Law in germany: An Overview of Employment, Education and Access Rights', German Law Journal, 5(11). Available at: http://www.certificazione.unimore.it/site/home/documento124002722.html.

Kouvonen, A. et al. (2006) 'Psychometric evaluation of a short measure of social capital at work', BMC Public Health, 6. doi: 10.1186/1471-2458-6-251.

Kullberg, C. and Danermark, B. (1999) Samverkan - välfärdsstatens nya arbetsform. Lund: Studentlitteratur.

Kvale, S. and Brinkmann, S. (2014) Den kvalitativa forskningsintervjun. Lund: Studentlitteratur.

Lexén, A., Emmelin, M. and Bejerholm, U. (2016) 'Individual Placement and Support is the keyhole: Employer experiences of supporting persons with mental illness', Journal of Vocational Rehabilitation, 44(2), pp. 135-147. doi: 10.3233/JVR-150786.

Lincoln, Y. and Guba, E. G. (1985) Naturalistic inquiry. Newbury Park, CA: Sage.

Lindallee, J. (2018) Beyond Retrenchment: Multi-Pillarization of Unemployment Benefit Provision in Sweden. Lund University. Available at: https://portal.research.lu.se/portal/en/publications/beyondretrenchment(365c5d8a-c871-41b2-a152-f934eef4a85c).html.

Löfström, M. (2010) Samverkan och gränser: studier av samverkansprojekt $i$ offentlig sektor. Högskolan i Borås.

Lundin, M. (2018) Arbetsmarknadspolitik för arbetslösa mottagare av försörjningsstöd. 2018:2. IFAU. Available at:

https://www.ifau.se/globalassets/pdf/se/2018/r-2018-12-arbetsmarknadspolitikfor-arbetslosa-forsorjningsstodsmottagare.pdf.

Lundqvist Medén, S. (2016) De nollklassade och samverkan. Sammanfattning av Samordningsförbundet arbete med gruppen nollklassade, genom projekt HälsoSam och Fira, samt diskussion kring fortsatt behov av samverkan. Available at:

https://samordning.org/images/ostra/dokument/Utvarderingrapporter/Utvardering _rapporter/2012/de_nollklassade_2.pdf.

Luo, Y. (1998) 'Joint Venture Success in China:How Schould We Select a Good Partner?', Journal of World Business, 33(2), pp. 125-44.

Martin, J. P. (2014) Activation and Active Labour Market Policies in OECD Countries: Stylized Facts and Evidence on their Effectiveness. IZA Policy Paper No. 84. Available at: https://www.iza.org/publications/pp/84/activation-andactive-labour-market-policies-in-oecd-countries-stylized-facts-and-evidence-ontheir-effectiveness.

Marton, F. (1981) 'Phenomenography- Describing conceptions of the world around us', Instructional Science, 10, pp. 177-200.

Marton, F. (1988) 'Phenomenography -a research approach to investigating different understandings of reality.', in Sherman, R. and Webb, R. (eds) Qualitative Research in Education: Focus and Methods. Basingstoke: Falmer Press. 
Mc Glinn, M. (2018) Translating Neoliberalism: The European Social Fund and the Governing of Unemployment and Social Exclusion in Malmö, Sweden. Malmö University. Available at: http://muep.mau.se/handle/2043/24006 (Accessed: 18 March 2019).

Michailakis, D. (2002) 'Arbetsmarknadssystemets slutenhet för funktionshindrade personer', Socialmedicinsk tidsskrift, 1, pp. 15-31.

Mörndal, M. (2018) "Vi måste takta!’ En studie av organisering för samverkan. Mälardalen universitet.

Nicolini, D. (2012) Practice Theory, Work and Organization. An Introduction. Oxford: Oxford University Press. doi: 10.1177/0170840615572590.

Nilsson, S. (2010) 'Enhancing individual employability: The perspective of engineering graduates', Education and Training, 52(6/7), pp. 540-551. Available at: $10.1108 / 00400911011068487$.

Nilsson, S. and Ekberg, K. (2014) 'Förutsättningar för arbetsförmåga och anställningsbarhet på arbetsmarknaden', in Den relativa arbetsförmågan: teoretiska och praktiska perspektiv. Lund: Studentlitteratur.

Nord, T. (2018) Arbete som rättighet eller skyldighet. Föreställningar om arbetsmarknadsfrånvaro $i$ välfärdsstaten. Karlstad University. Available at: https://kau.diva-portal.org/smash/get/diva2:1182964/FULLTEXT01.pdf.

Nordström, E. (2018) Rekryteringsenkäten 2018 - Jobbskaparna larmar! Kompetensbristen ökar. Svenskt näringsliv. Available at: https://www.svensktnaringsliv.se/sakomraden/arbetsmarknadspolitik/rekryterings enkaten-2018-jobbskaparna-larmar-kompetensbristen-oka_1003310.html.

Nylén, U. (2007) 'Interagency collaboration in human services: Impact of formalization and intensity on effectiveness', Public Administration, 85(143166). doi: https://doi.org/10.1111/j.1467-9299.2007.00638.xCitations: 29.

O'Leary, R. and Vij, N. (2012) 'Collaborative Public Management : Where Have We Been and Where Are We Going?', The American Review of Public Administration, 42(5), pp. 507-522. doi: 10.1177/0275074012445780.

OECD (2013) Activating jobseekers: Lessons from seven OECD countries, in OECD Employment Outlook 2013. doi: http://dx.doi.org/10.1787/empl_outlook-2013-7en.

Olofsson, J. (2011) Socialpolitik. Varför, hur och till vilken nytta? 3:e upplag. Falun: SNS Förlag.

Olofsson, J. and Wadensjö, E. (2009) Arbetsmarknadspolitik: förändrade förutsättningar och nya aktörer. Lund: Studentlitteratur.

Panican, A. and Ulmestig, R. (2017) Lokal arbetsmarknadspolitik. Vem gör vad, hur och för vem? Rapportserie i Socialt arbete nr. 36. Växjö: Linneuniversitetet. Available at:

http://portal.research.lu.se/portal/files/27446125/LOKAL_ARBETSMARKNAD SPOLITIK.pdf.

Patton, M. Q. (2015) Qualitative Research \& Evaluation Methods - Integrating Theory and Practice. Sage Publications Inc.

Pillai, K. G. et al. (2017) 'The Negative Effects of Social Capital in Organizations: A Review and Extension', International Journal of Management Reviews, 19(1), pp. 97-124. doi: 10.1111/ijmr.12085. 
Portes, A. (1998) 'Social Capital: Its Origins and Applications in Modern Sociology', Annual Review of Sociology, 24(1), pp. 1-24. doi: 10.1146/annurev.soc.24.1.1.

Raffass, T. (2017) 'Demanding activation', Journal of Social Policy, 46(2), pp. 349365. doi: https://doi.org/10.1017/S004727941600057X.

Regeringen (2019) 'Regleringsbrev för budgetåret 2020 avseende Arbetsförmedlingen'. Available at: https://www.esv.se/statsliggaren/regleringsbrev/?RBID=20264.

Reichertz, J. (2007) 'Abduction: The Logic of Discovery of Grounded Theory', Forum: Qualitative Social Research, 11(1).

Rostila, M. (2010) 'The Facets of Social Capital', Journal for the Theory of Social Behaviour, 41(3), pp. 308-326. doi: 10.1111/j.1468-5914.2010.00454.x.

Sawa, R. J. (2005) 'Foundations of interdisciplinary: A longergan perspective.', Medicine, Health Care and Philosophy, 8, pp. 53-61.

Schatzki, T. R., Knorr-Cetina, K. and von Savigny, E. (2001) The Practice Turn in Contemporary Theory. Routledge.

SFB (2010) 'Socialförsäkringsbalk 2010:110 (Social Insurance Code)'. Sveriges riksdag, Socialdepartementet.

SFS (1977) ‘Arbetsmiljölagen 1977:1160 (Work Environment Act)’. Sveriges riksdag, Arbetsmarknadsdepartementet.

SFS (1982) 'Lag om anställningsskydd 1982:80 (Employment Protection Act)'. Sveriges riksdag, Arbetsmarknadsdepartementet.

SFS (2001) 'Socialtjänstlagen 2001:453 (Social Services Act)'. Sveriges riksdag, Socialdepartementet.

SFS (2003) 'Lag om finansiell samordning av rehabiliteringsinsatser, 2003:1210. (The Act on Financial Coordination of Rehabilitation Efforts)'. Sveriges riksdag, Socialdepartementet.

SFS (2007) 'Förordning med instruktion för Arbetsförmedlingen 2007:1030'. Arbetsmarknadsdepartementet.

SFS (2017) 'Hälso- och sjukvårdslag, 2017:30. (Health and Medical Services Act)'. Sveriges riksdag, Socialdepartementet.

Shaw, L. E. et al. (2014) 'Examining Macro and Meso Level Barriers to Hiring Persons with Disabilities: A Scoping Review', Research in Social Science and Disability, 8, pp. 185-210. doi: 10.1108/S1479-354720140000008011.

Sjöström, B. and Dahlgren, L. (2002) 'Applying phenomenography in nursing research', $J$ Adv Nurs, 40, pp. 339-345.

SKR (2011) Kommunerna och arbetsmarknadspolitiken: En redogörelse för aktuell lagstiftning och samverkansformer. SKR. Available at: https://skr.se/tjanster/merfranskr/rapporterochskrifter/publikationer/kommunerna ocharbetsmarknadspolitikenenredogorelseforaktuelllagstiftningochsamverkansfor mer.30543.html.

SKR (2018) Extratjänster i kommuner och landsting. SKR. Available at: https://skr.se/tjanster/merfranskr/rapporterochskrifter/publikationer/extratjansteri kommunerochlandsting.27539.html.

SO (2016) Så fungerar arbetslöshetsförsäkringen, Arbetslöshetskassornas samorganisation. Stockholm.

Socialstyrelsen and Arbetsförmedlingen (2015) Kunskap och erfarenheter om 
samverkan kring arbetslösa personer med ekonomiskt bistånd. Available at: https://www.arbetsformedlingen.se/download/18.85bf99d14cb559b6f930/142899 7088295/Forskningsöversikten-kunskap+och+erfarenheter-samverkan.pdf.

SOU (2007) Från socialbidrag till arbete. SOU 2007:2. Available at: https://www.regeringen.se/rattsliga-dokument/statens-offentligautredningar/2007/01/sou-20072/.

SOU (2017a) Det handlar om oss - unga som varken arbetar eller studerar. SOU 2017:9. Available at: https://www.regeringen.se/rattsliga-dokument/statensoffentliga-utredningar/2017/02/sou-20179/.

SOU (2017b) Vägledning för framtidens arbetsmarknad. Delbetänkande av Arbetsmarknadsutredningen. SOU 2017:82. Available at: http://www.sou.gov.se/wp-content/uploads/2017/10/Delbetänkande-SOU2017_82.pdf.

SOU (2018) Uppdrag: Samverkan 2018. Många utmaningar kvarstår. Delbetänkande av Delegationen för unga och nyanlända till arbete (DUA). SOU 2018:12. Available at: https://www.dua.se/sites/default/files/sou_2018_12_webb.pdf.

SOU (2019) Effektivt, tydligt och träffsäkert - det statliga åtagandet för framtidens arbetsmarknad. SOU 2019:3. Available at: https://www.regeringen.se/rattsligadokument/statens-offentliga-utredningar/2019/01/sou-20193/.

SOU (2020) Kommuner som utförare av tjänster åt Arbetsförmedlingen - en analys av de rättsliga förutsättningarna. SOU 2020:41. Available at: http://www.sou.gov.se/wp-content/uploads/2020/06/SOU-2020_41_Webb.pdf.

Ståhl, C. (2010) In Cooperation We Trust: Interorganizational Cooperation in Return-to-Work and Labour Market Reintegration. Linköping University.

Ståhl, C. et al. (2017) 'Process evaluation of an interorganizational cooperation initiative in vocational rehabilitation: The Dirigo project', BMC Public Health, 17(1). doi: 10.1186/s12889-017-4357-x.

Ståhlberg, A.-C. (2014) Socialförsäkringarna i Sverige. Lund: Studentlitteratur.

Stenfors-Hayes, T., Hult, H. and Abrandt Dahlgren, M. (2013) 'A phenomenographic approach to research in medical education', Medical Education, 47, pp. 261-270. Available at: https://onlinelibrary.wiley.com/doi/pdf/10.1111/medu.12101.

Stengers, I. (1997) Power and invention: situating science. Minneapolis: University of Minnesota Press.

Svensson, L. et al. (2007) 'Interactive Research - an Attempt to Analyse two Change Programmes', International Journal of Action Research, 3(3), pp. 250-277.

Available at:

https://www.researchgate.net/publication/23646487_Interactive_Research__an_Attempt_to_Analyse_two_Change_Programmes.

Svensson, L., Brulin, G. and Sjöberg, K. (2009) Learning through On-going Evaluation. Lund: Studentlitteratur.

Swedberg, R. (2012) 'Theorizing in sociology and social science: turning to the context of discovery', Theory and Society, 41(1), pp. 1-40. doi: 10.1007/s11186011-9161-5.

Szreter, S. and Woolcock, M. (2004) 'Health by association? Social capital, social theory, and the political economy of public health', International journal of epidemiology, 33(4), pp. 650-667. 
Thorén, K. H. (2012) Kommunal arbetsmarknadspolitik - en kunskapsöversikt över åtgärder för arbetslösa socialbidragstagare. Rapporter från riksdagen 2011/12:RFR 14. Stockholm.

Thylefors, I., Persson, O. and Hellström, D. (2005) 'Team types, perceived efficiency and team climate in Swedish cross-professional teamwork', Journal of Interprofessional Care, 19(2).

Tillmar, M. et al. (2018) Sektorsöverskridande samverkan. En studie av organisering för välfärd mellan olika samhällssektorer. Helix rapport 18:002.

Torfing, J. (2016) Collaborative innovation in the public sector. Washington DC: Georgetown University Press.

Vangen, S. (2016) 'Developing Practice-Oriented Theory on Collaboration: A Paradox Lens', Public Administration Review, 77(2), pp. 263-272. doi: https://doi.org/10.1111/puar.12683.

Vetenskapsrådet (2017) 'Good research practice. Swedish Research Council.' Available at: https://www.vr.se/download/18.5639980c162791bbfe697882/1555334908942/G ood-Research-Practice_VR_2017.pdf.

Vikman, U. and Westerberg, A. (2017) Arbetar kommunerna på samma sätt? Om kommunal variation inom arbetsmarknadspolitiken. 2017:17. IFAU. Available at: https://www.ifau.se/globalassets/pdf/se/2017/r-2017-07-arbetar-kommunernapa-samma-satt.pdf.

Voelklein, C. and Howarth, C. (2005) 'A Review of Controversies about Social Representations Theory: A British Debate', Culture \& Psychology, 11(431-454).

Walsch, J., Wang, E. and Xin, K. (1999) 'Same bed, Different Dreams: Working Relationships in Sino-American Joint Ventures', Journal of World Business, 34(1), pp. 69-93.

Walter, L. (2011) 'Arbetsförmedlingens dubbla funktion: att stödja och att kontrollera', in Garsten, C. and Lindvert, J. (eds) Arbetets marknad: Arbetsmarknadens nya organisering. Malmö: Liber, pp. 49-63.

Weber, M. (2001) 'The protestant ethic debate: Max Webers's replies to his critics, 1907-1910.', Chalcraft, D. and Harrington, A. (eds). Liverpool: Liverpool University Press.

Wibeck, V. (2010) Fokusgrupper : om fokuserade gruppintervjuer som undersökningsmetod. Lund: Studentlitteratur.

Woolcock, M. (2010) 'The Rise and Routinization of Social Capital, 1988-2008', Annual Review of Political Science, 13(1), pp. 469-487. doi: 10.1146/annurev.polisci.031108.094151. 


\section{Papers}

The papers associated with this thesis have been removed for copyright reasons. For more details about these see:

http://urn.kb.se/resolve?urn=urn:nbn:se:liu:diva-171408 


\section{FACULTY OF MEDICINE AND HEALTH SCIENCES}

Linköping University Medical Dissertation No. 1753, 2020

Department of Health, Medicine and Caring Sciences

Linköping University

SE-581 83 Linköping, Sweden

\section{www.liu.se}

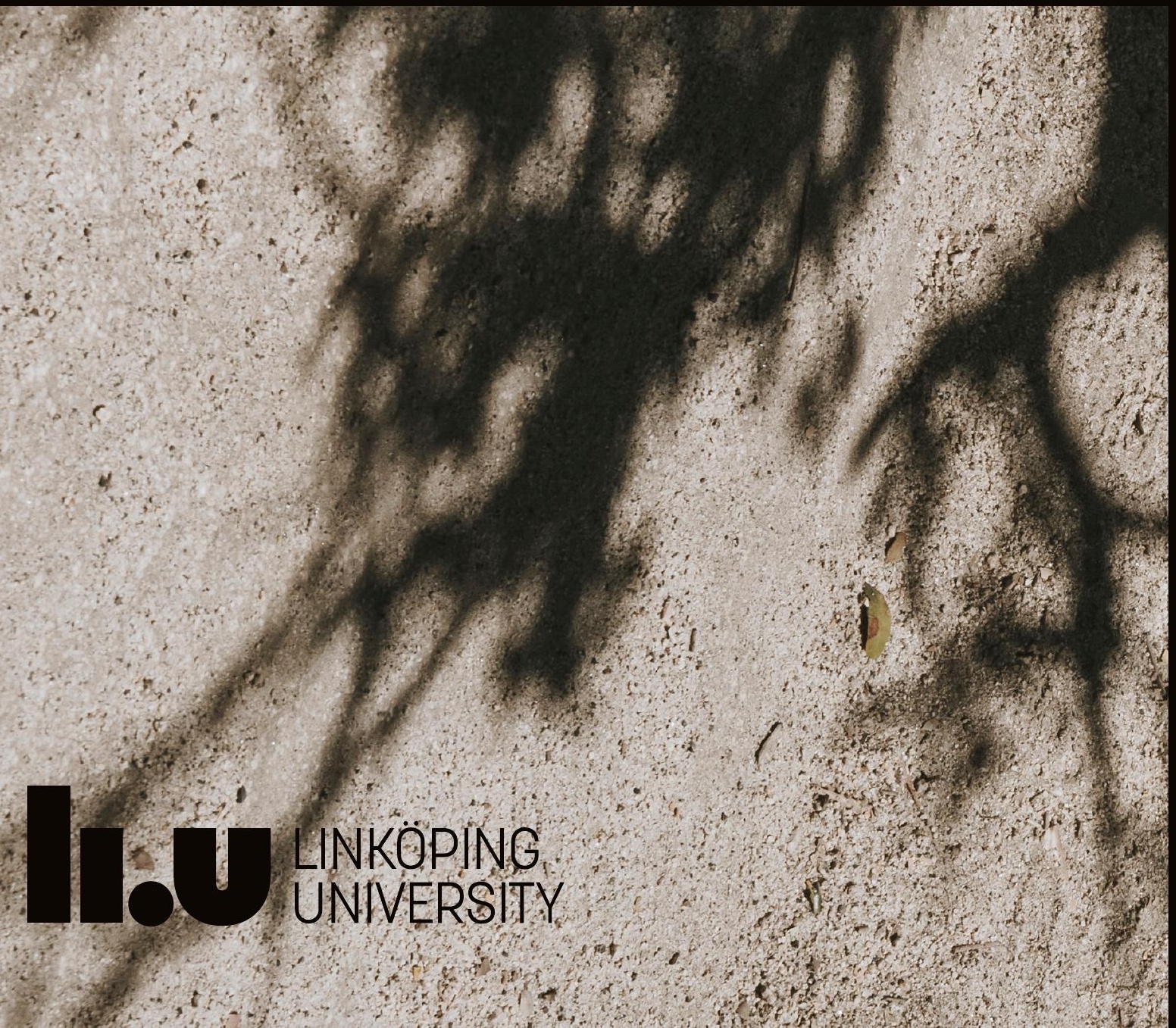

